\title{
Finer-Resolution Mapping of Global Land Cover: Recent Developments, Consistency Analysis, and Prospects
}

\author{
Liangyun Liu $\mathbb{D}^{\text {, }}$, Xiao Zhang, Yuan Gao, Xidong Chen, Xie Shuai, and Jun Mi \\ Key Laboratory of Digital Earth Science, Aerospace Information Research Institute, Chinese Academy of Sciences, \\ Beijing 100094, China \\ Correspondence should be addressed to Liangyun Liu; liuly@radi.ac.cn
}

Received 8 December 2020; Accepted 23 February 2021; Published 31 March 2021

Copyright (c) 2021 Liangyun Liu et al. Exclusive Licensee Aerospace Information Research Institute, Chinese Academy of Sciences. Distributed under a Creative Commons Attribution License (CC BY 4.0).

Land-cover mapping is one of the foundations of Earth science. As a result of the combined efforts of many scientists, numerous global land-cover (GLC) products with a resolution of $30 \mathrm{~m}$ have so far been generated. However, the increasing number of fineresolution GLC datasets is imposing additional workloads as it is necessary to confirm the quality of these datasets and check their suitability for user applications. To provide guidelines for users, in this study, the recent developments in currently available $30 \mathrm{~m}$ GLC products (including three GLC products and thematic products for four different land-cover types, i.e., impervious surface, forest, cropland, and inland water) were first reviewed. Despite the great efforts toward improving mapping accuracy that there have been in recent decades, the current $30 \mathrm{~m}$ GLC products still suffer from having relatively low accuracies of between $46.0 \%$ and $88.9 \%$ for GlobeLand30-2010, 57.71\% and 80.36\% for FROM_GLC-2015, and 65.59\% and $84.33 \%$ for GLC_FCS30-2015. The reported accuracies for the global $30 \mathrm{~m}$ thematic maps vary from $67.86 \%$ to $95.1 \%$ for the eight impervious surface products that were reviewed, $56.72 \%$ to $97.36 \%$ for the seven forest products, $32.73 \%$ to $98.3 \%$ for the six cropland products, and $15.67 \%$ to $99.7 \%$ for the six inland water products. The consistency between the current GLC products was then examined. The GLC maps showed a good overall agreement in terms of spatial patterns but a limited agreement for some vegetation classes (such as shrub, tree, and grassland) in specific areas such as transition zones. Finally, the prospects for fine-resolution GLC mapping were also considered. With the rapid development of cloud computing platforms and big data, the Google Earth Engine (GEE) greatly facilitates the production of global fine-resolution land-cover maps by integrating multisource remote sensing datasets with advanced image processing and classification algorithms and powerful computing capability. The synergy between the spectral, spatial, and temporal features derived from multisource satellite datasets and stored in cloud computing platforms will definitely improve the classification accuracy and spatiotemporal resolution of fineresolution GLC products. In general, up to now, most land-cover maps have not been able to achieve the maximum (per class or overall) error of 5\%-15\% required by many applications. Therefore, more efforts are needed toward improving the accuracy of these GLC products, especially for classes for which the accuracy has so far been low (such as shrub, wetland, tundra, and grassland) and in terms of the overall quality of the maps.

\section{Introduction}

Land cover is an essential climate variable and is widely used in numerous studies concerned with, for example, global climate change, Earth system modeling, natural resource management, food security, and conservation biology [1-3]. In recent decades, many global land-cover (GLC) products have been successfully generated using satellite remote sensing data, and GLC mapping is moving toward providing datasets with higher spatial resolution and finer classification [3-5]. The GLC products that have a coarse spatial resolution, such as the global land-cover classification product at $1 \mathrm{~km}$ (GLC_ 2000) [6] and IGBP (International Geosphere-Biosphere Programme) DISCover land-cover classification product (IGBP_DISCover) [7], the $500 \mathrm{~m}$ Moderate Resolution Imaging Spectroradiometer (MODIS) land-cover product (MOD12Q1) [8], and the $300 \mathrm{~m}$ global land-cover map (GlobCover) [9] and the European Space Agency (ESA) Climate Change Initiative land-cover product (CCI_LC) [10], have been used in many studies. However, these coarseresolution GLC products do not provide enough spatial detail for studies on, for example, urban expansion and 
resource management $[11,12]$. As pointed out by Herold et al. [13], more efforts based on the use of higherresolution satellite data should be made to improve the classification accuracy of heterogeneous landscapes, which is the most significant challenge for improving GLC mapping. Furthermore, fine-resolution $(\sim 30 \mathrm{~m})$ GLC products provide rich spatial information at the scale of most human activity, thus offering greater flexibility for application in a range of studies $[11,12,14]$.

The free availability of fine-resolution satellite remote sensing data (especially Landsat archive and Sentinel-2 data), together with improved computing and storage capacity, has resulted in the availability of GLC products with a resolution of $10-30 \mathrm{~m}$; these products include GlobeLand30 [14], FROM_GLC [12], GLC_FCS30 [15, 16], ESA-S2-LC20 [17], and FROM_GLC10 [18]. Many global thematic fine-resolution land-cover products have also been generated. For example, there are several global impervious surface datasets, including NUACI [19], ESA GHSL [20], GAIA [21], and MSMT_IS30 [22]; global inland water body datasets, including GLCFGIW [23], G3WBM [24], JRC_GSW [25], and GLAD_Water [26]; global cropland datasets, including GFSAD30 [27], GCAD30 [28], and FROM_GC [29]; and global forestcover datasets, including TreeCover-2010 [30], GFCC30TC [31], and GFC30 [32].

These fine-resolution GLC datasets have been generated as a result of various initiatives, so they differ in terms of classification systems, satellite data used, and classification methodologies [33, 34]. For example, there are huge discrepancies between CGLS-LC100, ESA-S2, and FROM_GLC, which have an overall spatial agreement of $56.87 \%$ and a disagreement of $43.13 \%$ for Africa [35]. Consequently, it is difficult to assess which GLC dataset fits user application best [36, 37]. Although many campaigns have been conducted with the aim of collecting reference datasets for validating fine-resolution GLC maps, their availability and role in applications outside their area of intended use have been very limited because of the inconsistencies between legends, sampling strategies, and response design protocols used [33, 38]. According to reports relating to global validation campaigns, there are large differences between the overall accuracies of fine-resolution GLC products: $64.9 \%$ for FROM_GLC [12], 80.3\% for GlobeLand30 [14], and $82.5 \%$ for GLC_FCS30 [16]. In spite of the validation assessments provided by the developers of these products, some third-party researchers have found considerably lower accuracies for some regions when verifying GLC products [39, 40].

The need to assess the quality of the increasing number of fine-resolution GLC datasets and check their suitability for different user applications is leading to additional workloads. The objectives of this study were (1) to review recent developments related to current fineresolution GLC products, (2) to compare the available $30 \mathrm{~m}$ GLC maps and quantify their spatial consistency, and (3) to summarize the trends in and prospects for fine-resolution GLC mapping.

\section{Consistency and Accuracy Assessment Metrics}

The area-based and pixel-based consistencies are widely used to assess the agreement between different global products. The area-based analysis mainly focuses on the consistency of the areal proportions of each LC type between the different GLC products [39, 41], whereas the pixel-based analysis is concerned with the spatial (dis)agreement for each LC type between the different GLC products [34, 41, 42]. In this study, both an analysis of the consistency of the current $30 \mathrm{~m}$ GLC products and an analysis for different classes (impervious surface, forest, cropland, and water body) of current global $30 \mathrm{~m}$ thematic products were performed to give a more comprehensive understanding of the process of global land-cover mapping.

2.1. Analysis of the Consistency of Current $30 \mathrm{~m}$ GLC Products. First, the area percentage of each land-cover type in each GLC product was calculated to give an overview of the consistency between the current GLC products. Then, in order to intuitively illustrate the spatial consistency between the different products, the spatial superposition method [41] was employed to obtain the pixel-by-pixel spatial correspondence for the different products. A maximum value (equal to 3) was assigned for highly consistent pixels when the target land-cover types for the three LC products were exactly the same; a value of 2 was assigned for moderately consistent pixels when only two land-cover types agreed; a minimum value (equal to 1 ) was assigned for lowconsistency pixels when the three LC products all had different target land-cover types [39]. To obtain more detailed information about the spatial consistency between the different products, the spatial superposition method was also applied to each pair of products. Pixels for which the target land-cover type was the same for both products were considered "consistent," whereas pixels with different target landcover types were labeled "inconsistent." The spatial consistency distribution for all three products and for each pair of products is given based on a spatial resolution of $0.05^{\circ}$. In the spatially aggregating step, the consistency metric was firstly calculated for each $30 \mathrm{~m}$ pixel; then, the proportion of highly consistent (PHC) pixels, proportion of moderately consistent (PMC) pixels, proportion of low-consistency (PLC) pixels within each $0.05^{\circ}$ grid were calculated and stored in three channels. Therefore, the spatial consistency was assessed at a resolution of $30 \mathrm{~m}$, while illustrated at a resolution of $0.05^{\circ}$.

2.2. Analysis of the Consistency of Current Global $30 \mathrm{~m}$ Thematic Products. The analysis of the consistency of the current global $30 \mathrm{~m}$ thematic products focused on the impervious surface, forest, cropland, and water body classes. First, the fractional areas for each thematic class were calculated at a spatial resolution of $0.05^{\circ}$. The total meridional and zonal fractional areas were then calculated for each class for each $0.05^{\circ}$ longitude and latitude bin. To quantitatively evaluate the consistency between each pair of thematic products, the linear regression approach was applied, and scatter plots for 
TABLE 1: Main parameters of the current three global $30 \mathrm{~m}$ land-cover products.

\begin{tabular}{|c|c|c|c|c|}
\hline Map name & Period & Satellite sensors & Method & Literature \\
\hline GlobeLand30 & $\begin{array}{l}2000 \\
2010\end{array}$ & $\begin{array}{l}\text { Landsat } \\
\text { TM/ETM+, } \\
\text { HJ-1 }\end{array}$ & $\begin{array}{l}\text { The classification of } 10 \text { land-cover types is carried out using a } \\
\text { split-and-merge strategy. Robust integration of pixel- and } \\
\text { object-based classification is applied to classify each land-cover } \\
\text { type; finally, a knowledge-based interactive verification } \\
\text { procedure is applied to improve the mapping accuracy. } \\
\text { Dataset link: http://www.globallandcover.com/GLC30Down-load/index.aspx }\end{array}$ & Chen et al. [14] \\
\hline FROM_GLC & $\begin{array}{l}2015 \\
2017\end{array}$ & $\begin{array}{l}\text { Landsat } \\
\text { TM, ETM+, } \\
\text { OLI }\end{array}$ & $\begin{array}{l}\text { Multitemporal Landsat imagery is used together with } 91,433 \\
\text { high-confidence training samples (visual interpretation) and a } \\
\text { random forest classifier to produce the land-cover maps. } \\
\text { Dataset link: http://data.ess.tsinghua.edu.cn/fromglc2015_v1.html }\end{array}$ & Gong et al. [12] \\
\hline GLC_FCS30 & $\begin{array}{l}2015 \\
2020\end{array}$ & Landsat OLI & $\begin{array}{l}\text { Combining time series of Landsat imagery and high-quality } \\
\text { training data from GSPECLib (Global Spatial Temporal } \\
\text { Spectral Library), local adaptive random forest models are } \\
\text { applied to each } 5^{\circ} \times 5^{\circ} \text { geographical grid element to } \\
\text { produce the land-cover maps. } \\
\text { Dataset link: https://zenodo.org/record/3986872, } \\
\text { https://zenodo.org/record/4280923 }\end{array}$ & Zhang et al. [16] \\
\hline
\end{tabular}

each pair of products were made. Based on the linear regression, the root-mean-squared difference (RMSD) and coefficient of determination $\left(R^{2}\right)$ were calculated as follows:

$$
\operatorname{RMSD}=\sqrt{\frac{1}{n} \sum_{i=1}^{n}\left(\operatorname{frac}_{x(i)}-\mathrm{frac}_{y(i)}\right)^{2}}
$$

where $\operatorname{frac}_{x(i)}$ is the fractional thematic class area for thematic product $x$ in the $i^{\text {th }} 0.05^{\circ} \times 0.05^{\circ}$ grid cell; frac $_{y(i)}$ is the fractional thematic class area for thematic product $y$ in the $i$ ${ }^{\text {th }} 0.05^{\circ} \times 0.05^{\circ}$ grid cell; and $n$ is the total number of grid cells in the thematic product. The RMSD value was used to reflect the discrepancy between the two thematic products in each pair:

$$
R^{2}=\frac{\left(\sum_{i=1}^{n}\left(\operatorname{frac}_{x(i)}-\overline{\operatorname{frac}_{x}}\right) \times\left(\operatorname{frac}_{y(i)}-\overline{\operatorname{frac}_{y}}\right)\right)^{2}}{\sum_{i=1}^{n}\left(\operatorname{frac}_{x(i)}-\overline{\operatorname{frac}_{x}}\right)^{2} \times \sum_{i=1}^{n}\left(\operatorname{frac}_{y(i)}-\overline{\operatorname{frac}_{y}}\right)^{2}}
$$

where $\overline{\text { frac }_{x}}$ is the average fractional thematic class area for thematic product $x$ and $\overline{\text { frac }_{y}}$ is the average fractional thematic class area for thematic product $y$. The higher the value of $R^{2}$, the better the fit between a pair of thematic products.

\section{Review of the Current Global $30 \mathrm{~m}$ Products}

\subsection{Review of Global $30 \mathrm{~m}$ Land-Cover Products}

3.1.1. Overview of the Global $30 \mathrm{~m}$ Land-Cover Products. There are three $30 \mathrm{~m}$ global land-cover products that are currently available free of charge: GlobeLand30 [14], FROM_ GLC [12], and GLC_FCS30 [16]. Some basic information about these three products is listed in Table 1.

The GlobeLand30 product, which is one of the most widely used land-cover products, was developed by using the pixel-object-knowledge-based (POK) method and multi- temporal Landsat and HJ-1 A/B imagery [14]. This product has been validated as having an overall accuracy of $80.3 \%$ based on 154,586 validation samples from across the globe [14]. FROM_GLC was the first global $30 \mathrm{~m}$ land-cover product. Currently, the 2015 version (which has a $30 \mathrm{~m}$ resolution) and the 2017 version (which has a $10 \mathrm{~m}$ resolution) are available. FROM_GLC30-2015, which was produced using multitemporal Landsat imagery combined with over 90,000 visually interpreted training samples and random forest classifiers [12], has been validated as having an overall accuracy of $80.6 \%$ [43]. The GLC_FCS30 product, which contains a large variety of land-cover types, was developed on the GEE platform by combining time series of Landsat imagery, a global prior training dataset obtained from GSPECLib [44], and local adaptive random forest models [16]. GLC_FCS30-2015 has been validated as having an overall accuracy of $82.5 \%$ and a kappa coefficient of 0.784 based on 44,043 global validation samples [16].

There are also some differences between the classification systems employed by the three different GLC products. GlobeLand30 consists of 10 basic land-cover types, whereas FROM_GLC30 uses a two-level hierarchical classification system with 10 land-cover types at level 1, which is the same classification system used by GlobeLand30. GLC_FCS30 employs the Climate Change Initiative land-cover dataset (CCI_LC) classification system, which has 16 level 1 landcover types. As a uniform classification system is the basis of the comparative analysis of different GLC products, these different classification systems were transformed into a target classification system with 10 basic land-cover types based on the study of Gao et al. [45] before the consistency analysis was carried out. Details of the classification systems used in the three GLC products and the correspondence between them are shown in Table 2.

3.1.2. Review of the Accuracy Assessments of the Three GLC30 Products. There have been numerous validations of the $30 \mathrm{~m}$ GLC products at both the regional and global scales. Table 3 
TABLE 2: Classification systems used for the three current global $30 \mathrm{~m}$ land-cover products.

\begin{tabular}{|c|c|c|}
\hline GlobeLand30 & FROM_GLC & GLC_FCS30 \\
\hline \multirow{5}{*}{ Cropland } & Rice paddy & Rainfed cropland \\
\hline & Greenhouse & Herbaceous cover \\
\hline & Other & Tree or shrub cover (orchard) \\
\hline & Orchard & Irrigated cropland \\
\hline & Bare farmland & \\
\hline \multirow{5}{*}{ Forest } & Broadleaf, leaf-on/leaf-off & Evergreen broadleaf forest \\
\hline & Needleleaf, leaf-on/leaf-off & (Closed/open) deciduous broadleaf forest \\
\hline & Mixed-leaf, leaf-on/leaf-off & (Closed/open) evergreen needleleaf forest \\
\hline & & (Closed/open) deciduous needleleaf forest \\
\hline & & Mixed-leaf forest \\
\hline \multirow{3}{*}{ Grassland } & Pasture & Grassland \\
\hline & Natural grassland & \\
\hline & Grassland, leaf-off & \\
\hline \multirow{2}{*}{ Shrubland } & Shrubland, leaf-on & Shrubland \\
\hline & Shrubland, leaf-off & Evergreen/deciduous shrubland \\
\hline \multirow{3}{*}{ Wetland } & Marshland & Wetlands \\
\hline & Mudflat & \\
\hline & Marshland, leaf-off & \\
\hline Water body & Water body & Water body \\
\hline Impervious surface & Impervious surface & Impervious surface \\
\hline \multirow{2}{*}{ Tundra } & Scrub and brush tundra & Lichens and mosses \\
\hline & Herbaceous tundra & Sparse herbaceous cover/sparse shrubland (part) $(\mathrm{fc}<15 \%)$ \\
\hline \multirow{4}{*}{ Bareland } & Bareland & Bare areas \\
\hline & & Consolidated bare areas \\
\hline & & Unconsolidated bare areas \\
\hline & & Sparse herbaceous cover/sparse shrubland (part) $(\mathrm{fc}<15 \%)$ \\
\hline \multirow{2}{*}{ Permanent ice/snow } & Snow & Permanent ice and snow \\
\hline & Ice & \\
\hline
\end{tabular}

summarizes the reported accuracies. Generally, the accuracies vary according to the validation dataset used. All producers provide accuracy reports for their own products based on different global validation datasets. The reported accuracy of GLC_FCS30 is the highest-an overall accuracy of $82.5 \%$ [16] —as against $80.3 \%$ for GlobeLand30 [14] and $64.9 \%$ for FROM_GLC [12]. Since GlobeLand30 and FROM_GLC were released earlier, numerous validations of these products have been conducted, and the reported accuracies have ranged from $46.0 \%$ for Central Asia [46] to $88.9 \%$ for the European Union [45] and from $57.71 \%$ for Indonesia [39] to $80.36 \%$ for Beijing, China [47], for GlobeLand30 and FROM_GLC, respectively. Recently, two sets of reported results for GLC_FCS30-2015 gave an accuracy of $65.59 \%$ for Indonesia [39] and 84.33\% for the European Union [45].

Only three published studies simultaneously compared the accuracy of the three GLC products using the same validation dataset. Based on the 44,043 global validation points derived from the reference land-cover datasets that are currently available [15], GLC_FCS30-2015 was reported to achieve the best accuracy (82.5\%), compared to $75.9 \%$ for GlobeLand30-2010 and 59.1\% for FROM_GLC-2015 [15]. Gao et al. [45] investigated the performance of the three $30 \mathrm{~m}$ GLC products for the European Union and found that GlobeLand30-2010 had the highest overall accuracy of $88.90 \pm 0.68 \%$; this was followed by $84.33 \pm 0.80 \%$ for GLC_FCS30-2015 and 65.31 \pm 1.0\% for FROM_GLC-2015. Kang et al. [39] investigated the performance of the three $30 \mathrm{~m}$ GLC products for Indonesia and found that the accuracy of the $30 \mathrm{~m}$ GLC products requires further improvement in tropical rainforest regions: the highest overall accuracy was $65.59 \%$ for GLC_FCS30-2015. Accuracies of $61.65 \%$ and $57.71 \%$ were found for GlobeLand30-2010 and FROM_ GLC-2015, respectively.

Furthermore, the mapping accuracy varies for different land-cover types. For land-cover types that have relatively pure spectral properties or occupy a large proportion of the Earth's surface, such as forest, cropland, and water, relatively high accuracies have usually been found. In contrast, complex land-cover types such as shrubland, grassland, and 
TABLE 3: Summary of the reported accuracies for the three $30 \mathrm{~m}$ GLC products.

\begin{tabular}{|c|c|c|}
\hline Study & Region & Accuracy description \\
\hline Zhang et al. [16] & Global & $\begin{array}{l}\text { GLC_FCS30-2015 achieved the best performance of 82.5\%, compared with } \\
\text { 59.1\% for FROM_GLC-2015 and 75.9\% for GlobeLand30-2010. } \\
\text { Validation dataset link: https://zenodo.org/record/3551995\#.XdttCugzZPY }\end{array}$ \\
\hline Kang et al. [39] & Indonesia & $\begin{array}{l}\text { GLC_FCS30-2015 has the highest overall accuracy (65.59\%), followed by } \\
\text { GlobeLand30-2010 (61.65\%) and FROM_GLC-2015 (57.71\%). }\end{array}$ \\
\hline Gao et al. [45] & European Union & $\begin{array}{l}\text { The overall accuracy coefficient of the GlobeLand30-2010 product is the highest at } \\
88.90 \pm 0.68 \% \text {. This is followed by GLC_FCS30-2015 }(84.33 \pm 0.80 \%) \text { and } \\
\text { FROM_GLC-2015 (65.31 } \pm 1.0 \%) \text {. } \\
\text { Validation dataset link: https://ec.europa.eu/eurostat/web/lucas/data/lucas-grid }\end{array}$ \\
\hline Chen et al. [14] & Global & An overall classification accuracy of $80.3 \%$ was achieved by GlobeLand 30 . \\
\hline Tsendbazar et al. [87] & Africa & The overall accuracy of GlobeLand $30-2010$ is $57.1 \%$ over the African continent. \\
\hline Sun et al. [46] & Central Asia & $\begin{array}{c}\text { GlobeLand30-2010 data have an overall accuracy of } 46 \% \text { and a } \\
\text { kappa coefficient of } 0.283 \text {. }\end{array}$ \\
\hline Wang et al. [84] & China & The overall accuracy of GlobeLand $30-2010$ for China is $84.2 \%$. \\
\hline Yang et al. [34] & China & The overall accuracy of GlobeLand $30-2010$ is $82.39 \%$. \\
\hline See et al. [88] & Kenya & The GlobeLand 30 gave an overall accuracy ranging from $53 \%$ to $61 \%$. \\
\hline Fonte et al. [89] & Nepal & $\begin{array}{l}\text { The overall accuracy is } 61 \% \text { and } 54 \% \text { in Tanzania and } \\
\text { Kathmandu, Nepal, respectively. }\end{array}$ \\
\hline Brovelli et al. [90] & Italy & $\begin{array}{l}\text { The overall accuracy is higher than } 80 \% \text { according to a } \\
\text { validation covering eight regions across Italy. }\end{array}$ \\
\hline Balogun et al. [91] & Malaysia & $\begin{array}{l}\text { Overall accuracies of } 63.45 \% \text { and } 65.70 \% \text {, respectively, } \\
\text { were obtained from the error matrix using sample counts and the } \\
\text { new unbiased area estimator with GlobeLand } 30 \text {. }\end{array}$ \\
\hline Manakos et al. [92] & Thessaly, Greece & $\begin{array}{l}\text { GlobeLand30-2010 achieved an overall accuracy of } 84 \% \text { and } \\
\text { a weighted overall accuracy of } 86 \% \text { using } 539 \text { validation samples. }\end{array}$ \\
\hline Zhang et al. [93] & Siberia & $\begin{array}{c}\text { GlobeLand } 30-2000 \text { and GlobeLand } 30-2010 \text { achieved overall } \\
\text { accuracies of } 85.8 \% \text { and } 86.9 \% \text { and kappa coefficients of } \\
0.79 \text { and } 0.81 \text { over Siberia. }\end{array}$ \\
\hline Jokar Arsanjani et al. [94] & Iran & $\begin{array}{l}\text { GlobeLand30-2010 achieved an overall accuracy of } 77.95 \% \\
\text { based on } 738,900 \text { validation samples from Iran. }\end{array}$ \\
\hline Jokar Arsanjani et al. [95] & Germany & $\begin{array}{l}\text { Overall, good correspondence was confirmed between the GlobeLand } 30 \\
\text { and the other datasets, ranging from } 74 \% \text { for OSM to } 92 \% \text { for CORINE. }\end{array}$ \\
\hline Gong et al. [12] & Global & $\begin{array}{l}\text { FROM_GLC achieved an overall accuracy of } 64.9 \% \text { for the complete set of } \\
\text { validation samples and } 71.5 \% \text { for the homogeneous validation samples. } \\
\text { Validation dataset link: http://data.ess.tsinghua.edu.cn/data }\end{array}$ \\
\hline Yu et al. [96] & Global & The overall accuracy of FROM_GLC is $63.69 \%$, and the kappa coefficient is 0.543 . \\
\hline Zhao et al. [97] & Global & $\begin{array}{l}\text { The overall accuracy of the improved version of FROM_GLC } \\
\text { (FROM_GLC_agg) is } 65.51 \% \text {. } \\
\text { Validation dataset link: http://data.ess.tsinghua.edu.cn/data }\end{array}$ \\
\hline Xu et al. [35] & Africa & $\begin{array}{l}\text { The second version of the FROM_GLC African land-cover } \\
\text { map has an overall accuracy of } 74.40 \% \text {. }\end{array}$ \\
\hline Dong et al. [98] & Beijing, China & $\begin{array}{l}\text { The overall accuracy for FROM_GLC based on comparable } \\
\text { vector datasets, Google Earth images, and field } \\
\text { survey data is } 71.08 \%, 79.63 \% \text {, and } 80.36 \% \text {, respectively. }\end{array}$ \\
\hline Guo et al. [99] & Pakistan & $\begin{array}{c}\text { The overall accuracy of FROM_GLC in summer }(61.2 \%) \text { is } \\
\text { slightly higher than that in winter }(59.0 \%) .\end{array}$ \\
\hline
\end{tabular}

wetland are often confused with other types. For example, for the forest class, according to their producers, the mapping accuracies are 94.0\% (GLC_FCS30) [16], 76.5\% (FROM_ GLC30) [12], and 83.6\% (GlobeLand30) [14]. For shrubland, the accuracies reported by the producers are significantly lower at 56.8\% (GLC_FCS30) [16], 33.9\% (FROM_GLC30)
[12], and 72.6\% (GlobeLand30) [14]. A similar trend was found by the comparative studies. In [45], the accuracies found for cropland were 99.0\% (GlobeLand30), 83.6\% (GLC_FCS30), and 63.5\% (FROM_GLC30); these were much higher than accuracies for wetland, which were 35.8\% (GlobeLand30), 36.2\% (GLC_FCS30), and $0.0 \%$ 
(FROM_GLC30). In the accuracy comparison analysis made by Zhang et al. [16], the accuracies for cropland were $94.0 \%$ (GLC_FCS30), 4.9\% (FROM_GLC30), and 92.6\% (GlobeLand30), whereas the accuracies for wetland were $61.8 \%$ (GLC_FCS30), 3.3\% (FROM_GLC30), and $52.6 \%$ (GlobeLand30).

\subsection{Review of the Global Impervious Surface Maps}

3.2.1. Overview of the Global Impervious Surface Maps. Impervious surfaces are a special land-cover type that usually relates to surfaces that are covered by anthropogenic materials such as roads, driveways, sidewalks, parking lots, and rooftops which prevent or retard the entry of water into the soil [48]. Mapping the global distribution and dynamics of global impervious surfaces using satellite remote sensing data is extremely important to improve our understanding of the intensity of human activity and of global change.

In this study, eight global $30 \mathrm{~m}$ impervious surface products were acquired and investigated. Some details of these products are presented in Table 4. Most global impervious surface products cover the long time period stretching from 1985 to 2020 and include multiepoch impervious surface maps; the exceptions to this are MSMT_IS30, HBASE, and GUF. In this study, an analysis of the spatial consistency between these eight impervious surface products in 2015 was conducted. Three products were not available-GlobeLand30 and HBASE/GMIS for 2010 and GUF for 2012. The temporal variations between 2010 and 2015 were, therefore, neglected, which may have led to a certain amount of bias, especially in the case of developing countries. Most of the impervious surface products (MSMT_IS30, NUACI, GAIA, FROM_GLC, GlobeLand30, and GHSL) use similar definitions of "covered by anthropogenic materials which prevent water penetrating into the soil" for impervious surfaces. HBASE defines impervious surfaces as the sum of all surfaces constructed by humans and the area surrounding these surfaces, including urban green spaces; GUF defines impervious surfaces from the perspective of spatial structures- "impervious surfaces should show obvious vertical components"-and so does not define roads, parking lots, airport runways, etc. as impervious surfaces. Lastly, almost all impervious surface products are produced using classification-based methods, including independent random forest classification (MSMT_IS30 and FROM_GLC), a combination of segmentation, classification, and prior knowledge (GlobeLand30 and HBASE), or a combination of unsupervised classification, supervised classification, and prior knowledge (GHSL and GUF). The NUACI is different as it uses a novel built-up index to generate a global multiepoch impervious surface product; GAIA uses normalized scores (the exclusion-inclusion method) and knowledge-driven temporal checking methods to produce annual global impervious surface products.

3.2.2. Review of the Accuracy Assessments of the Global Impervious Surface Maps. Table 5 lists the accuracy metrics produced by various researchers at different scales for eight global $30 \mathrm{~m}$ impervious surface products. Firstly, from the perspective of the global accuracy of each product, the overall accuracy of the impervious surface class in GAIA is $89 \%$, which exceeds the values of $80 \%$ in GlobeLand30, $81 \%-$ $84 \%$ in NUACI, and $84.18 \%$ in GHSL using the corresponding validation points. At the regional scale, MSMT_IS30 has been validated as having an overall accuracy of $95.1 \%$ and a kappa coefficient of 0.898 for 15 test sites of size $1^{\circ} \times 1^{\circ}$ [22] and as having the user's and producer's accuracies of $73.61 \%$ and $99.07 \%$, respectively, in Indonesia [39] and $73.96 \% \pm 0.08 \%$ and $85.46 \% \pm 0.08 \%$, respectively, in the European Union [45]. As for the GlobeLand30 impervious layer, an overall accuracy of $88.4 \%$ was found for $151^{\circ} \times 1^{\circ}$ test sites [22], along with accuracies of $91.37 \%$ in Beijing [49], $80.54 \%$ in Malaysia [50], and $67.86 \%$ for $4501^{\circ} \times 1^{\circ}$ test sites [51]. GHSL has also been widely used and assessed and has been validated as having an overall accuracy of $90.3 \%$ for $151^{\circ} \times 1^{\circ}$ test sites [22], as well as accuracies of $89.21 \%$ in Malaysia [50] and $70.64 \%$ for $4501^{\circ} \times 1^{\circ}$ test sites [51]. This product has been shown to have an accuracy of $96.28 \%$ and a kappa coefficient of 0.3233 in Europe [52] and a kappa coefficient of 0.562 for 26 counties of the US [53]. Lastly, using 15 $1^{\circ} \times 1^{\circ}$ test sites, Zhang et al. [22] found that the overall accuracies of NUACI, FROM_GLC, and HBASE were 85.6\%, $89.6 \%$, and $88.0 \%$, respectively. Kang et al. [39] and Gao et al. [45] found that the producer's and user's accuracies of FROM_GLC were $81.31 \%$ and $52.41 \%$, respectively, in Indonesia and $51.68 \% \pm 0.05 \%$ and $69.21 \% \pm 0.09 \%$, respectively, in the European Union. Wang et al. [48] analyzed the performance of HBASE and found that it had an overall accuracy of 97.9\% and a kappa coefficient of 0.90 .

In summary, although the global $30 \mathrm{~m}$ impervious surface products have improved markedly in recent decades, there is still a lack of a comprehensive accuracy assessment for these global products that uses a common validation dataset. Furthermore, the accuracy metrics of these global impervious surface products vary according to the geographical region and the validation datasets used.

\subsection{Review of the Global Forest Maps}

3.3.1. Overview of the Global Forest Maps. Forest is an important natural land-cover type that usually describes surfaces covered by trees or by a canopy that exceeds a certain treecover percentage and height [30]. Monitoring global forestcover distribution and disturbances using remote sensing techniques is critical for understanding the intensification of human activities, climate change, and the global carbon cycle. In recent decades, as the intensity of human activities has increased and free access to medium- and highresolution remote sensing imagery has become available, global forest mapping and monitoring has experienced a transition from coarse-resolution to medium- and highresolution mapping. In this study, seven global $30 \mathrm{~m}$ forest products were acquired and investigated. These products are listed in Table 6.

All of these forest products define the forest land-cover type using the tree-cover percentage (TCP) and tree height (TH); however, they do not all use the same thresholds for the TCP and TH. For example, a TCP of $15 \%$ is used as the 


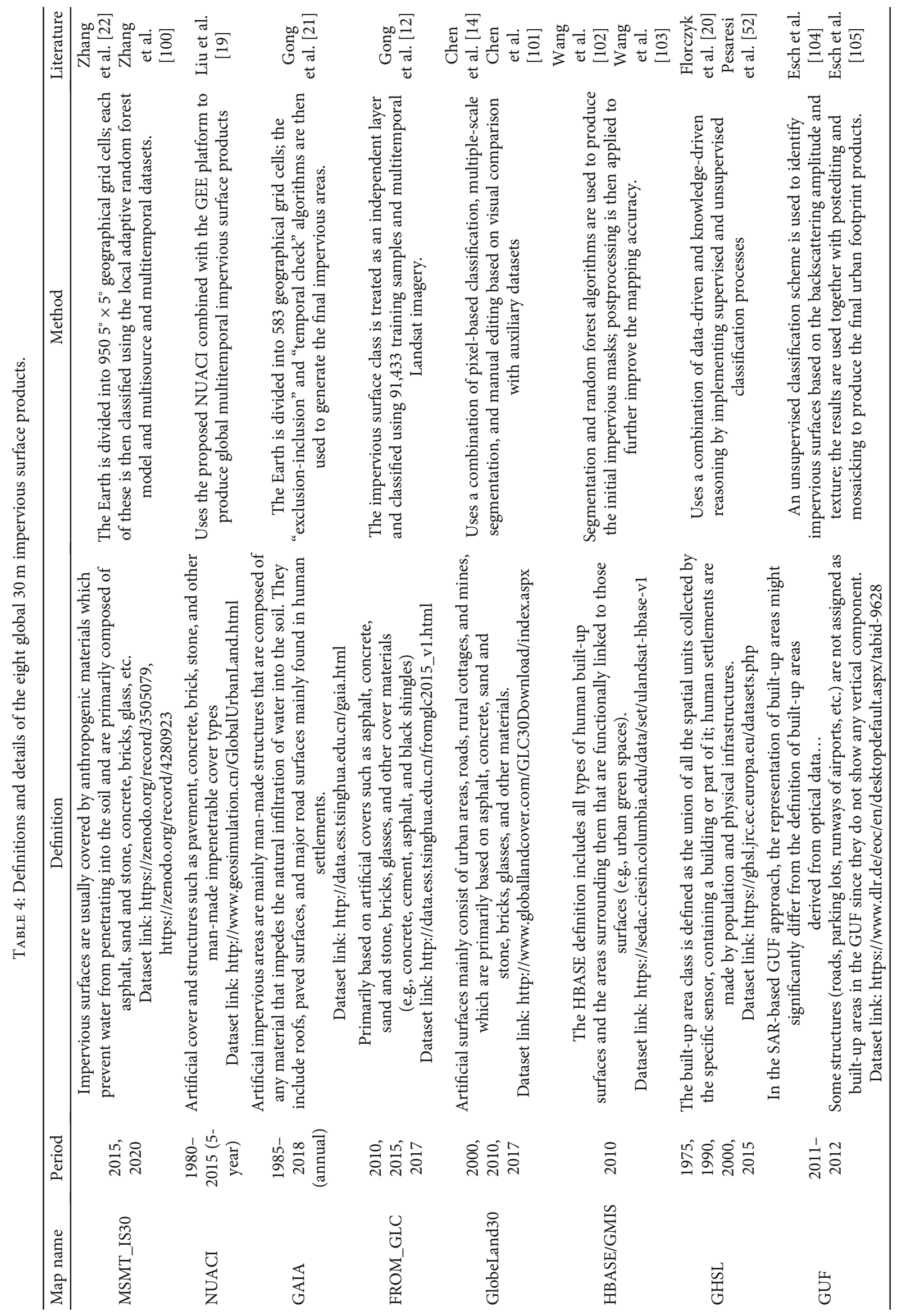


TABLE 5: Summary of the reported accuracies of the different $30 \mathrm{~m}$ impervious surface products.

\begin{tabular}{|c|c|c|}
\hline Study & Region & Accuracy description \\
\hline Zhang et al. [22] & 15 local regions & $\begin{array}{c}\text { MSMT_IS30 had an overall accuracy of } 95.1 \% \text { and kappa coefficient of } \\
0.898 \text { as against } 85.6 \% \text { and } 0.695 \text { for NUACI, } 89.6 \% \text { and } 0.780 \text { for FROM_GLC, } \\
90.3 \% \text { and } 0.794 \text { for GHSL, } 88.4 \% \text { and } 0.753 \text { for GlobeLand30, and } \\
88.0 \% \text { and } 0.745 \text { for HBASE. }\end{array}$ \\
\hline Kang et al. [39] & Indonesia & $\begin{array}{l}\text { The user's accuracies of MSMT_IS30, FROM_GLC, and GlobeLand30 } \\
\text { were } 73.61 \%, 52.41 \% \text {, and } 75.68 \% \text {, respectively, and the corresponding } \\
\text { producer's accuracies were } 99.07 \%, 81.31 \% \text {, and } 78.50 \% \text {, respectively. }\end{array}$ \\
\hline Sun et al. [106] & China & $\begin{array}{c}\text { The consistency between GlobeLand30, GHSL, and NUACI and a reference } \\
\text { dataset gave values of } R^{2} \text { of } 0.57,0.47 \text {, and } 0.36 \text {, respectively. }\end{array}$ \\
\hline Gao et al. [45] & European Union & $\begin{array}{l}\text { Using the LUCAS (Land Use/Cover Area frame Survey) reference data, } \\
\text { the producer's accuracies of MSMT_IS30, FROM_GLC, and GlobeLand30 } \\
\text { were } 85.46 \% \pm 0.08 \%, 51.68 \% \pm 0.05 \% \text {, and } 84.88 \% \pm 0.06 \% \text {, respectively; } \\
\text { the corresponding user's accuracies were } 73.96 \% \pm 0.08 \% \text {, } \\
69.21 \% \pm 0.09 \% \text {, and } 87.39 \% \pm 0.07 \% \text {, respectively. } \\
\text { Validation dataset link: https://ec.europa.eu/eurostat/web/lucas/data/lucas-grid }\end{array}$ \\
\hline Gong et al. [21] & Global & $\begin{array}{c}\text { Based on } 500 \text { validation points, GAIA had an overall accuracy of } \\
89 \% \text {, kappa coefficient of } 0.78 \text {, producer's accuracy of } 78 \%, \\
\text { and user's accuracy of } 99 \% \text { in } 2015 \text {. }\end{array}$ \\
\hline $\begin{array}{l}\text { Chen et al. [14] } \\
\text { Chen et al. [101] }\end{array}$ & Global & $\begin{array}{l}\text { Independent accuracy assessments of the artificial surface class in GlobeLand30 } \\
\text { showed that the user's accuracy of this product is higher than } 80 \% \text {. }\end{array}$ \\
\hline Xing et al. [49] & Beijing & $\begin{array}{c}\text { The GlobeLand } 30-2010 \text { impervious layer was validated as having an overall } \\
\text { accuracy of } 91.37 \% \text {, producer's accuracy of } 92.76 \% \text {, and user's accuracy of } \\
98.19 \% \text { using } 66,058 \text { validation points in Beijing. }\end{array}$ \\
\hline Liu et al. [19] & Global & $\begin{array}{l}\text { The global overall accuracy, producer's accuracy, and user's accuracy for } \\
\text { NUACI are } 0.81-0.84,0.50-0.60 \text {, and } 0.49-0.61 \text {, respectively. The values of } \\
\text { the kappa coefficient for NUACI and GlobeLand } 30 \text { are } 0.43-0.50 \text { and } \\
0.25-0.49 \text { at the global level, respectively. } \\
\text { Validation dataset link: http://www.geosimulation.cn/GlobalUrbanLand.html }\end{array}$ \\
\hline Yang et al. [50] & Malaysia & $\begin{array}{c}\text { The overall accuracies of GHSL and GlobeLand } 30 \text { were } 89.21 \% \\
\text { and } 80.54 \% \text {, respectively, the corresponding producer's accuracies } \\
\text { were } 87 \% \text { and } 73 \% \text {, and the user's } \\
\text { accuracies were } 86 \% \text { and } 77 \% \text {. }\end{array}$ \\
\hline Marconcini et al. [51] & Global $\left(4501^{\circ} \times 1^{\circ}\right.$ test sites $)$ & $\begin{array}{l}\text { GHSL and GlobeLand } 30 \text { had an overall accuracy of } 70.64 \% \text { and } \\
67.86 \% \text {, respectively, the kappa coefficients were } 0.4603 \text { and } 0.4051 \text {, } \\
\text { the producer's accuracies were } 45.98 \% \text { and } 40.03 \% \text {, and the user's } \\
\text { accuracies were } 84.26 \% \text { and } 83.55 \% \text {, respectively. }\end{array}$ \\
\hline Liu et al. [107] & Global (45 cities) & $\begin{array}{l}\text { GHSL had an overall accuracy of } 84.18 \%, F \text {-measure of } 0.71 \text {, } \\
\text { user's accuracy of } 84.06 \% \text {, and producer's accuracy of } 68.77 \% \\
\text { for } 45 \text { cities across the globe. In addition, GHSL had an overall } \\
\text { accuracy of } 78.92 \% \text { and } 85.86 \% \text {, a user's accuracy of } 85.46 \% \text { and } \\
81.51 \% \text {, and a producer's accuracy of } 82.77 \% \text { and } 56.78 \% \\
\text { for urban and rural areas, respectively. }\end{array}$ \\
\hline Pesaresi et al. [52] & Europe & $\begin{array}{c}\text { GHSL had an overall accuracy of } 96.28 \% \text { and a kappa coefficient of } \\
0.3233 \text { based on LUCAS reference data. }\end{array}$ \\
\hline Leyk et al. [53] & 26 counties in the US & $\begin{array}{l}\text { GHSL had an } F \text {-measure of } 0.650, G \text {-mean of } 0.767 \text {, and kappa coefficient } \\
\text { of } 0.562 \text { for the built-up layer in } 2015 \text {. }\end{array}$ \\
\hline Wang et al. [48] & Asia & $\begin{array}{l}\text { For the Asian HBASE classification model, according to the result } \\
\text { of the cross-validation, the user's accuracy, producer's accuracy, } \\
\text { overall accuracy, and kappa coefficient were } 91.5 \% \text {, } \\
\qquad 90.3 \%, 97.9 \% \text {, and } 0.90 \text {, respectively. }\end{array}$ \\
\hline
\end{tabular}

threshold for forest by GLC_FCS30 and FROM_GLC, 10\% is used by GlobeLand30 and GFC30, and $49 \%$ is used by the TreeCover product. GLC_FCS30 and FROM_GLC have a TH threshold of $3 \mathrm{~m}$, whereas $5 \mathrm{~m}$ is used by the GLADForest and GFC30 products. In terms of the methodology used, supervised classification methods are widely used: for example, GLC_FCS30, FROM_GLC, and GFC30 are generated using training samples and supervised classification models 
TABLE 6: Definition and details of the seven global $30 \mathrm{~m}$ forest products.

\begin{tabular}{|c|c|c|c|c|}
\hline Map name & Period & Definition & Method & Literature \\
\hline GLC_FCS30 & $\begin{array}{l}2015 \\
2020\end{array}$ & $\begin{array}{c}\text { Tree-cover percentage }>15 \% \text {; tree height }>3 \mathrm{~m} \\
\text { Forest is divided into five subclasses (evergreen } \\
\text { broadleaf forest, deciduous broadleaf forest, } \\
\text { evergreen needleleaf forest, deciduous needleleaf } \\
\text { forest, and mixed forest) } \\
\text { Dataset link: https://zenodo.org/record/3986872, } \\
\text { https://zenodo.org/record/4280923 }\end{array}$ & $\begin{array}{l}\text { Local adaptive random forest models, Global } \\
\text { Spatial Temporal Spectral Library (GSPECLib), } \\
\text { and time series of Landsat imagery are used to } \\
\text { automatically generate forest products for each } \\
\qquad 5^{\circ} \times 5^{\circ} \text { geographical grid cell. }\end{array}$ & $\begin{array}{l}\text { Zhang et al. } \\
\text { [22] } \\
\text { Liu et al. } \\
{[15]}\end{array}$ \\
\hline FROM_GLC & $\begin{array}{l}2010 \\
2015 \\
2017\end{array}$ & $\begin{array}{l}\text { Tree-cover percentage }>15 \% \text {; tree height }>3 \mathrm{~m} \\
\text { Consists of broadleaf forest, needleleaf forest, } \\
\text { mixed forest, and orchards } \\
\text { Dataset link: http://data.ess.tsinghua.edu.cn/ } \\
\text { fromglc2015_v1.html }\end{array}$ & $\begin{array}{c}\text { Forest is treated as an independent layer and } \\
\text { classified using 91,433 training samples and } \\
\text { multitemporal Landsat imagery. }\end{array}$ & $\begin{array}{l}\text { Gong et al. } \\
{[12]}\end{array}$ \\
\hline GlobeLand30 & $\begin{array}{l}2000 \\
2010 \\
2017\end{array}$ & $\begin{array}{l}\text { Land covered by trees that cover more than } 30 \% \\
\text { includes deciduous broadleaf forest, evergreen } \\
\text { broadleaf forest, deciduous coniferous forest, } \\
\text { evergreen coniferous forest, mixed forest, and } \\
\text { open woodland with a tree cover of } 10-30 \% \text {. } \\
\text { Dataset link: http://www.globallandcover.com/ } \\
\text { GLC30Download/index.aspx }\end{array}$ & $\begin{array}{c}\text { Forest is an independent layer and classified by } \\
\text { combining pixel-based and object-based } \\
\text { methods using multitemporal Landsat and } \mathrm{HJ} \\
\text { imagery. }\end{array}$ & $\begin{array}{l}\text { Chen et al. } \\
\text { [14] }\end{array}$ \\
\hline GFCC30TC & $\begin{array}{l}2000 \\
2005 \\
2010 \\
2015\end{array}$ & $\begin{array}{c}\text { "Forest" is defined as a class of land cover } \\
\text { wherein tree (canopy) cover, } c \text {, exceeds a } \\
\text { predefined threshold value, } c^{*} \text {. The probability of } \\
\text { belonging to "forest," } p(F) \text {, is therefore the } \\
\text { probability of } c \text { exceeding the threshold } c^{*} \\
\text { Dataset link: https://lpdaac.usgs.gov/products/ } \\
\text { gfcc30tcv003/ }\end{array}$ & $\begin{array}{l}\text { The } 250 \mathrm{~m} \text { MODIS Vegetation Continuous } \\
\text { Fields (VCF) tree-cover layer is downscaled } \\
\text { using c. } 2000 \text { and } 2005 \text { Landsat images. The } \\
\text { MODIS cropland layer is included to improve } \\
\text { accuracy in agricultural areas. }\end{array}$ & $\begin{array}{l}\text { Sexton et al. } \\
\quad \text { [108] } \\
\text { Townshend } \\
\text { et al. [109] } \\
\text { Sexton et al. } \\
\quad \text { [31] }\end{array}$ \\
\hline TreeCover & 2010 & $\begin{array}{c}\text { Forest cover is defined using certain tree canopy } \\
\text { cover thresholds without attribution to specific } \\
\text { land-cover categories and land use. The forest } \\
\text { cover class is identified using a threshold } \geq 49 \% \\
\text { tree canopy cover. } \\
\text { Dataset link: https://glad.umd.edu/dataset/ } \\
\text { global-2010-tree-cover-30-m }\end{array}$ & $\begin{array}{l}\text { A regression tree model is applied to estimate the } \\
\text { maximum (peak of the growing season) tree- } \\
\text { canopy cover for each pixel from cloud-free } \\
\text { annual growing season composite Landsat-7 } \\
\text { ETM+ data from c. } 2010 \text {. }\end{array}$ & $\begin{array}{l}\text { Hansen } \\
\text { et al. [30] } \\
\text { Potapov } \\
\text { et al. [110] }\end{array}$ \\
\hline GLADForest & $\begin{array}{c}2000- \\
2019 \\
\text { (annual) }\end{array}$ & $\begin{array}{l}\text { Trees are defined as vegetation taller than } 5 \mathrm{~m} \text { in } \\
\text { height and are expressed as a percentage per } \\
\text { output grid cell as " } 2000 \text { Percent Tree Cover." } \\
\text { "Forest Cover Loss" is defined as a stand- } \\
\text { replacement disturbance or a change from a } \\
\text { forest to a nonforest state, during the period } \\
\text { 2000-2019. "Forest Cover Gain" is defined as the } \\
\text { inverse of loss or a nonforest to forest change } \\
\text { entirely within the period 2000-2012. } \\
\text { Dataset link: http://earthenginepartners.appspot } \\
\text {.com/science-2013-global-forest/download_v1.7 } \\
\text {.html }\end{array}$ & $\begin{array}{l}\text { Tree-cover percentage, forest loss, and forest gain } \\
\text { training data are related to the time series metrics } \\
\text { using a decision tree. For the tree-cover and } \\
\text { change products, a bagged decision tree } \\
\text { methodology is employed. Forest loss is } \\
\text { disaggregated to annual time scales using a set of } \\
\text { heuristics derived from the maximum annual } \\
\text { decline in the tree-cover percentage and the } \\
\text { maximum annual decline in minimum growing } \\
\text { season NDVI. }\end{array}$ & $\begin{array}{l}\text { Hansen } \\
\text { et al. [30] }\end{array}$ \\
\hline GFC30 & 2018 & $\begin{array}{c}\text { Land spanning more than } 0.5 \text { ha with trees } \\
\text { higher than } 5 \mathrm{~m} \text { and a canopy cover of more than } \\
\text { 10\%, or trees able to reach these thresholds in } \\
\text { situ } \\
\text { Dataset link: http://www.chinageoss.cn/geoarc/ } \\
\text { data/2019-GEOARC-01.zip }\end{array}$ & $\begin{array}{l}\text { The Earth is divided into } 45 \text { forest ecological } \\
\text { zones. Each zone is classified using the random } \\
\text { forest model and time series of Landsat imagery. }\end{array}$ & $\begin{array}{c}\text { Zhang et al. } \\
\text { [32] }\end{array}$ \\
\hline
\end{tabular}

and GlobeLand30 is produced by combining supervised classification with an object-based segmentation method. The decision tree regression model is used by TreeCover and GLADForest to generate continuous forest-cover percentage products. The GFCC30TC forest product is derived by com- bining the $250 \mathrm{~m}$ MODIS Vegetation Continuous Fields (VCF) tree-cover layer and Landsat imagery.

3.3.2. Review of the Accuracy Assessments of the Global Forest Maps. To help with understanding the accuracy of each 
global $30 \mathrm{~m}$ forest map, Table 7 lists the accuracy metrics of each forest product based on the results of different studies. It should be noted that the forest land-cover type exists as an independent layer in GLC_FCS30, FROM_GLC, and GlobeLand 30 and also as a single thematic element in the GFCC30TC, TreeCover-2010, GLADForest, and GFC products.

For the products where forest is an independent layer (GLC_FCS30, GlobeLand30, and FROM_GLC), the producer's accuracies are $94.0 \%, 92.4 \%$, and $76.5 \%$, respectively, and the user's accuracies are 90.4\%, 84.1\%, and 80.5\%, respectively, at the global scale. Kang et al. [39] and Gao et al. [45] comprehensively assessed the forest layers in these three different products at a regional scale, and the results indicated that GlobeLand30 and GLC_FCS30 have the same producer's and user's accuracies and that these values were higher than those of FROM_GLC. Furthermore, MorenoSanchez et al. [54] found that the overall accuracy of "forest" in GlobeLand30 was higher in tropical forest areas than in temperate forests, and Tsendbazar et al. [55] confirmed that the accuracy of the forest layer in GlobeLand30 is poorer in Africa than in other regions. Overall, the accuracy of the forest land-cover type in GlobeLand30 and GLC_FCS30 was found to be better than that in FROM_GLC.

Secondly, the global thematic forest products GFCC30TC and GFC30 have been validated as having accuracies of $90 \%$ and $90.94 \%$ at the global scale. GFCC30TC performs differently in different geographical regions: for example, it underestimates the high-canopy forest (canopy cover $>70 \%$ ) but overestimates the low-canopy forest (canopy cover $<30 \%$ ) in the boreal forest in Finland [56] and has a higher accuracy over North America (82\% in Maryland) [57] than in South America (where the producer's and user's accuracies are $73.4 \% \pm 0.09 \%$ and $94.7 \% \pm 0.11 \%$, respectively) [58]. TCC2010 has been shown to have a higher accuracy than other forest products: for example, the producer's and user's accuracies were shown to be $88.4 \% \pm 0.07 \%$ and $91.3 \% \pm 0.07 \%$, as against $73.4 \% \pm 0.09 \%$ and $94.7 \% \pm 0.11 \%$ for GFCC30TC, in South America [58]. In Kyrgyzstan, TCC2010 was found to have an overall accuracy of $94.50 \%$ against $88.27 \%$ for GlobeLand30 [59]. Finally, GLADForest, which is the most widely used forest change product, has been validated to have an overall accuracy of $99.6 \% \pm 0.7 \%$ for forest loss and $99.7 \% \pm 0.6 \%$ for forest gain based on only 1500 validation points [30]. However, regional validations have indicated that this product has an overall accuracy of $81 \%$ in Maryland [57], 66\%-56\% in Indonesia [60], and 80.8\% \pm $2.3 \%$ in Costa Rica [61].

Therefore, as shown by the accuracy metrics in Table 7, the global thematic forest products (GFCC30TC, TreeCover-2010, GLADForest, and GFC30) generally have a higher overall accuracy than the global "forest layer" products (where forest is an independent layer), and the regional accuracies are usually lower than the global values.

\subsection{Review of the Global Cropland Maps}

3.4.1. Overview of the Global Cropland Maps. Cropland is an important land-cover type related to global food and water security. Cropland has a close relationship with human activities and usually consists of land cultivated with plants that are harvested for food, animal feed, and fibers. In recent decades, as the global population has rapidly grown, the growing demand for food has put added pressure on the food supply system, particularly because of the demand for grains used as livestock feed in regions where food security remains elusive [62]. Therefore, accurate global mapping of cropland is of great importance to assessing and monitoring global food security and production potential. In this study, six global $30 \mathrm{~m}$ cropland products were acquired. These products are summarized in Table 8 .

Most global cropland products (GLC_FCS30, GlobeLand30, GCAD30, GFSAD30, and FROM_GC) contain single-epoch cropland information; the exceptions are the FROM_GLC and GlobeLand30 cropland products. In this study, the nominal year of 2015 was selected for analyzing the consistency between the global products. However, the GCAD30 stopped sharing after GFSAD30 was released and two of these products (FROM_GC and GlobeLand30) were available for 2010. The temporal variations between 2010 and 2015 were, therefore, neglected, and this may have led to a certain amount of bias in the comparison. Furthermore, from the point of view of the definition of cropland, there are obvious differences between these global cropland products. For example, GLC_FCS30 defines cropland using only human management as the criterion and FROM_GC excludes "permanent pastures." GlobeLand30, FROM_GLC, and GFSAD30 define cropland from a functional perspective as being land cultivated with plants that are harvested for food, animal feed, and fiber; however, FROM_GLC excludes fruit trees and classifies them as belonging to "forest." Finally, in terms of the methodology used, these products can be divided into three groups: GLC_FCS30 and FROM_GLC are produced using pixel-based supervised classification; GlobeLand30, GCAD30, and GFSAD30 use a combination of pixel-based classification and object-based segmentation; and FROM_GC is composited from four previously produced cropland maps.

3.4.2. Review of the Accuracy Assessments of the Global Cropland Maps. The results of assessments of the accuracy of five global $30 \mathrm{~m}$ cropland maps are summarized in Table 9. Similar to the forest land-cover type that was discussed in Section 4.2, cropland exists as a single layer in the GLC_FCS30, FROM_GLC, and GlobeLand30 land-cover products and also as an independent thematic product in FROM_GC and GFSAD30. (Note that GCAD30 has not been available since the release of GFSAD30.)

Looking first at the products in which cropland is an independent layer, in GLC_FCS30, GlobeLand30, and FROM_GLC, cropland has been shown to have the producer's accuracies of $88.0 \%, 88.2 \%$, and $47.7 \%$ and the user's accuracies of $83.9 \%, 88.7 \%$, and $74.7 \%$, respectively [16]. The accuracy of the cropland class in GlobeLand30 and FROM GLC varies according to the geographical zone and validation dataset used; for example, Zhong et al. [63] found an overall accuracy of $79.61 \%$ and kappa coefficient of 0.58 for FROM_GLC as against $76.23 \%$ and 0.52 found by Lu et al. 
TABLE 7: Summary of the reported accuracies of the $30 \mathrm{~m}$ global forest products.

\begin{tabular}{|c|c|c|}
\hline Study & Region & Accuracy description \\
\hline Chen et al. [14] & Global & $\begin{array}{l}\text { The producer's and user's accuracies of the forest class of } \\
\text { GlobeLand } 30 \text { are } 92.4 \% \text { and } 84.1 \% \text {, respectively. }\end{array}$ \\
\hline Gong et al. [12] & Global & $\begin{array}{c}\text { The producer's and user's accuracies of the forest class of } \\
\text { FROM_GLC are } 76.5 \% \text { and } 80.5 \% \text {, respectively. } \\
\text { Validation data link: } \\
\text { http://data.ess.tsinghua.edu.cn/data/temp/GlobalLandCoverValidationSampleSet_v1 } \\
\text {.xlsx }\end{array}$ \\
\hline Zhang et al. [16] & Global & $\begin{array}{c}\text { GLC_FCS30, GlobeLand30, and FROM_GLC had the producer's } \\
\text { accuracies of } 94.0 \%, 92.6 \% \text {, and } 74.9 \% \text {, respectively, and user's } \\
\text { accuracies of } 90.4 \%, 90.5 \% \text {, and } 77.1 \% \text {, respectively, for } \\
\text { the forest land-cover type. } \\
\text { Validation data link: } 10.5281 / \text { zenodo. } 3551994\end{array}$ \\
\hline Kang et al. [39] & Indonesia & $\begin{array}{l}\text { GLC_FCS30, GlobeLand30, and FROM_GLC had the } \\
\text { producer's accuracies of } 82.96,56.72 \% \text {, and } 58.15 \% \text {, } \\
\text { respectively, and user's accuracies of } 83.21 \%, 95.05 \% \text {, and } 96.25 \% \text {, } \\
\text { respectively, for the forest land-cover type. }\end{array}$ \\
\hline Gao et al. [45] & European Union & $\begin{array}{c}\text { GLC_FCS30, GlobeLand30, and FROM_GLC had the producer's } \\
\text { accuracies of } 92.86 \%, 93.60 \% \text {, and } 81.59 \% \text {, respectively, and } \\
\text { user's accuracies of } 92.14 \%, 97.36 \% \text {, and } 74.91 \% \text {, respectively, } \\
\text { for the forest land-cover type. } \\
\text { Validation data link: } \\
\text { https://ec.europa.eu/eurostat/web/lucas/data/lucas-grid }\end{array}$ \\
\hline Yang et al. [111] & $\begin{array}{l}\text { The Loess } \\
\text { Plateau, China }\end{array}$ & $\begin{array}{l}\text { The forest class in GlobeLand30, FROM_GLC, } \\
\text { GLADForest, and GFCC30TC had an overall accuracy of } \\
97 \% \pm 0.2 \%, 95 \% \pm 0.2 \%, 94 \% \pm 0.3 \% \text {, and } \\
93 \% \pm 0.3 \% \text {, respectively. The producer's and user's accuracies of } \\
\text { these four forest products were } 93 \% \pm 0.9 \% \text { and } 84 \% \pm 0.1 \% \text {, } \\
92 \% \pm 0.1 \% \text { and } 72 \% \pm 0.1 \%, 63 \% \pm 0.1 \% \text { and } 94 \% \pm 0.8 \% \\
\text { and } 79 \% \pm 0.1 \% \text { and } 75 \% \pm 0.1 \% \text {, respectively. }\end{array}$ \\
\hline Moreno-Sanchez et al. [54] & Mexico & $\begin{array}{l}\text { The accuracy of the forest class of GlobeLand } 30 \text { is } \\
\text { higher in tropical forests than in temperate forests } \\
\text { (around } 90 \% \text { compared with around } 77 \% \text { ). }\end{array}$ \\
\hline Tsendbazar et al. [55] & Africa & $\begin{array}{c}\text { GlobeLand } 30-2010 \text { had a producer's accuracy of } 63.6 \% \pm 3.5 \% \\
\text { and a user's accuracy of } 76.1 \% \pm 3.2 \% \text { using } 15,252 \text { validation } \\
\text { samples for the forest land-cover type. }\end{array}$ \\
\hline $\mathrm{Xu}$ et al. [35] & Africa & $\begin{array}{l}\text { The producer's and user's accuracies of the forest class of } \\
\text { the second version of the African land-cover mapping in } \\
\text { FROM_GLC are } 82.4 \% \text { and } 72.6 \% \text {, respectively. }\end{array}$ \\
\hline Song et al. [57] & $\begin{array}{l}\text { Maryland, } \\
\text { United States }\end{array}$ & $\begin{array}{l}\text { The overall accuracy, producer's accuracy, and user's } \\
\text { accuracy of GFCC30TC were } 82 \%, 80 \% \text {, and } 91 \% \text {, respectively, } \\
\text { and of GLADForest were } 81 \%, 86 \% \text {, and } 85 \% \text {, respectively, } \\
\text { for Maryland, United States. }\end{array}$ \\
\hline Townshend et al. [109] & Global & $\begin{array}{l}\text { The overall accuracy of GFCC30TC is above or near } 90 \% \text {; } \\
\text { the average user's accuracy and producer's accuracy for } \\
\text { persisting forests are } 92.5 \% \text { and } 95.4 \% \text {, respectively. } \\
\text { For persisting nonforest, forest loss, and forest gain, the } \\
\text { corresponding accuracies are } 94.8 \% \text { and } 91.1 \%, 87.1 \% \\
\text { and } 91.1 \% \text {, and } 84.7 \% \text { and } 81.5 \% \text {, respectively. }\end{array}$ \\
\hline Sexton et al. [31] & Global & $\begin{array}{l}\text { The overall accuracy of the static forest-cover layers in } \\
\text { GFCC30TC was } 91 \% \text {, and the overall accuracy of } \\
\text { forest-cover change was }>88 \% \text { - these are among the highest } \\
\text { accuracies reported for recent global } \\
\text { forest- and land-cover products. }\end{array}$ \\
\hline
\end{tabular}


TABLe 7: Continued.

\begin{tabular}{|c|c|c|}
\hline Study & Region & Accuracy description \\
\hline Hadi et al. [56] & Finland & $\begin{array}{l}\text { GFCC30TC underestimated the high-canopy cover forest } \\
\text { (cover }>70 \%) \text { and overestimated the low-canopy } \\
\text { cover forest }(\text { cover }<30 \%) \text { in boreal forests, giving an } R^{2} \text { of } 0.53 \\
\text { and a bias of }-2.1 \% \text { for the comparison with the field-measured data. }\end{array}$ \\
\hline Qin et al. [58] & South America & $\begin{array}{c}\text { The user's and producer's accuracies of GFCC30TC were } \\
73.4 \% \pm 0.09 \% \text { and } 94.7 \% \pm 0.11 \% \text {, respectively, } \\
\text { and of TCC-2010 were } 88.4 \% \pm 0.07 \% \text { and } \\
91.3 \% \pm 0.07 \% \text {, respectively. }\end{array}$ \\
\hline Zhang et al. [112] & China & $\begin{array}{l}\text { TCC-2000 had an overall accuracy of } 94.5 \% \text {, a producer's } \\
\text { accuracy of } 82.13 \% \text {, and a user's accuracy of } 89.26 \% \text {. }\end{array}$ \\
\hline Pengra et al. [113] & South America & $\begin{array}{c}\text { TCC-2010 had an overall accuracy of } 89.3 \% \pm 2.3 \% \\
\text { a producer's accuracy of } 98.2 \% \pm 0.4 \% \text {, and a } \\
\text { user's accuracy of } 84.9 \% \pm 4.2 \%\end{array}$ \\
\hline Jia et al. [59] & Kyrgyzstan & $\begin{array}{l}\text { TCC- } 2010 \text { and GlobeLand } 30-2010 \text { had the overall } \\
\text { accuracies of } 94.50 \% \text { and } 88.27 \% \text {, kappa coefficients of } 0.80 \\
\text { and } 0.65 \text {, producer's accuracies of } 75.71 \% \text { and } 79.50 \%, \\
\text { and user's accuracies of } 94.42 \% \text { and } 66.07 \%, \\
\text { respectively, using } 9923 \text { validation points. }\end{array}$ \\
\hline Hansen et al. [30] & Global & $\begin{array}{l}\text { The GLADForest product was validated in terms of } \\
\text { forest losses and gains using } 1500 \text { points. The results showed } \\
\text { that it had an overall accuracy of } 99.6 \% \pm 0.7 \% \text { and the } \\
\text { producer's and user's accuracies of } 87.8 \% \pm 2.8 \% \text { and } 87.0 \% \pm 2.8 \% \text {, } \\
\text { respectively, for forest losses; it had an overall accuracy of } \\
99.7 \% \pm 0.6 \% \text { and the producer's and user's accuracies } \\
\text { of } 73.9 \% \pm 0.07 \% \text { and } 76.4 \% \pm 0.6 \% \text {, respectively, for forest gains. }\end{array}$ \\
\hline Arjasakusuma et al. [60] & $\begin{array}{l}\text { Central Kalimantan } \\
\text { Province, Indonesia }\end{array}$ & The overall accuracy of GLADForest is $66 \%-56 \%$ \\
\hline Cunningham et al. [61] & Costa Rica & $\begin{array}{l}\text { The overall accuracy of GLADForest is } 80.8 \% \pm 2.3 \% \text {, } \\
\text { and the producer's and user's accuracies are } 79 \% \text { and } \\
81 \% \text {, respectively, based on } 1154 \text { validation points. }\end{array}$ \\
\hline Zhang et al. [32] & Global & $\begin{array}{l}\text { GFC30 had an overall accuracy of } 90.94 \% \text {, a producer's } \\
\text { accuracy of } 93.95 \% \text {, and a user's accuracy of } 87.12 \% \text {. } \\
\text { By continent, the PA and UA were } 90.43 \% \text { and } 85.43 \% \text { in } \\
\text { Africa, } 92.65 \% \text { and } 89.05 \% \text { in Asia, } 94.95 \% \text { and } 95.66 \% \text { in } \\
\text { Europe, } 92.19 \% \text { and } 78.86 \% \text { in North America, } 93.95 \% \text { and } 89.00 \% \text { in } \\
\text { Oceania, and } 96.33 \% \text { and } 89.51 \% \text { in South America, respectively. }\end{array}$ \\
\hline
\end{tabular}

[64]. GlobeLand30, which is the most widely used land-cover product [65], was demonstrated to have an overall accuracy of $80 \%$ in Africa, America, and Asia [66], an accuracy of $79.61 \%$ and a kappa coefficient of 0.58 in China [64], an accuracy of $80.61 \%$ in Shaanxi Province, China [67], an accuracy of $86.98 \%$ and a kappa coefficient of 0.692 in East Africa [68], an accuracy of $47 \% \pm 1 \%$ in Tanzania [69], and an accuracy of $79.5 \%$ over five West African countries [70].

FROM_GC and GFSAD30 are two widely used thematic cropland products-this applies to GFSAD30 in particular. GFSAD30, which was derived and optimized from GCAD30 [71], was assessed for different continents and countries. Globally, an overall accuracy of $91.7 \%$, a producer's accuracy of $83.4 \%$, and a user's accuracy of $78.3 \%$ were found using 19,171 validation points [27, 72]. Regionally, this product was found to have an overall accuracy of $94 \%$ in Australia and China [73], an overall accuracy of $90.8 \%$ and a weighted accuracy of $93.8 \%$ in Europe, the Middle East, Russia, and Central Asia [74], a weighted overall accuracy of $94.5 \%$ in Africa $[75,76]$, an overall accuracy of $88.1 \%$ in Southeast and Northeast Asia [77], and an average user's accuracy of $73.1 \%$ over five West African countries [70]. As for the FROM_GC cropland product, it was assessed to have a significant linear relationship with FAOSTAT data (with an $R^{2}$ of 0.97 ) globally [29], and overall accuracies of $77.67 \%$ and $36 \%$ $\pm 1 \%$ were demonstrated for Shaanxi Province, China [67] and Tanzania [69], respectively. FROM_GC and GFSAD30 matched for $68.8 \%$ of cropland samples from Africa [75, 76].

Comparisons between GlobeLand30 (in which cropland is a single land-cover layer) and GFSAD30 (in which cropland is an independent thematic product) have also been conducted. The results have indicated that the two products have an overall similarity of $88.8 \%$ and a kappa coefficient of 0.7 in Europe, the Middle East, Russia, and Central Asia [74]. GlobeLand30 was shown to have a higher overall accuracy than GFSAD30 over five West African countries [70]. 
TABLE 8: Definitions and details of the six global $30 \mathrm{~m}$ cropland products.

\begin{tabular}{|c|c|c|c|c|}
\hline Map name & Period & Definition & Method & Literature \\
\hline GLC_FCS30 & $\begin{array}{l}2015 \\
2020\end{array}$ & $\begin{array}{l}\text { Refers to areas where the natural vegetation has } \\
\text { been removed or modified and replaced by other } \\
\text { types of the vegetative cover of anthropogenic } \\
\text { origin. It is artificial and requires human activities } \\
\text { to maintain it in the long term. } \\
\text { Dataset link: https://zenodo.org/record/3986872, } \\
\text { https://zenodo.org/record/4280923 }\end{array}$ & $\begin{array}{l}\text { Cropland was treated as consisting of four } \\
\text { subclasses and classified using the local adaptive } \\
\text { random forest models, Global Spatial Temporal } \\
\text { Spectral Library (GSPECLib), and time series of } \\
\text { Landsat imagery. }\end{array}$ & $\begin{array}{l}\text { Zhang et al. } \\
\text { [22] } \\
\text { Liu et al. } \\
\text { [15] }\end{array}$ \\
\hline FROM_GLC & $\begin{array}{l}2010 \\
2015 \\
2017\end{array}$ & $\begin{array}{l}\text { This type of land has clear traits of intensive } \\
\text { human activity. It varies a lot from bare field, } \\
\text { seeding, and crop growing to harvesting. It can be } \\
\text { easily identified if edges or textures are visible and } \\
\text { the land parcels are sufficiently large. Fruit trees } \\
\text { are classified as forests. Pasture can include the } \\
\text { transition from cropland to natural grassland. } \\
\text { Dataset link: http://data.ess.tsinghua.edu.cn/ } \\
\text { fromglc2015_v1.html }\end{array}$ & $\begin{array}{c}\text { Cropland was treated as an independent layer and } \\
\text { classified using 91,433 training samples and } \\
\text { multitemporal Landsat imagery. }\end{array}$ & $\begin{array}{c}\text { Gong et al. } \\
{[12]}\end{array}$ \\
\hline GlobeLand30 & $\begin{array}{l}2000 \\
2010 \\
2017\end{array}$ & $\begin{array}{l}\text { Land used for planting crops including paddy } \\
\text { fields, irrigated dry land, and rainfed dry land; land } \\
\text { used for growing vegetables, herbage, greenhouses, } \\
\text { or fruit trees and other economically valuable } \\
\text { trees; also land used for planting shrub cash crops } \\
\text { such as tea and coffee } \\
\text { Dataset link: http://www.globallandcover.com/ } \\
\text { GLC30Download/index.aspx }\end{array}$ & $\begin{array}{l}\text { Developed based on both crop phenology and the } \\
\text { regular distribution patterns of cultivated land; } \\
\text { object-based segmentation was then overlaid onto } \\
\text { potential images of cultivated land. Using virtual } \\
\text { interpretation, only objects displaying regular } \\
\text { man-made patterns such as circles or rectangles } \\
\text { were identified as cultivated land. }\end{array}$ & $\begin{array}{c}\text { Chen et al. } \\
{[14]}\end{array}$ \\
\hline FROM_GC & 2010 & $\begin{array}{l}\text { The definition of cropland in this study is } \\
\text { consistent with FAO's definition of "arable lands } \\
\text { and permanent crops"; "permanent pastures" is } \\
\text { not included. } \\
\text { Dataset link: http://data.ess.tsinghua.edu.cn/data }\end{array}$ & $\begin{array}{l}\text { Composited from four existing cropland maps, } \\
\text { including FROM_GLC and FROM_GLC_agg, and } \\
\text { two } 250 \mathrm{~m} \text { masked cropland layers }\end{array}$ & $\begin{array}{c}\text { Yu et al. } \\
\text { [29] }\end{array}$ \\
\hline GCAD30 & 2010 & $\begin{array}{l}\text { There are several rules for defining cropland } \\
\text { including the following: (1) the minimum } \\
\text { mapping unit of a particular crop is an area of } 3 \\
\times 3 \text { Landsat pixels ( } 0.81 \text { hectares); (2) all } \\
\text { cultivated plants harvested for food, feed, and } \\
\text { fiber, including plantations (e.g., orchards, } \\
\text { vineyards, coffee and tea, and rubber plantations), } \\
\text { are included; ( } 3 \text { ) }>50 \% \text { of the pixel is cropped; and } \\
\text { (4) irrigation is defined as the artificial application } \\
\text { of any amount of water to overcome crop water } \\
\text { stress. } \\
\text { Dataset link: not available }\end{array}$ & $\begin{array}{l}\text { An ensemble of methods was employed, including } \\
\text { spectral matching techniques, the Automated } \\
\text { Cropland Classification Algorithm (ACCA), and } \\
\text { the hierarchical segmentation (HSeg) algorithm } \\
\text { based on the Landsat } 30 \text { m Global Land Survey } \\
2010 \text { (GLS2010) dataset and a suite of secondary } \\
\text { data (e.g., long-term precipitation and } \\
\text { temperature data and a DEM). }\end{array}$ & $\begin{array}{l}\text { Teluguntla } \\
\text { et al. [71] } \\
\text { Teluguntla } \\
\text { et al. [114] }\end{array}$ \\
\hline GFSAD30 & 2015 & $\begin{array}{l}\text { Lands cultivated with plants harvested for food, } \\
\text { feed, and fiber, including both seasonal crops (e.g., } \\
\text { wheat, rice, corn, soybeans, and cotton) and } \\
\text { continuous plantations (e.g., coffee, tea, rubber, } \\
\text { cocoa, and oil palm). Cropland fallows are lands } \\
\text { uncultivated during a season or a year but are } \\
\text { farmlands and are equipped for cultivation, } \\
\text { including plantations. } \\
\text { Dataset link: https://lpdaac.usgs.gov/news/release- } \\
\text { of-gfsad-30 meter-cropland-extent-products/ }\end{array}$ & $\begin{array}{l}\text { Integration of pixel-based classifiers (random } \\
\text { forest and support vector machines) and an } \\
\text { object-based classifier (Recursive Hierarchical } \\
\text { Image Segmentation) to obtain the cropland map } \\
\text { for each ecological zone }\end{array}$ & $\begin{array}{l}\text { Oliphant } \\
\text { et al. [27] } \\
\text { Phalke } \\
\text { et al. [74] }\end{array}$ \\
\hline
\end{tabular}

\subsection{Review of the Global Water Maps}

3.5.1. Overview of the Global Inland Water Maps. Inland water refers to fresh and brackish water bodies such as lakes, reservoirs, and rivers [78]. These water bodies play a vital role in the global and regional hydrological and biogeochemical water cycles [23, 79]. However, due to their sensitivity to changes in the environment and climate, the distribution of water bodies varies over time. The resulting variations in water bodies have significant implications for the water balance and regional biodiversity [80]. In this study, three $30 \mathrm{~m}$ global inland water thematic products (G1WBM, 


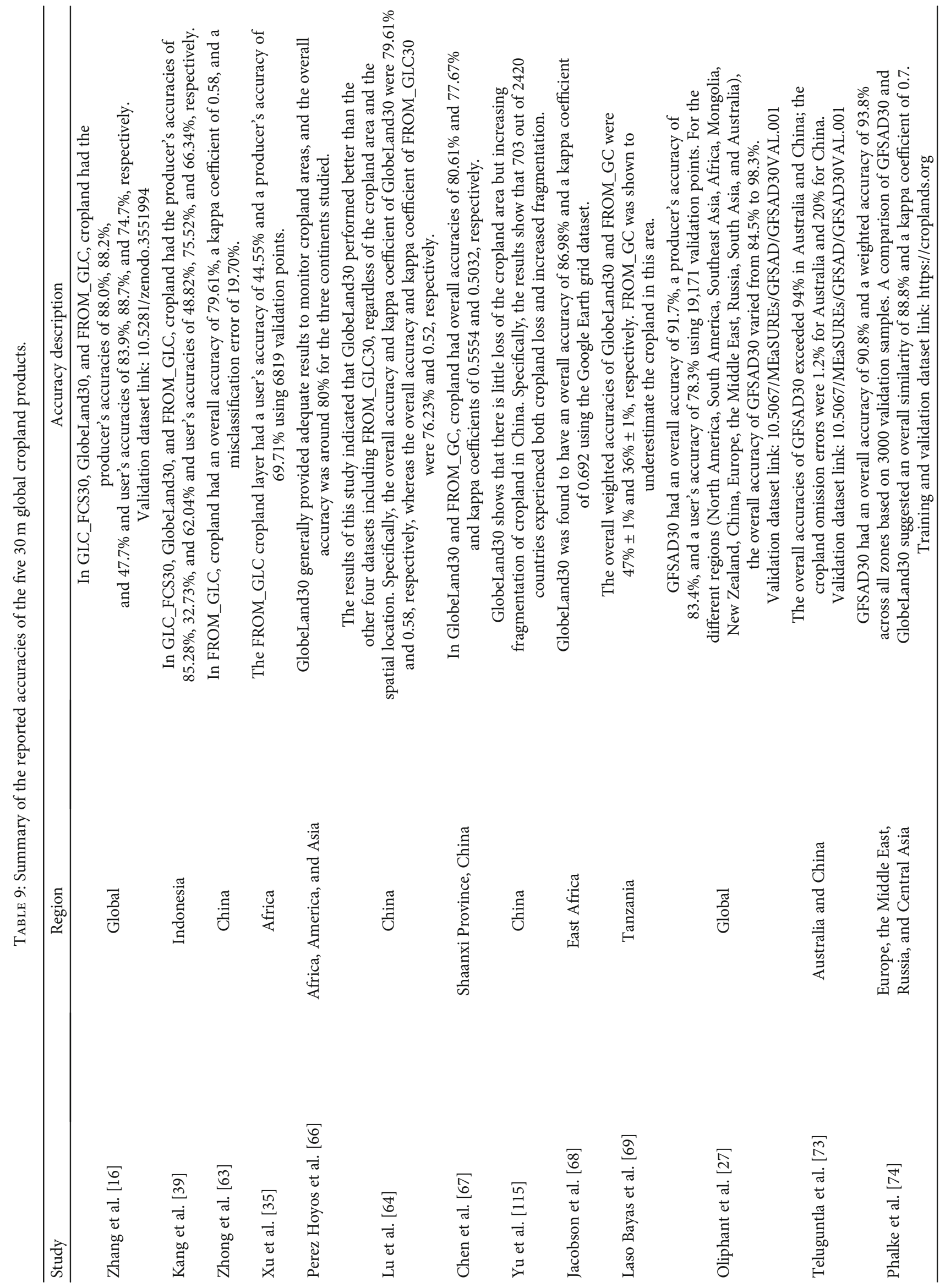




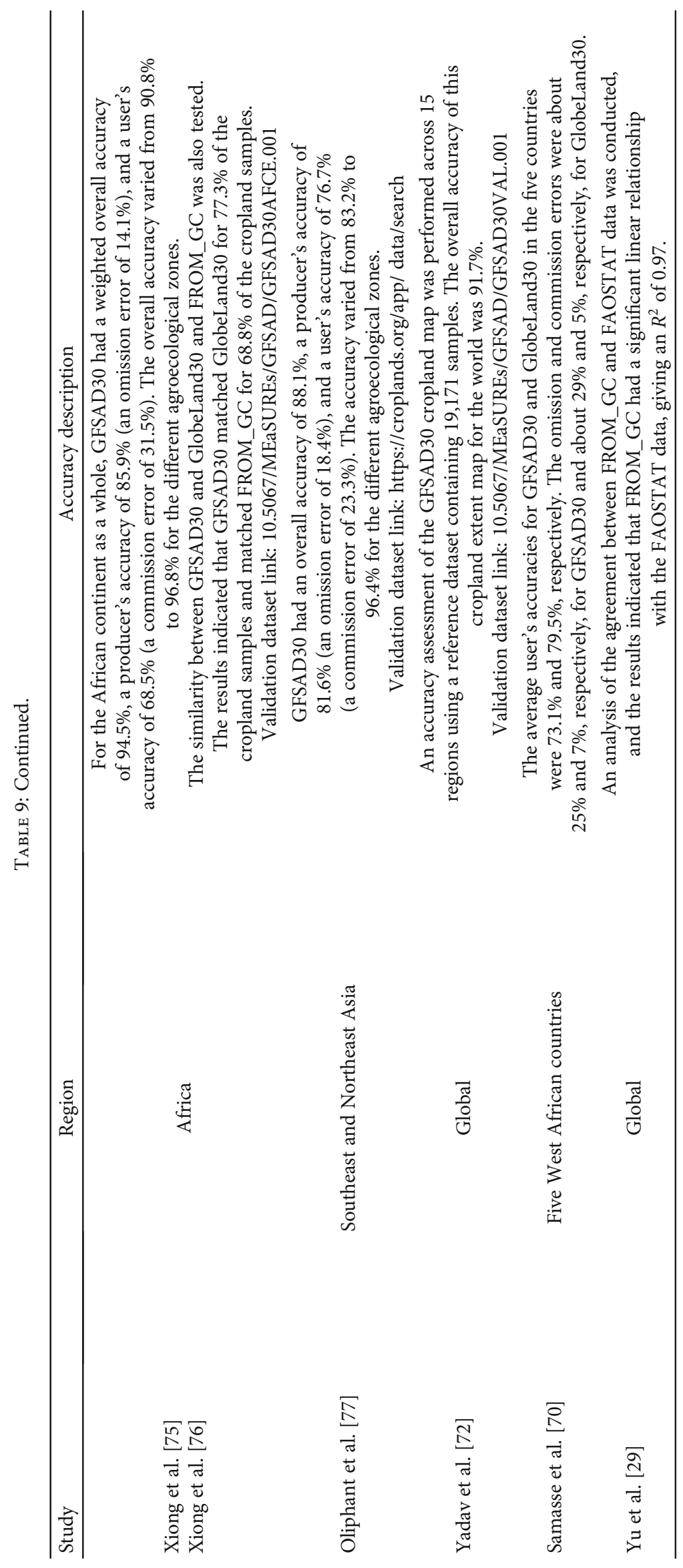


JRC_GSW, and GLADWater) and three $30 \mathrm{~m}$ GLC products (GLC_FCS30, FROM_GLC, and GlobeLand30) were acquired for carrying out a spatial consistency analysis of inland water bodies for 2015. Details of these products are shown in Table 10.

Apart from JRC_GSW and GLADWater, for which annual water maps are available for periods of a number of years (1984-2015 and 1999-2018, respectively), these products were only produced in certain individual years. Specifically, G1WBM was only produced in 2010, GLC_FCS30 is only available for 2015, FROM_GLC is only available for 2010, 2015, and 2017, and GlobeLand30 was only produced in 2000 and 2010. Because 2015 was chosen as the nominal year for comparison and because there was no G1WBM and GlobeLand30 available for 2015, any discrepancies between 2015 and the actual years used may also have caused some discrepancies in the results. Regarding the definitions of "water body" used by the different products, the three thematic water products were distinguished between the permanent and seasonal water types based on the frequency of the presence of water occurrence, whereas the three GLC products were not distinguished between the permanent and seasonal water bodies. In addition, there were also differences between the definitions of permanent water and seasonal water used by the three thematic products. G1WBM defines permanent water as corresponding to pixels where water is present more than $70 \%$ of the year; however, JRC_GSW defines pixels as permanent water only if the water is present throughout the year. GLADWater also labels as permanent water the pixels where the difference between the maximum frequency and the minimum frequency of the presence of water over three consecutive years is less than or equal to $33 \%$ and the average frequency over these years is greater than $90 \%$. In order to reduce the discrepancies caused by these different definitions of water bodies, we combined the permanent and seasonal water types in the thematic products into one water class. The three GLC products are all derived using supervised classification methods. However, two of the thematic water products (G1WBM and JRC_GSW) are generated based on classification rules and globally consistent thresholds; only GLADWater is produced using a supervised classification method.

\subsubsection{Review of the Accuracy Assessments of the Global Water} Maps. The results of the assessment of the accuracy of the six products that include global inland water maps are summarized in Table 11. Among the three GLC products, the results for GlobeLand30 and FROM_GLC include regional and global results, whereas the assessment of GLC_FCS30 was performed for Indonesia only. Among the global thematic inland water products, global results were available for JRC_GSW and GLADWater, whereas, for G1WBM, only the report for the United States could be found.

For GlobeLand30 and FROM_GLC, the water class has a satisfactory global accuracy. The overall accuracies of this class in GlobeLand30-2000 and GlobeLand30-2010 are $96.51 \%$ and $96.48 \%$, respectively [81]; the user's and producer's accuracies are $81.97 \%$ and $85.66 \%$, respectively, in FROM_GLC-2010 [82] and $81.97 \%$ and $86.39 \%$, respectively, in FROM_GLC-2017 [18]. At the regional scale, the accuracy was found to vary with the location. For example, Guo et al. [83] found that the overall accuracy for water in FROM GLC-2017 was $95.87 \%$ in West Asia-Northeast Africa, 89.75\% in Central and Eastern Europe, $87.01 \%$ in Central Asia, and $15.67 \%$ in South Asia. Also, the user's and producer's accuracies for GlobeLand30-2010 were $93.44 \%$ and $54.42 \%$, respectively, in Indonesia [39] and $94.00 \%$ and $79.00 \%$, respectively, in China [84]. Additionally, it was found that the producer's accuracy (which is related to the omission error) was generally much lower than the user's accuracy at the regional level. For instance, the user's and producer's accuracies of the water class in GLC_FCS30, GlobeLand30, and FROM_GLC in Indonesia were $97.74 \%$ and $60.19 \%, 93.44 \%$ and $54.42 \%$, and $89.97 \%$ and $68.52 \%$, respectively [39]. Also, the user's and producer's accuracies of the water class in FROM_GLC-2015 in Africa were 93.50\% and $66.90 \%$, respectively [85]. These results indicate that these GLC products are not sufficiently accurate to fully support the analysis of water bodies at the regional scale and that they are more likely to omit water bodies in specific regions.

In the three thematic inland water products, the accuracies of the permanent water body class are quite high. The global commission and omission accuracies of this class in JRC_GSW are greater than 99\% and 97\%, respectively [25]. Also, for the United States, more than 85\% of the permanent water bodies in G1WBM were proved to be accurately mapped [86]. For GLADWater, the global user's and producer's accuracies are $97.8 \pm 1.8 \%$ and $85.8 \pm 2.4 \%$, respectively [26]. However, the accuracies for the seasonal water body class are much lower than those for permanent water bodies. Pekel et al. [25] reported that the omission accuracy of the seasonal water body class in JRC_GSW was only about $75 \%$. The accuracy of seasonal water in JRC_GSW was found to be even lower in the research of Pickens et al. [26], which gave the user's and producer's accuracies of $17.4 \% \pm 12.1 \%$ and $36.3 \% \pm 8.3 \%$, respectively. Similarly, the user's and producer's accuracies for GLADWater were only $44.0 \pm 7.1 \%$ and $73.0 \pm 5.6 \%$, respectively, based on the time series of stable seasonal water bodies [26]. These results show that it was still difficult to accurately detect seasonal water bodies.

\section{Assessment of the Spatial Consistency of the Current Global $30 \mathrm{~m}$ Products}

4.1. Spatial Consistency of the Three GLC30 Products. All these $30 \mathrm{~m}$ GLC datasets were aggregated to a spatial resolution of $0.05^{\circ}$ for visual comparison of the spatial pattern, in which the land-cover type in each $0.05^{\circ}$ grid was determined by the land-cover type with the largest proportion. Figure 1 shows the spatial distributions of the different land-cover types in the three fine-resolution GLC maps both at the global scale with a resolution of $0.05^{\circ}$ (Figure $1(\mathrm{a})$ ) and at four typical inconsistent regions with a size of $0.5^{\circ} \times 1^{\circ}$ and a resolution of $30 \mathrm{~m}$ (Figure 1(b)).

Overall, the three products are consistent and roughly capture the actual distribution of land-cover types at the global scale. Specifically, bareland is mainly found between latitudes $15^{\circ} \mathrm{N}-50^{\circ} \mathrm{N}$ and $15^{\circ} \mathrm{S}-35^{\circ} \mathrm{S}$, including parts of Central 


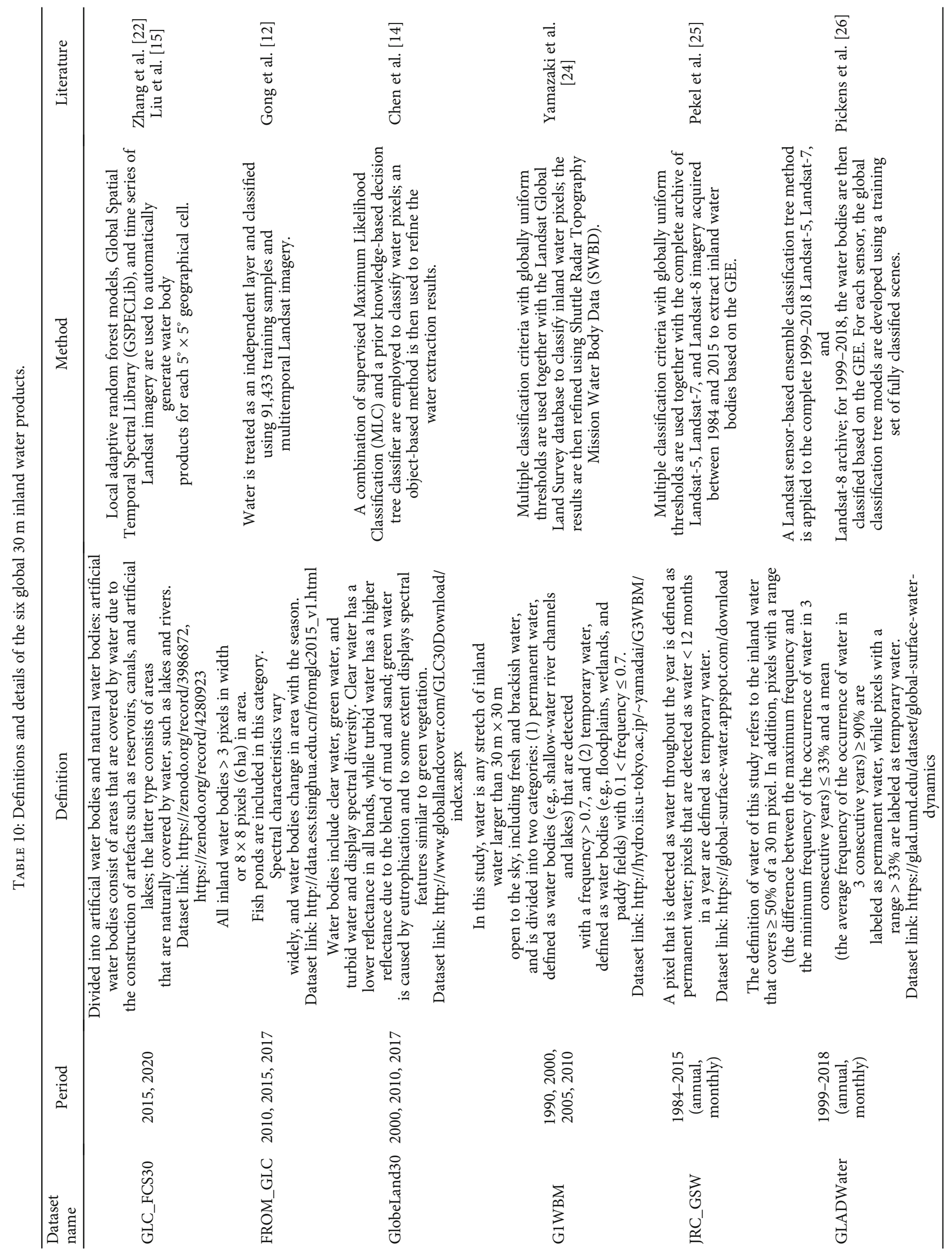


TABLE 11: Summary of the reported accuracies of the $30 \mathrm{~m}$ global inland water products.

\begin{tabular}{|c|c|c|}
\hline Study & Region & Accuracy description \\
\hline Kang et al. [39] & Indonesia & $\begin{array}{l}\text { The user's and producer's accuracies of the water class are } 97.74 \% \text { and } 60.19 \% \text { for GLC_ } \\
\text { FCS30-2015, 93.44\% and } 54.42 \% \text { for GlobeLand30-2010, and } 89.97 \% \text { and } 68.52 \% \text { for FROM_ } \\
\text { GLC-2015, respectively. }\end{array}$ \\
\hline Chen et al. [14] & Shaanxi, China & $\begin{array}{l}\text { The user's and producer's accuracies of the water class of GlobeLand } 30-2000 \text { are } 99.00 \% \text { and } \\
79.60 \% \text {, respectively. The user's accuracy of the water class of GlobeLand30-2010 is } 84.70 \% \text {. }\end{array}$ \\
\hline Wang et al. [84] & China & $\begin{array}{l}\text { The user's and producer's accuracies of the water class of GlobeLand } 30-2010 \text { are } 94.00 \% \text { and } \\
79.00 \% \text {, respectively. }\end{array}$ \\
\hline Cao et al. [81] & Global & $\begin{array}{l}\text { The overall accuracies of the water class of GlobeLand30-2000 and GlobeLand30-2010 are } \\
\qquad 96.51 \% \text { and } 96.48 \% \text {, respectively. }\end{array}$ \\
\hline $\begin{array}{l}\text { Manakos et al. } \\
{[116]}\end{array}$ & Thessaly, Greece & The water class of GlobeLand30-2010 shows a $91.9 \%$ overlap with the reference data. \\
\hline Ji et al. [82] & Global & $\begin{array}{c}\text { The user's and producer's accuracies of the water class of FROM_GLC-2010 are } 81.97 \% \text { and } \\
85.66 \% \text {, respectively. }\end{array}$ \\
\hline Gong et al. [18] & Global & $\begin{array}{l}\text { The user's and producer's accuracies of the water class of the } 10 \mathrm{~m} \text { version of FROM_GLC- } \\
\qquad 2017 \text { are } 81.97 \% \text { and } 86.39 \% \text {, respectively. }\end{array}$ \\
\hline Feng et al. [85] & Africa & $\begin{array}{c}\text { The user's and producer's accuracies of the water class of FROM_GLC-2015 are } 93.50 \% \text { and } \\
66.90 \% \text {, respectively. }\end{array}$ \\
\hline Guo et al. [83] & $\begin{array}{l}\text { Asia, Europe, and } \\
\text { Africa }\end{array}$ & $\begin{array}{l}\text { The user's and producer's accuracies of the water class of FROM_GLC-2017 are } 71.14 \% \text { and } \\
\text { 80.87\%, respectively. Regionally, the accuracy for the water class is highest in West Asia- } \\
\text { Northeast Africa (95.87\%), followed by Central and Eastern Europe (89.75\%), Central Asia } \\
(87.01 \%) \text {, and South Asia (15.67\%). }\end{array}$ \\
\hline Pekel et al. [25] & Global & $\begin{array}{l}\text { The commission accuracy of the permanent water class of JRC_GSW is } 99.6 \%, 99.5 \% \text {, and } \\
\text { 99.7\% for the TM, ETM+, and OLI data, respectively; the corresponding omission accuracies } \\
\text { are } 98.8 \%, 97.8 \% \text {, and } 99.1 \% \text {. The commission accuracy of the seasonal water class is } 98.8 \% \\
\text { (TM), } 98.4 \%(\mathrm{ETM}+\text { ), and } 98.5 \%(\mathrm{OLI}) \text {; the omission accuracy of the seasonal water class is } \\
74.9 \% \text { (TM), } 73.8 \% \text { (ETM+), and } 77.4 \% \text { (OLI), respectively. }\end{array}$ \\
\hline $\begin{array}{l}\text { Worden and de } \\
\text { Beurs [117] }\end{array}$ & $\begin{array}{l}\text { Georgia, Armenia, and } \\
\text { Azerbaijan }\end{array}$ & $\begin{array}{l}\text { The overall accuracy of the monthly history water map of the JRC_GSW is } 89.4 \%, 90.7 \% \text {, and } \\
96.1 \% \text { in Georgia, Armenia, and Azerbaijan, respectively. Specifically, the overall accuracies of } \\
\text { the monthly water map for the months of July and October are } 88.6 \% \text { and } 90.5 \% \text { in Georgia, } \\
88.9 \% \text { and } 92.6 \% \text { in Armenia, and } 96.4 \% \text { and } 95.9 \% \text { in Azerbaijan, respectively. }\end{array}$ \\
\hline Pickens et al. [26] & Global & $\begin{array}{l}\text { The user's and producer's accuracies at } 30 \mathrm{~m} \text { resolution are } 95.2 \% \pm 1.2 \% \text { and } 90.3 \% \pm 2.3 \% \\
\text { for the monthly mapped water class of JRC_GSW, } 95.1 \% \pm 1.8 \% \text { and } 89.9 \% \pm 2.6 \% \text { for the } \\
\text { time series of permanent water, and } 17.4 \% \pm 12.1 \% \text { and } 36.3 \% \pm 8.3 \% \text { for the time series of } \\
\text { stable seasonal water, respectively. } \\
\text { Validation dataset link: https://www.glad.umd.edu/dataset/global-surface-water-dynamics }\end{array}$ \\
\hline
\end{tabular}

Asia and the western United States. In the northern hemisphere, cropland is mainly found in India and southern China in Asia, mid- to high-latitude parts of Europe, and the southeastern United States; in the southern hemisphere, cropland is mainly found in southern Brazil and northern Argentina. The forest class is concentrated in rainforest areas (including the Amazon rainforest, African rainforest, and Indian-Malay rainforests) and high-latitude areas. However, the three GLC30 products show large inconsistency in the transition zones or heterogeneous regions (as illustrated in Figure 1(b) A-D). For example, the disagreement is noticeable in the transition zones from bareland to grassland or cropland (Figure 1(b) A, B) and in the heterogeneous mountainous areas with complicated land-cover types (Figure 1(b) C, D).

Figure 2 illustrates the percentage areas covered by each class according to the three GLC products. The percentages show roughly the same pattern for the different products: forest has the highest percentage area, accounting for about $30 \%$ of the global total, followed by grassland, bareland, and shrubland.
The area percentages of grassland, shrubland, and tundra in the GLC_FCS30-2015 product are very different from those in the other two products. The shrubland percentage in GLC_FCS30-2015 (11.38\%) is higher than that in FROM_GLC30-2015 (7.47\%) and GlobeLand30-2010 $(5.18 \%)$; in contrast, the grassland and tundra percentages are significantly smaller than those in the other two products. In particular, the tundra percentage (4.79\%) in GLC_FCS302015 is about half of the area in the other two products. Furthermore, the area percentages of cropland and wetland in FROM_GLC30-2015 are much lower than those in GLC_ FCS30-2015 and GlobeLand30-2010. In FROM_GLC302015 , wetland accounts for only $0.02 \%$ of the global total, whereas in GLC_FCS30-2015 and GlobeLand30-2010, the corresponding percentages are $2.24 \%$ and $2.52 \%$, respectively. In FROM_GLC30-2015, cropland covers only $7.44 \%$ of the total area-much lower than the figures of $13.96 \%$ for GlobeLand30-2010 and 15.64\% for GLC_FCS30-2015.

Figure 3 illustrates the spatial consistency between the three GLC products. It is obvious from Figure 3 that the 

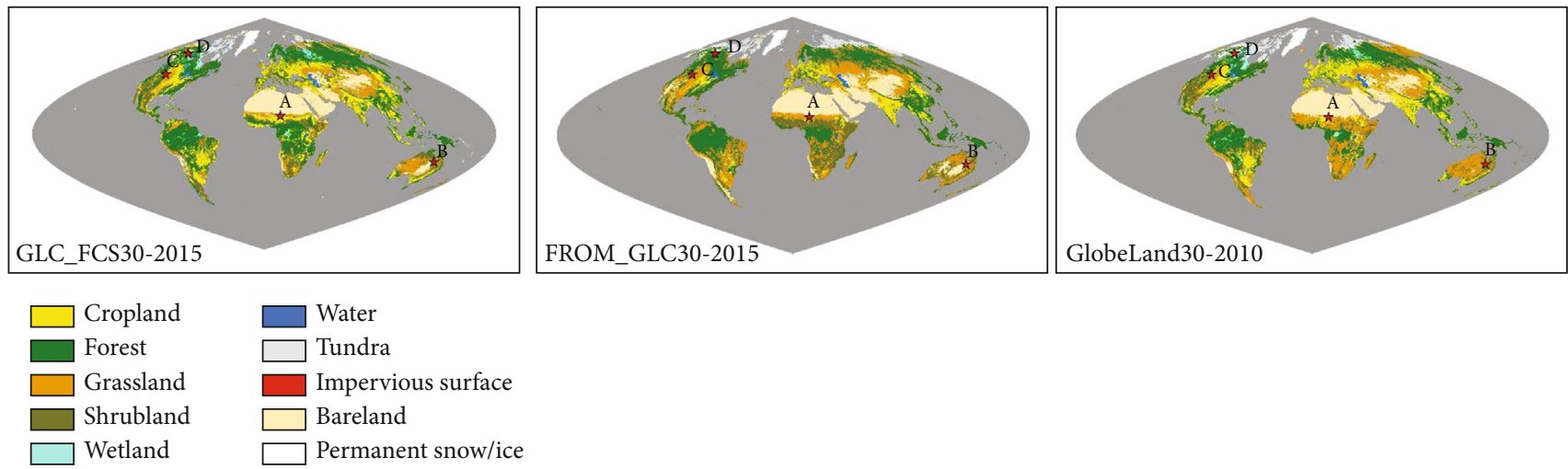

(a)

GLC_FCS30-2015
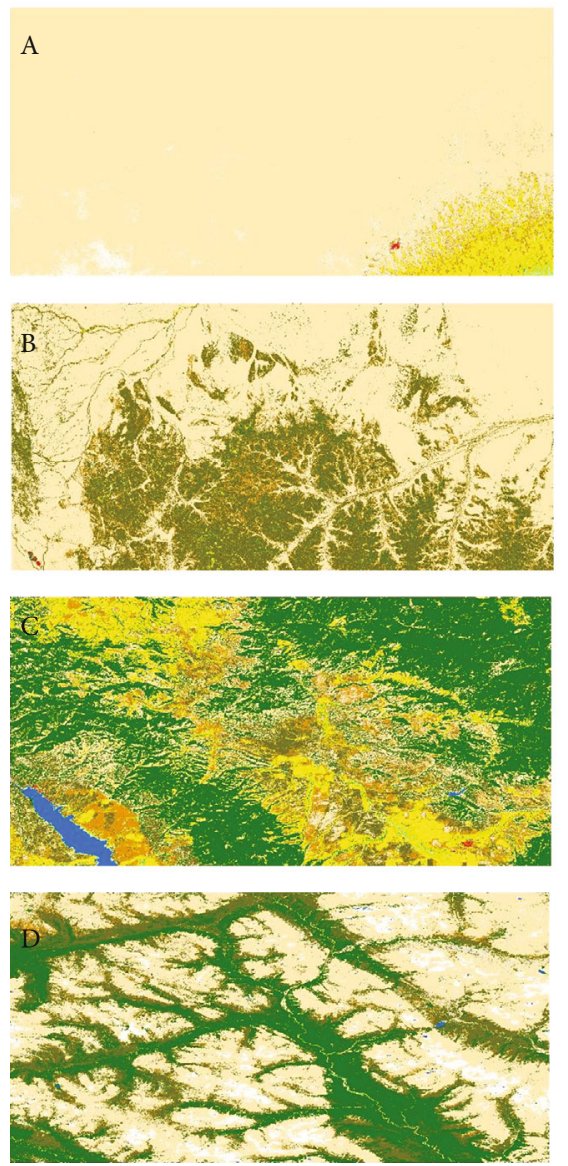

FROM_GLC30-2015
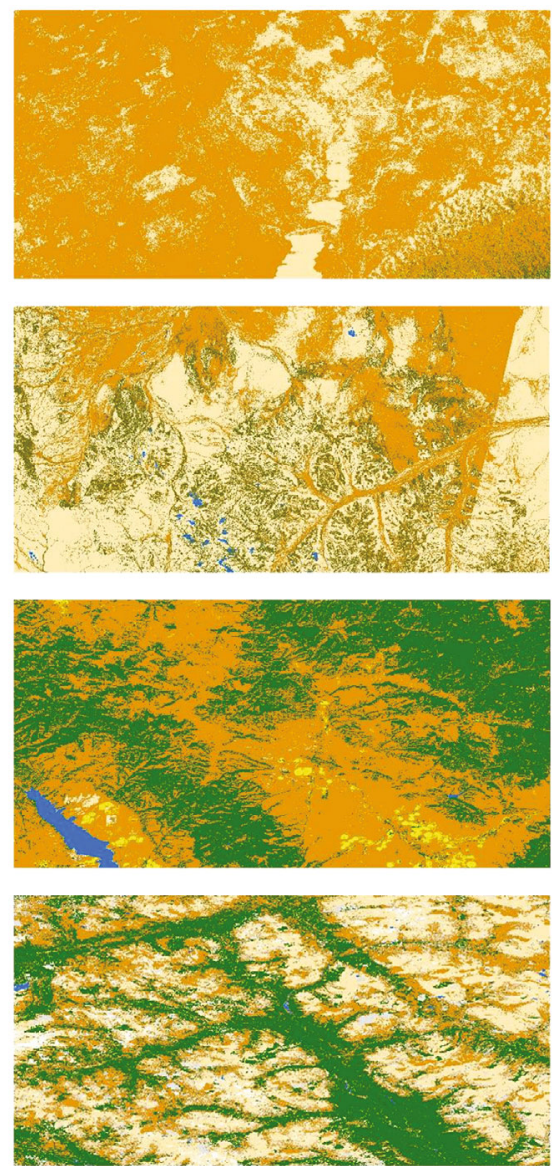

(b)
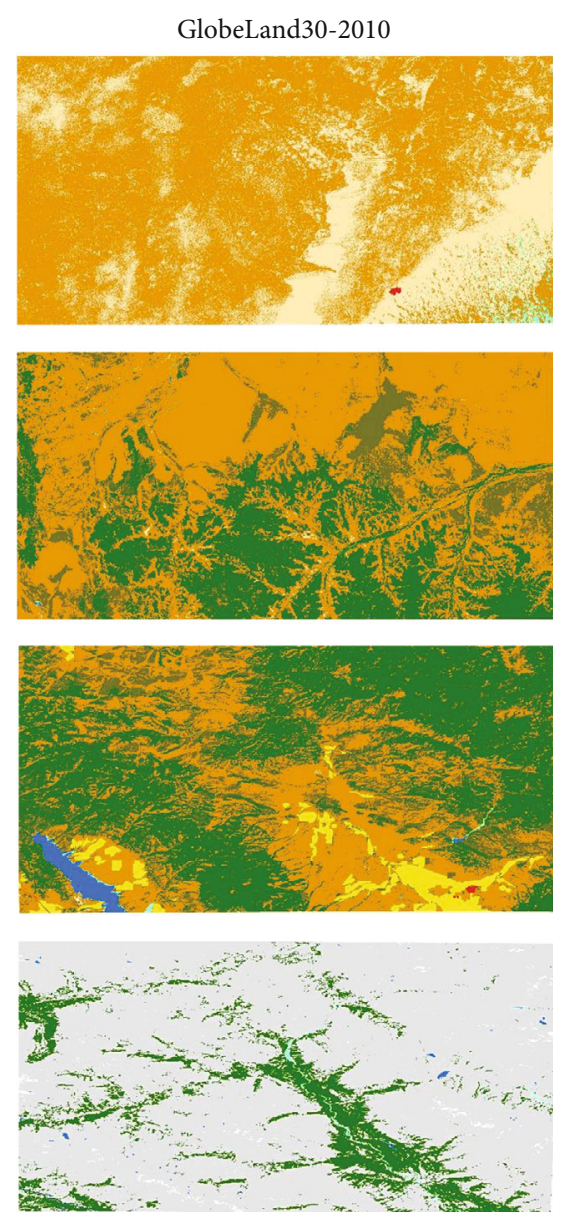

FIgURE 1: The spatial distribution of different land-cover classes according to the three global $30 \mathrm{~m}$ land-cover products (GLC_FCS30-2015, FROM_GLC-2015, and GlobeLand30-2010) according to the basic classification system after aggregation to a resolution of $0.05^{\circ}$ (a). The spatial distribution of four typical inconsistent regions in the transition or heterogeneous zones (A: centered at $\left(12.903^{\circ} \mathrm{E}, 14.444^{\circ} \mathrm{N}\right)$ in Africa; B: centered at $\left(141.368^{\circ} \mathrm{E}, 21.631^{\circ} \mathrm{S}\right)$ in Australia; C: centered at $\left(111.249^{\circ} \mathrm{W}, 46.755^{\circ} \mathrm{N}\right)$ in North America; D: centered at $\left(128.120^{\circ} \mathrm{W}, 62.681^{\circ} \mathrm{N}\right)$ in Canada) with a resolution of $30 \mathrm{~m}(\mathrm{~b})$.

spatial distribution of the three products is relatively consistent in homogeneous regions such as the northern part of the African continent (mainly bareland) and the northern region of South America (forest). However, the spatial consistency is low in heterogeneous or transition zones such as Australia and southern Africa and the transition zone from the vegetation to nonvegetation classes in Africa and also central North America. It can be seen from Figure 1(b) A$\mathrm{C}$ that the disagreement in these areas mainly occurs in areas labeled as grassland, shrubland, or bareland. This is mainly due to the maximum fraction of vegetation coverage that the different classification systems permit in areas defined 


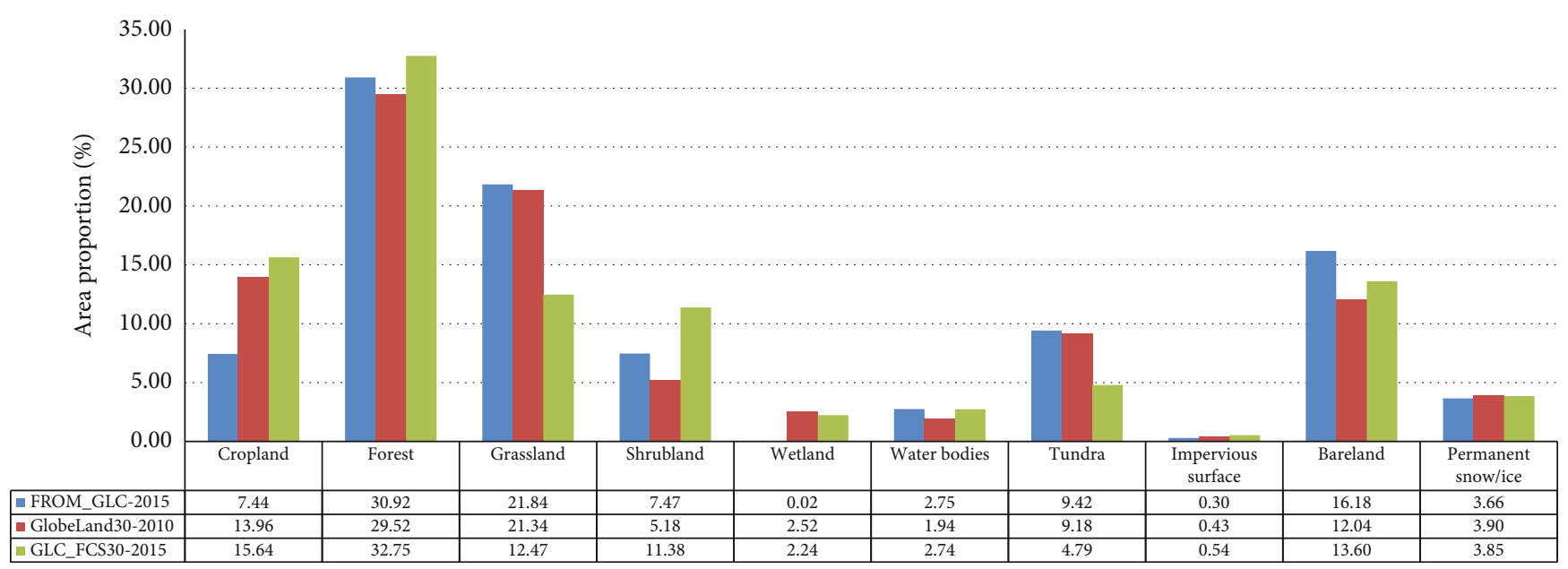

FIGURE 2: Comparisons of the area percentages for each class for the different GLC products.

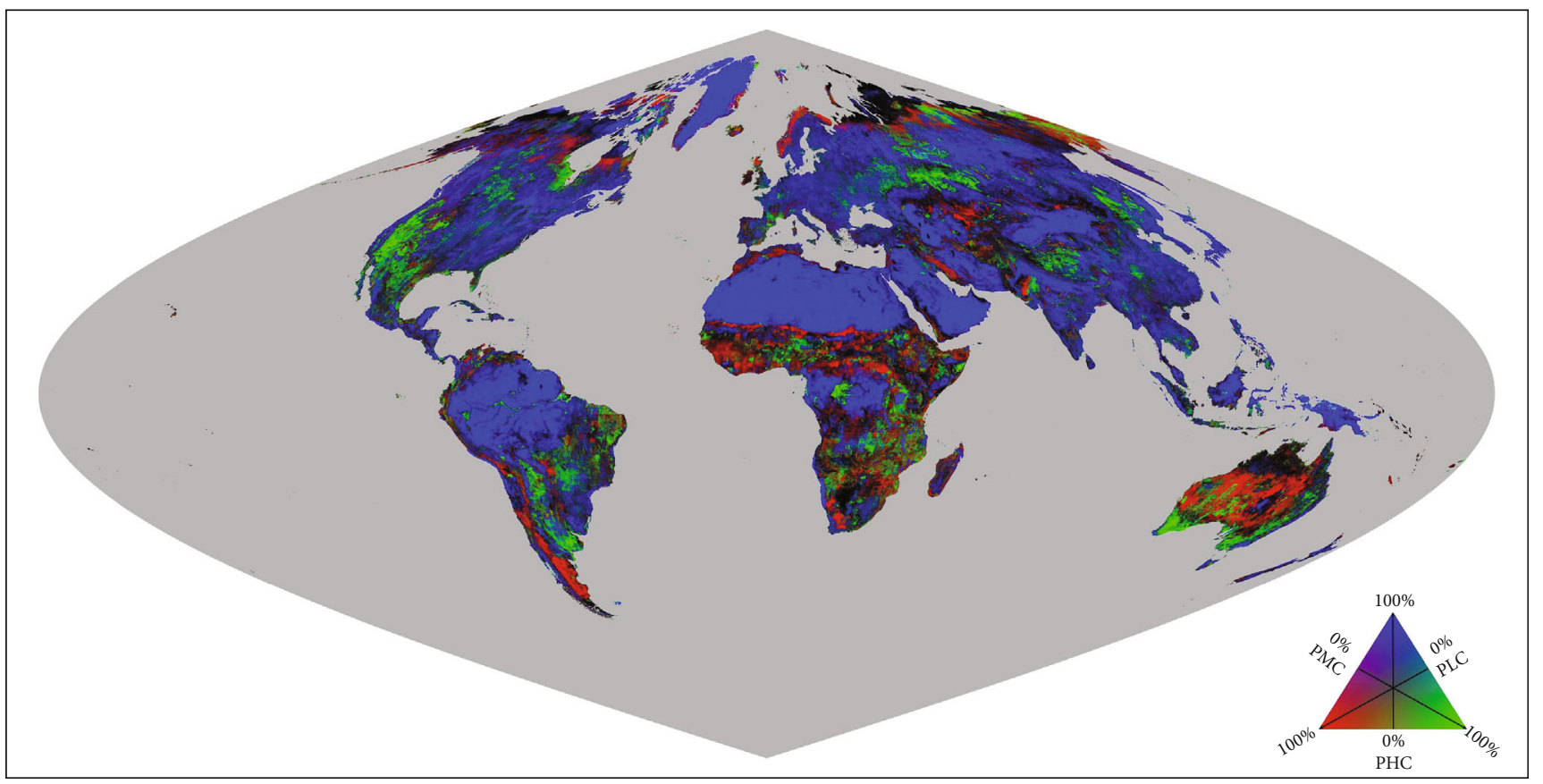

Figure 3: The spatial consistency between the three GLC products. PHC: proportion of highly consistent pixels (whose consistency metric equals 3) within each $0.05^{\circ} \times 0.05^{\circ}$ grid cell; PMC: proportion of moderately consistent pixels (whose consistency metric equals 2 ) within each $0.05^{\circ} \times 0.05^{\circ}$ grid cell; PLC: proportion of low-consistency pixels (whose consistency metric equals 1 ) within each $0.05^{\circ} \times 0.05^{\circ}$ grid cell .

as not being covered by vegetation. For example, the maximum fraction of vegetation coverage in bareland, as defined by the GlobeLand30 product, is $10 \%$, whereas the maximum fraction defined by GLC_FCS30 is $15 \%$. Therefore, using the former definition, sparse shrubland or grassland will be classified as shrubland, whereas using the latter definition, sparse shrubland and grassland will be wrongly classified as bareland.

To further analyze the spatial consistency between each pair of GLC products, the superposition method was applied to each pair of products. Figure 4 shows the spatial distribution of the proportion of consistent pixels within each $0.05^{\circ} \times 0.05^{\circ}$ grid cell for each pair of the compared GLC products (Figure 4(a)) and the spatial consistency at four typical inconsistent regions with a size of $0.5^{\circ} \times 1^{\circ}$ and a resolution of $30 \mathrm{~m}$ (Figure 4(b)). Among all of the pairs, GlobeLand30-2010 and FROM_GLC30-2015 have the highest consistency with the consistent area accounting for about $63.35 \%$ of the total area; in terms of consistency, this is followed by GLC_FCS30-2015 and GlobeLand30-2010 (59.73\%) and then GLC_FCS30-2015 and FROM_GLC302015 (57.11\%). These results may have been affected by the conversion between the different classification systems. Also, similar to the results for the spatial consistency between the three different products, there is a low degree of consistency in the areas with complex land-cover types and in the 

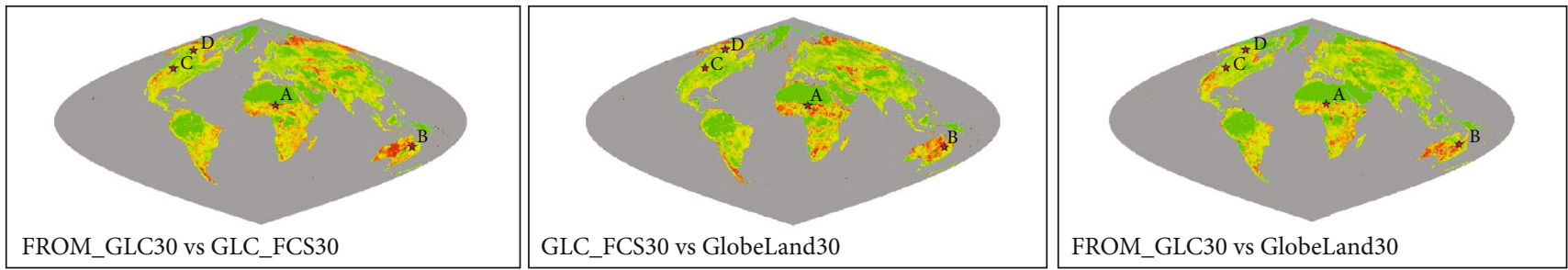

$\begin{array}{ll}\square .000-.005 & \square .500-.600 \\ \square .005-.050 & \square .600-.700 \\ \square .050-.100 & \square .700-.800 \\ \square .100-.250 & \square .800-.900 \\ \square .250-.350 & \square .900-1.00\end{array}$

$\square .350-.500$

(a)
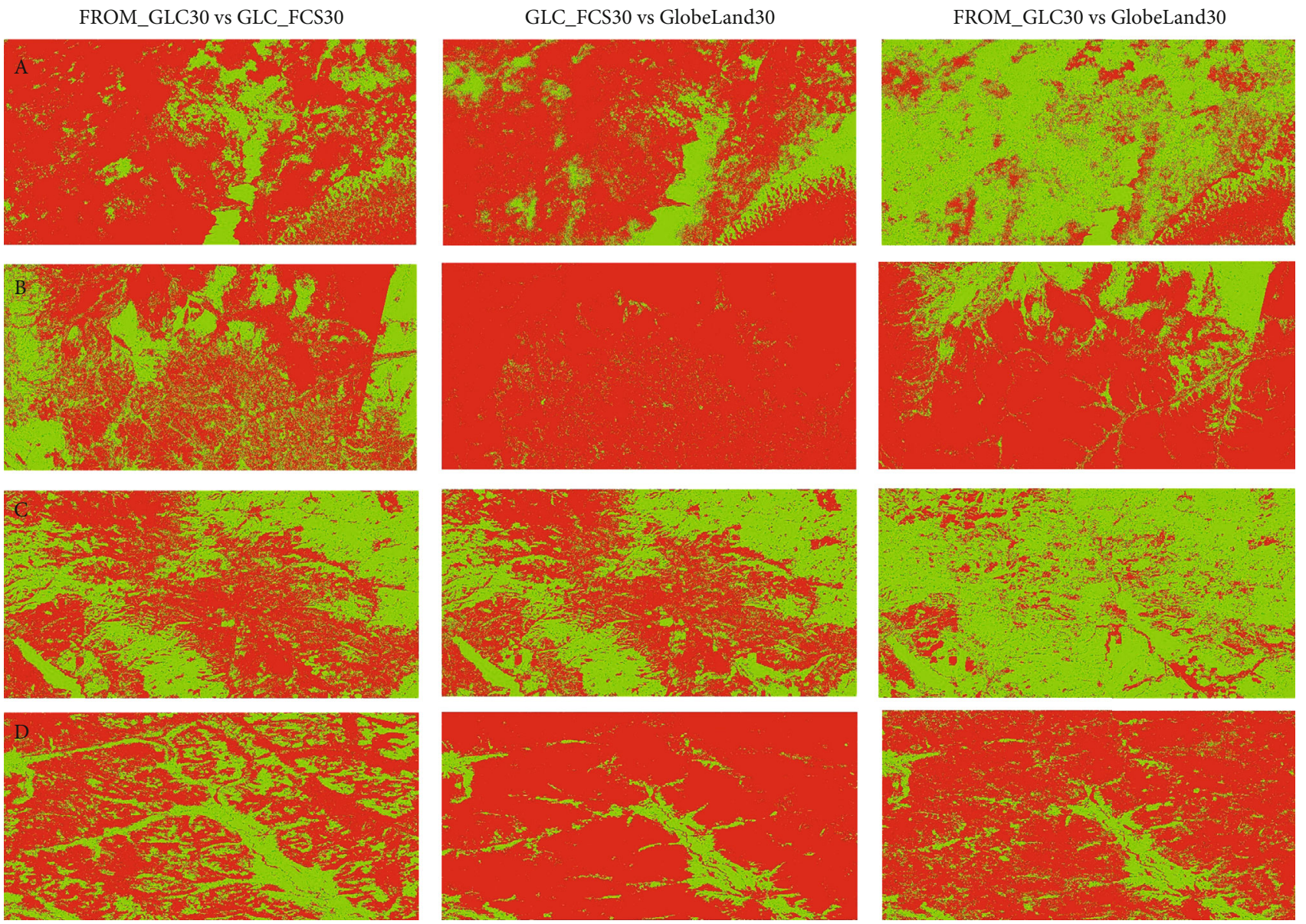

Inconsistent

Consistent

(b)

FIGURE 4: Spatial consistency between the basic classification systems of GLC_FCS30-2015 and FROM_GLC30-2015 (left), GlobeLand302010 and GLC_FCS30-2015 (middle), and GlobeLand30-2010 and FROM_GLC30-2015 (right) at the global scale with a resolution of $0.05^{\circ}$ (a). Spatial consistency between each pair of the compared GLC products at four typical inconsistent regions in the transition or heterogeneous zones (A: centered at $\left(12.903^{\circ} \mathrm{E}, 14.444^{\circ} \mathrm{N}\right)$ in Africa; B: centered at $\left(141.368^{\circ} \mathrm{E}, 21.631^{\circ} \mathrm{S}\right)$ in Australia; C: centered at $\left(111.249^{\circ} \mathrm{W}, 46.755^{\circ} \mathrm{N}\right)$ in North America; D: centered at $\left(128.120^{\circ} \mathrm{W}, 62.681^{\circ} \mathrm{N}\right)$ in Canada) with a resolution of $30 \mathrm{~m}(\mathrm{~b})$.

transition zones from the vegetation to nonvegetation classes. For example, there is a low degree of consistency in the heterogeneous regions with complex land-cover types and in the transition zones from the vegetation to nonvegetation classes. For example, there is significant disagreement between each pair of products in the transition zones from bareland to grassland or cropland in Africa (Figures 1(b) A and 4(b) A). The same phenomenon can be seen in highlatitude heterogeneous mountainous areas with complicated land-cover types (Figures 1(b) D and 4(b) D). Further 

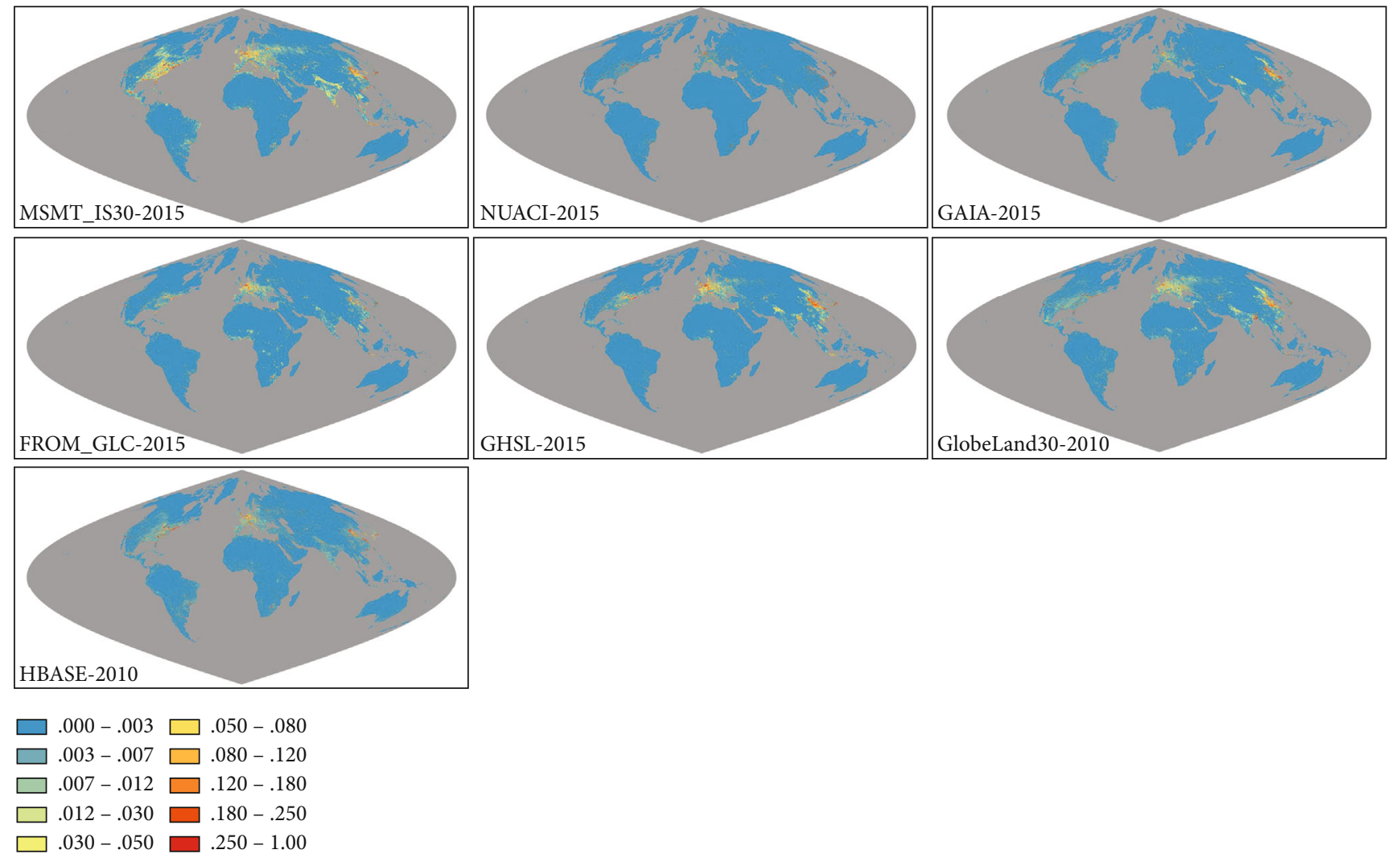

Figure 5: The fraction of impervious surfaces across the globe according to the seven global $30 \mathrm{~m}$ impervious surface products after aggregating the data to a resolution of $0.05^{\circ}$.

analysis showed that the areas of inconsistency between GlobeLand30-2010 and GLC_FCS30-2015 corresponding to transition zones are mostly distributed in areas which are classified as grassland by the GlobeLand30-2010 product but as cropland or shrubland by GLC_FCS30-2015.

\subsection{Spatial Consistency of Global $30 \mathrm{~m}$ Impervious Surface} Maps. Figure 5 illustrates the fraction of impervious surfaces across the globe according to the seven global $30 \mathrm{~m}$ impervious surface products using a grid size of $0.05^{\circ}$. Overall, all these products accurately capture the global patterns of impervious surfaces. For example, impervious surfaces can be seen to be mainly found between $20^{\circ} \mathrm{N}$ and $60^{\circ} \mathrm{N}$ (including central and eastern parts of North America, the whole of Europe, and eastern parts of China). This agrees with the general patterns of global economic development and population distribution. However, considering the patterns shown in more detail, NUACI-2015, FROM_GLC-2015, and GAIA2015 clearly produce lower estimates of the amount of impervious surface cover over America and India compared with other products.

To quantitatively assess the spatial consistency between the seven global impervious surface products, the total meridional and zonal areas classified as impervious surfaces were calculated using $0.05^{\circ}$ steps (Figure 6). It can be seen from the meridional histogram that all of the products share similar curve shapes that exhibit significant volatility. Four peak intervals in the longitude direction are also captured; these include the region between $60^{\circ} \mathrm{W}$ and $100^{\circ} \mathrm{W}$ covering the central and eastern parts of North America, the region between $10^{\circ} \mathrm{W}$ and $40^{\circ} \mathrm{E}$ covering the whole of the European Union, the region between $60^{\circ} \mathrm{E}$ and $90^{\circ} \mathrm{E}$, which covers India, and the region between $100^{\circ} \mathrm{E}$ and $120^{\circ} \mathrm{E}$, which covers the east of China and Southeast Asia. Looking at the different products in more detail, using a $0.05^{\circ}$ step, HBASE-2010 and GAIA-2015 have the biggest and smallest impervious surface areas among these products, respectively. The values for GAIA-2015 in the $10^{\circ} \mathrm{W}-40^{\circ} \mathrm{E}$ region (Europe) are clearly low, which is consistent with the results shown in Figure 5.

Similarly, the zonal histogram illustrates that all the global products accurately capture the global distribution patterns of impervious surfaces and shows that this cover type is mainly concentrated between $20^{\circ} \mathrm{N}$ and $60^{\circ} \mathrm{N}$, which is where most of the world's population and economic activity are also concentrated. HBASE-2010 has the biggest area classified as impervious surfaces in almost all latitude regions except for $45^{\circ} \mathrm{N}-55^{\circ} \mathrm{N}$, where GHSL-2015 has a bigger area. In terms of the total area classified as impervious surfaces, HBASE-2010 has the largest area, followed in order by MSMT_IS30-2015, GHSL-2015, GlobeLand302010, FROM_GLC-2015, NUACI-2015, and GAIA-2015 (see Figure 6).

Together with the area-based analyses, scatter plots were also used to analyze the spatial consistency between the different global impervious surface products (Figure 7). In this study, MSMT_IS30-2015 was selected as the reference 

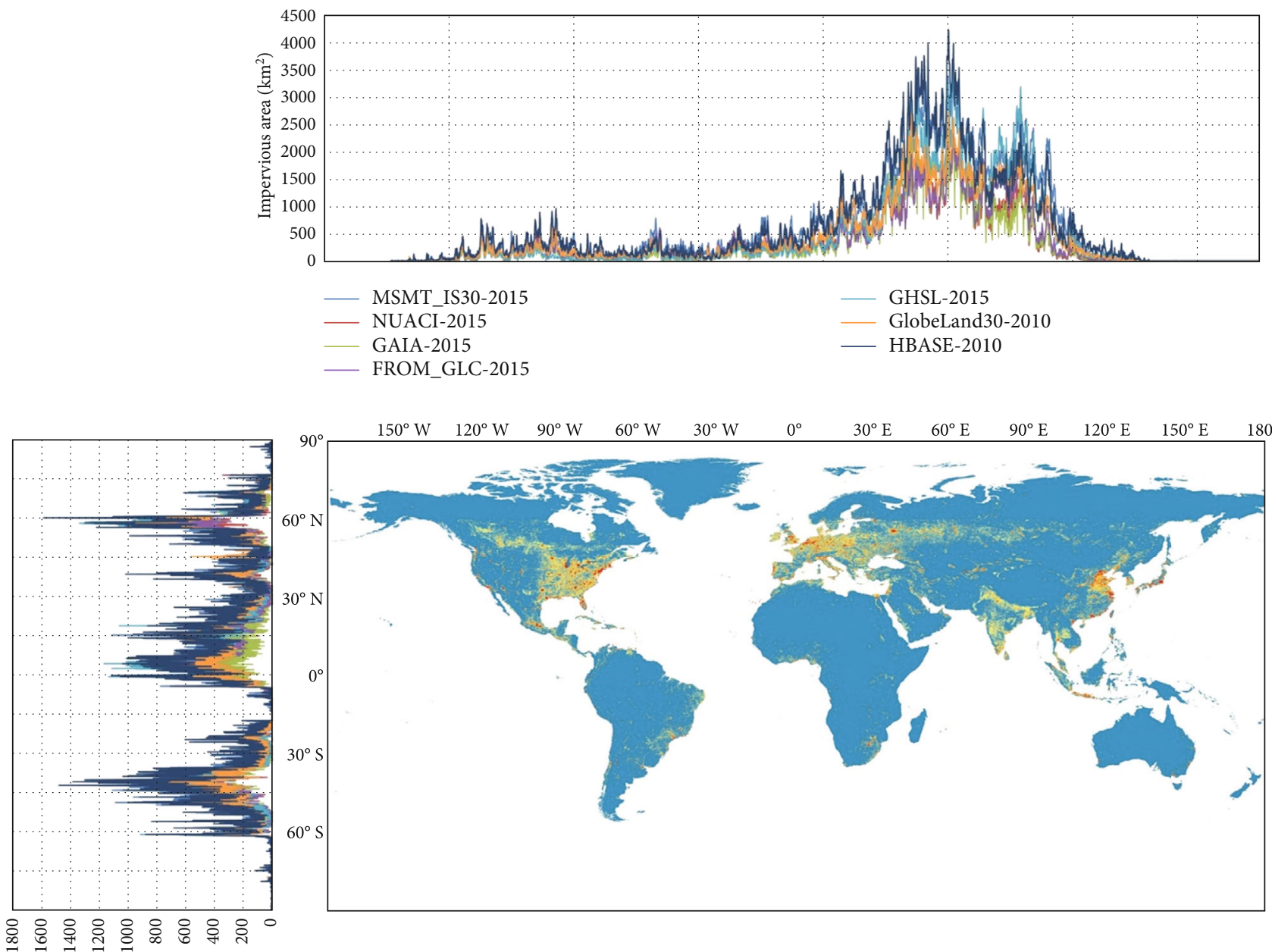

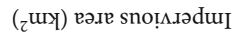
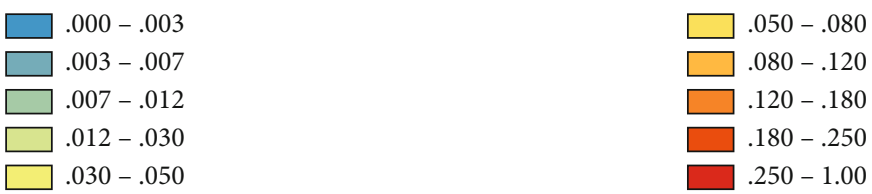

Figure 6: The meridional and zonal distributions of impervious surfaces according to the seven global $30 \mathrm{~m}$ products using $0.05^{\circ}$ intervals. The global reference impervious surface map is MSMT_IS30-2015.

because it has been demonstrated [22] to have a better performance than most other products. First, it was found that the two products that are most consistent with each other are MSMT_IS30-2015 and GHSL-2015: the relationship between these two products gave an $R^{2}$ of 0.783 , an RMSD of 0.038 , and a regression slope of 0.921 , with the points in the scatter plot being distributed around the $1: 1$ line. The second best agreement was found between FROM_GLC2015 and MSMT_IS30-2015, for which $R^{2}$ was 0.740 and the RMSD was 0.042 ; in this case, there was a better agreement between the points in the "high-density" regions than in the "low-density" regions, which resulted in a regression slope of less than 1. In GlobeLand30-2010, there is a temporal interval of 5 years between 2010 and 2015 and a minimum mapping unit of $4 \times 4$ pixels, and so it was expected that GlobeLand30-2010 would have a smaller impervious area than MSMT_IS30-2015; in this case, the points in the scatter plot are mainly located below the $1: 1$ line. HBASE-2010 is the only dataset that has a bigger impervious surface area than MSMT_IS30-2015-the slope of the regression is 1.07. This is especially the case in "high-density" regions because, in HBASE, impervious surfaces are defined as comprising all types of man-made built-up surfaces and the areas surrounding them that are functionally linked to those surfaces (e.g., urban green spaces) [102]. Lastly, NUACI-2015 and GAIA-2015 clearly produce underestimates of the impervious surface area (using MSMT_IS30-2015 as a reference) and most of the points in the scatter plots are distributed below the $1: 1$ line, especially in the case of GAIA-2015, for which $R^{2}$ is 0.491 , the RMSD is 0.063 , and the slope of the regression is 0.568 .

4.3. Spatial Consistency of Global 30 m Forest Maps. Figure 8 illustrates the areal proportions of forest across the globe according to the seven global $30 \mathrm{~m}$ forest maps after aggregating the data to a resolution of $0.05^{\circ}$. Overall, all of the global 

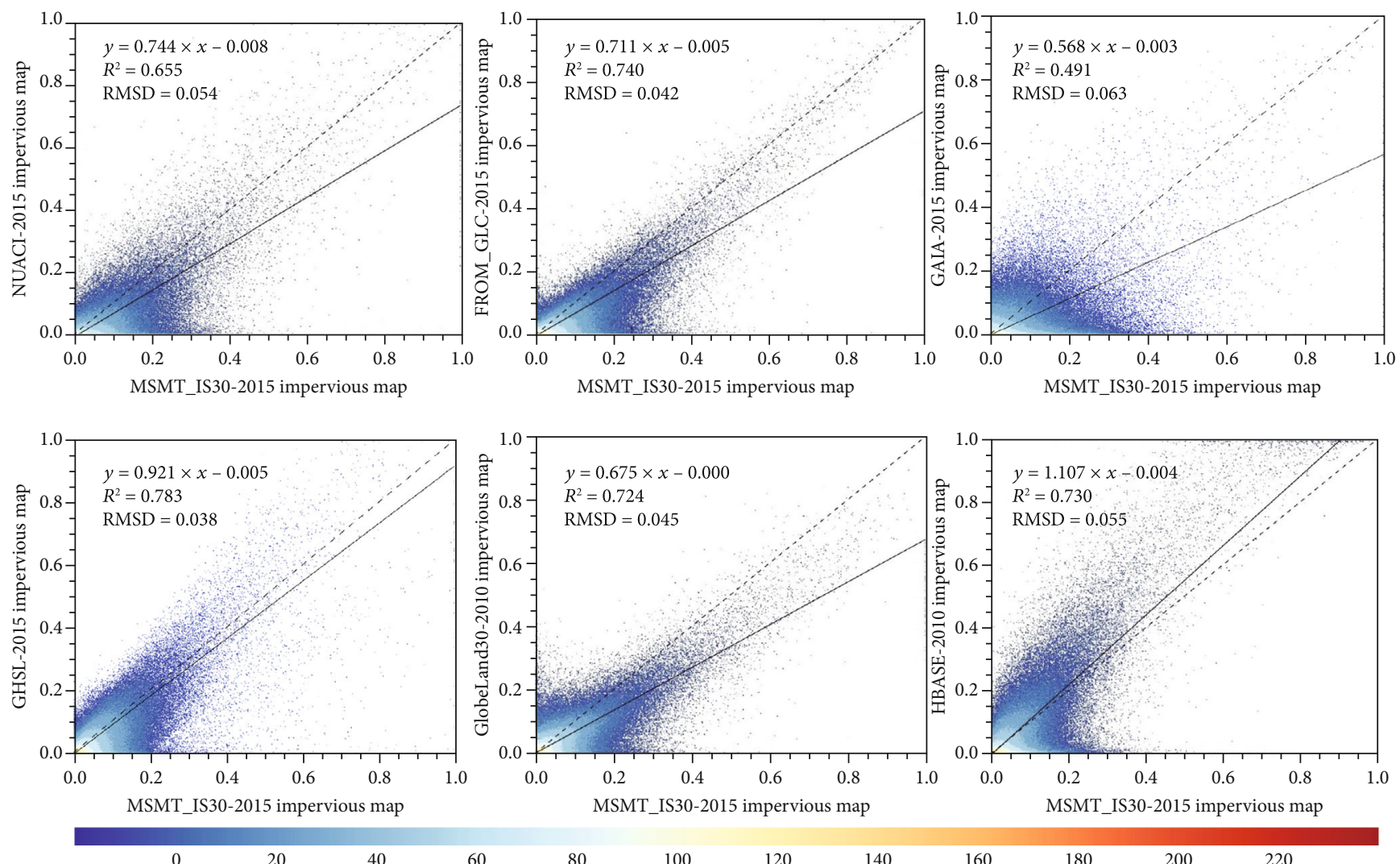

FIGURE 7: Scatter plots showing the relationship between the MSMT_IS30-2015 and the NUACI-2015, FROM_GLC-2015, GAIA-2015, GHSL-2015, GlobeLand30-2010, and HBASE-2010 global impervious surface products using a grid with a resolution of $0.05^{\circ} \times 0.05^{\circ}$. The axes represent the fraction of impervious surfaces within each $0.05^{\circ} \times 0.05^{\circ}$ grid cell of seven global $30 \mathrm{~m}$ impervious surface products, and the different colors represent the number of grids with different fractions of impervious surface.

forest maps accurately capture the real patterns in the forest land-cover type. For example, forests can be seen to be mainly concentrated in rainforest areas, including the Amazon rainforest, African rainforests, and Indian-Malay rainforests, and in high-latitude areas where needleleaf forests are found. In high-latitude areas, the forest cover according to GFCC30TC-2015 is obviously sparser than the other forest products; TreeCover30-2010 and GLADForest-2018 give higher densities than the other forest products in the African rainforest areas.

Figure 9 illustrates the distribution of forest in the meridional and zonal directions in steps of $0.05^{\circ}$ according to the seven global forest products. Specifically, in terms of the meridional direction, all the forest products capture the global forest spatial patterns, including three peak intervals between $90^{\circ}$ and $50^{\circ} \mathrm{W}$ (the Amazon rainforest), $0^{\circ}$ and $40^{\circ} \mathrm{E}$ (which includes the African rainforests), and $60^{\circ}$ and $150^{\circ} \mathrm{E}$. There is greater consistency between these products in the western hemisphere than in the eastern hemisphere. It can also be seen that GFCC30TC-2015 generally exhibits the smallest forest areas while TreeCover-2010 exhibits the largest areas, particularly between $0^{\circ}$ and $40^{\circ} \mathrm{E}$ (which includes the African rainforests).

The consistency between the seven products is also illustrated by the forest area curves for the zonal direction. Over- all, there is a greater agreement between the products in the southern hemisphere than in the northern hemisphere. The greatest difference occurs between GFCC30TC and the other products around $60^{\circ} \mathrm{N}$ (where the total forest area in TreeCover-2010 is nearly twice that in GFCC30TC-2015). Looking at the patterns in the curves, the seven forest products can be divided into three groups: GFCC30TC-2015 on its own, GFC30-2015 and GlobeLand30-2010, and the remaining four products as the final group.

Figure 10 shows scatter plots of the seven global $30 \mathrm{~m}$ forest products after aggregation to a spatial resolution of $0.05^{\circ}$ with the GLC_FCS30-2015 forest layer used as the reference dataset. GLADForest-2018 has the best agreement with GLC_FCS30-2015 and has an $R^{2}$ of 0.742 and an RMSD of 0.197 . This is followed by TreeCover-2010 $\left(R^{2}=0.731\right.$, RMSD $=0.204)$, FROM_GLC-2015 $\left(R^{2}=0.688\right.$, RMSD = $0.217), \quad$ GFC30-2018 $\quad\left(R^{2}=0.678, \quad \mathrm{RMSD}=0.221\right)$, GlobeLand30-2010 $\quad\left(R^{2}=0.679, \quad \mathrm{RMSD}=0.226\right), \quad$ and GFCC30TC-2015 $\left(R^{2}=0.659, \mathrm{RMSD}=0.238\right)$. Except for the plot of GLC_FCS30-2015 against GFCC30TC-2015, in which the "high-density" scatter points are mainly distributed below the $1: 1$ line (which also explains why GFCC30TC-2015 has a sparser forest cover than the other products over high-latitude areas in Figures 8 and 9), it can be seen that most of the points in these scatter plots are 

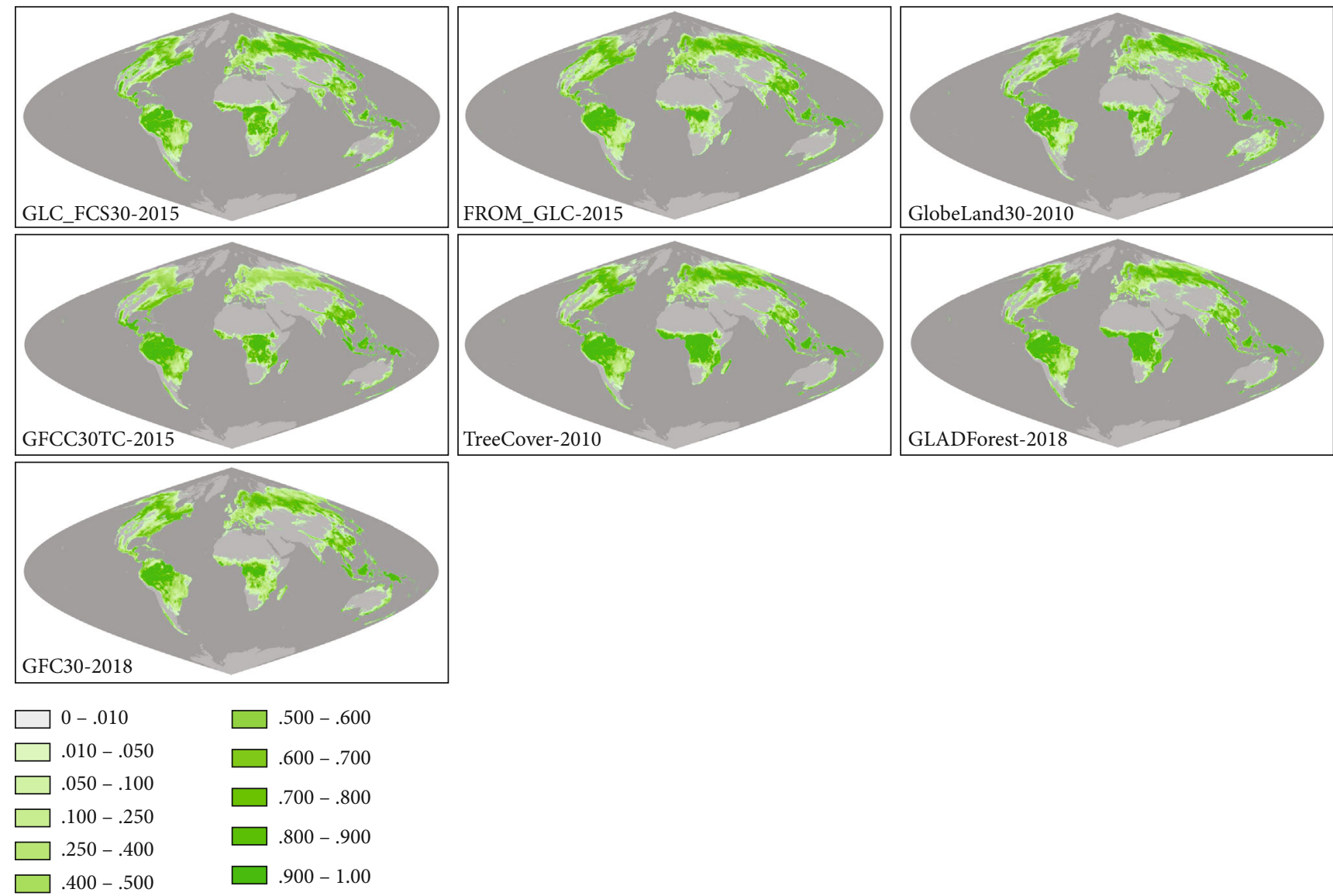

Figure 8: The fraction of the forest cover across the globe according to the seven global $30 \mathrm{~m}$ forest products after aggregating the data to a resolution of $0.05^{\circ}$.

concentrated around the 1:1 line. Finally, from the regression slope coefficients, it can be seen that the spatial consistency between GLC_FCS30, TreeCover-2010, and GLADForest is more significant than that between other pairs of products (the slopes of TreeCover-2010 and GLADForest are closer to 1.0).

4.4. Spatial Consistency of Global $30 \mathrm{~m}$ Cropland Maps. Figure 11 illustrates the spatial distributions of the crop class in the five global $30 \mathrm{~m}$ cropland products after aggregation of the data to a resolution of $0.05^{\circ}$. Overall, the greatest spatial consistency is between GlobeLand30-2010, FROM_GC2010, and GFSAD30-2015. In GLC_FCS30-2015, there is a greater extent and density of cropland in Africa than in the other products. The spatial patterns of cropland on the African continent in the CCI_LC land-cover product and GLC_ FCS30-2015 are similar. Furthermore, FROM_GLC-2015 obviously underestimates the amount of cropland compared to other cropland products, especially in North America and Eastern Europe. Comparing FROM_GLC-2015 and FROM_ GC-2010, it can be seen that, in FROM_GC, which is derived from the FROM_GLC cropland layer, the extent and density of cropland are greater and the omissions in Europe and North America are greatly decreased.

Figure 12 illustrates the total cropland area in the meridional and zonal directions using steps of $0.05^{\circ}$. The meridio- nal curves indicate that the global distribution of cropland varies a lot with longitude. FROM_GLC-2015 has the lowest cropland area at most longitudes, which also explains the omissions in FROM_GLC-2015 at the global scale. Also, compared with GFSAD30-2015 and GlobeLand30-2010, the amount of cropland in GLC_FCS30-2015 is larger in the $0^{\circ}-40^{\circ} \mathrm{E}$ region (which includes Africa) and between $100^{\circ} \mathrm{E}$ and $130^{\circ}$ E; GLC_FCS30-2015 basically agrees well with GFSAD30-2015 at other longitudes. The area classed as cropland in FROM_GC-2010 generally falls between the FROM_ GLC-2015 value and the values in the three other products, which also indicates that the FROM_GC is a significant improvement on the FROM_GLC cropland product.

The zonal cropland area curves show that, globally, cropland is mainly distributed in the northern hemisphere. The greatest agreement is between GFSAD30-2015 and GlobeLand30-2010. The GLC_FCS30-2015 values are obviously high in the $25^{\circ} \mathrm{S}-15^{\circ} \mathrm{N}$ region and are consistent with GFSAD30-2015 and GlobeLand30-2010 elsewhere. The FROM_GLC-2015 and FROM_GC-2015 cropland products clearly have low values in the $30^{\circ} \mathrm{N}-60^{\circ} \mathrm{N}$ region (which includes the croplands in North America, Europe, and eastern Asia).

Figure 13 displays scatter plots for the five global $30 \mathrm{~m}$ cropland products after aggregation of the data to $0.05^{\circ}$ and using the GLC_FCS30-2015 cropland layer as a baseline. It 

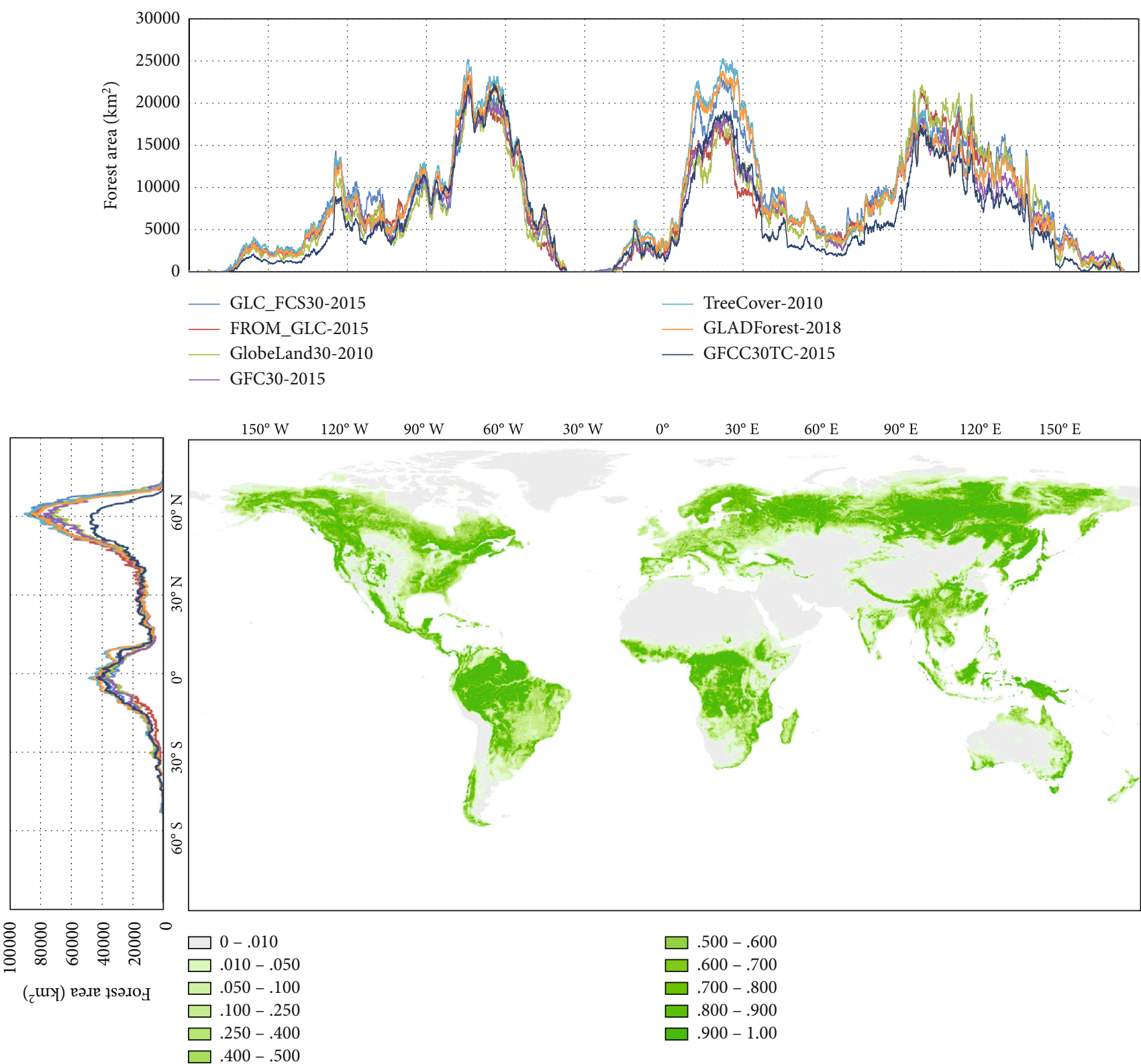

Figure 9: The meridional and zonal area distributions of forest in the seven global $30 \mathrm{~m}$ forest products based on $0.05^{\circ}$ intervals. The global reference forest map is the forest layer of GLC_FCS30-2015.

can be seen that there is a significant agreement between GLC_FCS30-2015, GlobeLand30-2010, and GFSAD30-2015 because most of the points are concentrated around the $1: 1$ line in these plots. However, the points in the plots showing the relationship between GLC_FCS30-2015, FROM_GLC2015, and FROM_GC-2010 deviate a lot from the 1:1 line and are mainly located below it. In addition, combining the spatial patterns and the area statistics from Figures 11 and 12, it can be concluded that FROM_GC-2010 still suffers from commission and omission errors even if, visually, it appears to capture the overall distribution of cropland at the global scale. According to the accuracy metrics shown in Figure 13, there is a high degree of spatial consistency between GLC_FCS30-2015 and GFSAD30-2015, for which
$R^{2}=0.669, \quad \mathrm{RMSD}=0.190$, and the regression slope is 0.842 . This is followed by the GLC_FCS30-2015-GlobeLand30-2015 pair, for which $R^{2}=0.607, \mathrm{RMSD}=0.209$, and the regression slope is 0.800 . It should be noted that some of the points in this scatter plot are located below the $1: 1$ line because the density and extent of cropland in GLC_FCS30-2015 in Africa are higher.

4.5. Spatial Consistency of Global $30 \mathrm{~m}$ Water Maps. Figure 14 shows the spatial distribution of the water class in the six global $30 \mathrm{~m}$ inland water maps after aggregation of the data to a resolution of $0.05^{\circ}$. Overall, the spatial patterns in the inland water maps are reasonably consistent. For instance, there is a relative abundance of water bodies in the eastern 

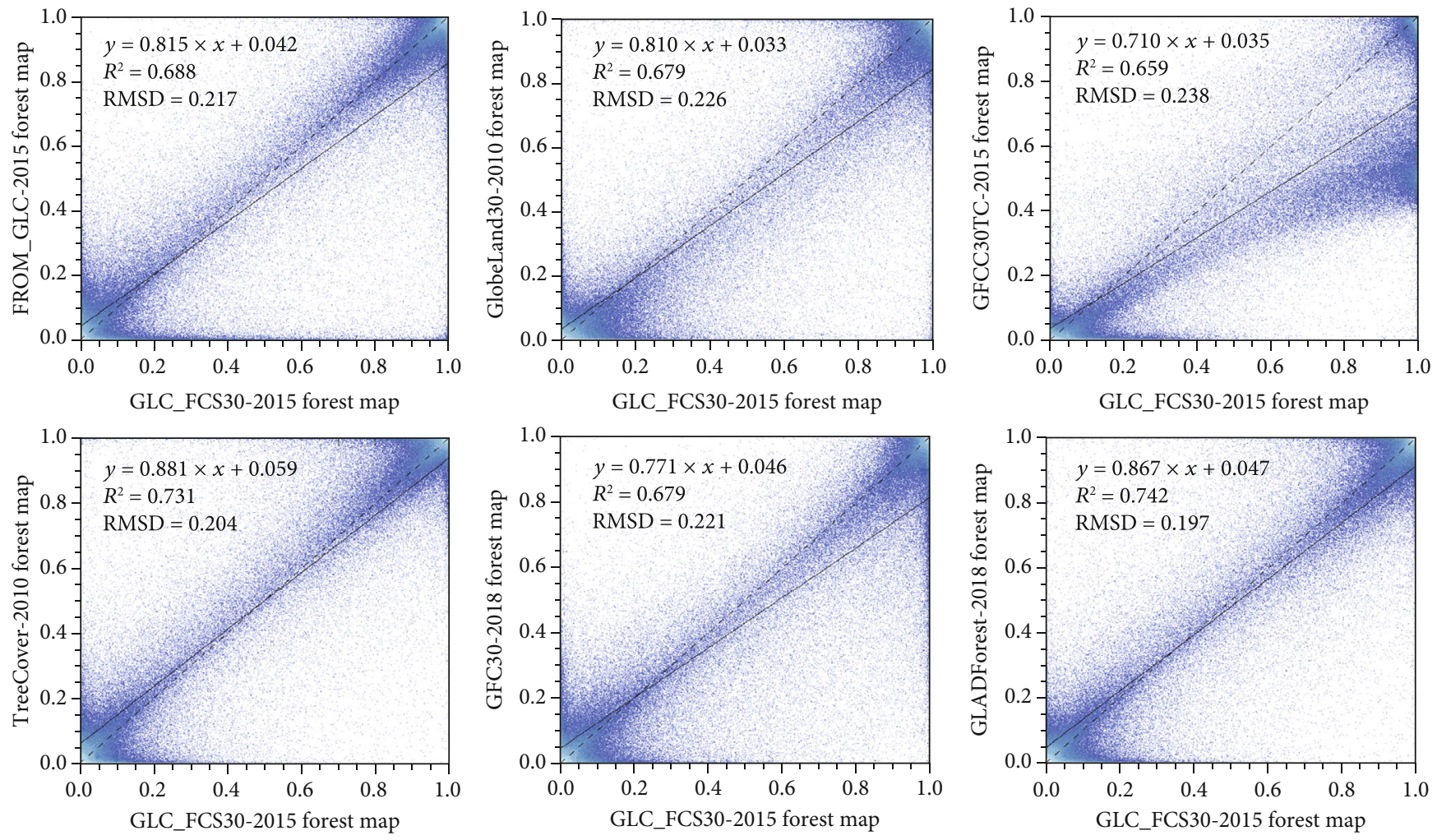

$$
\begin{array}{llll}
0 & 20 & 40
\end{array}
$$

$60 \quad 80$

100

120

140

160

180

200

220

Figure 10: Scatter plots between the GLC_FCS30-2015 and the FROM_GLC-2015, GlobeLand30-2010, GFCC30TC-2015, TreeCover-2010, GFC30-2018, and GLADForest-2018 global forest products based on results obtained using a $0.05^{\circ} \times 0.05^{\circ}$ grid. The axes represent the fraction of forest within each $0.05^{\circ} \times 0.05^{\circ}$ grid cell of seven global $30 \mathrm{~m}$ forest products, and the different colors represent the number of grids with different fractions of forest.
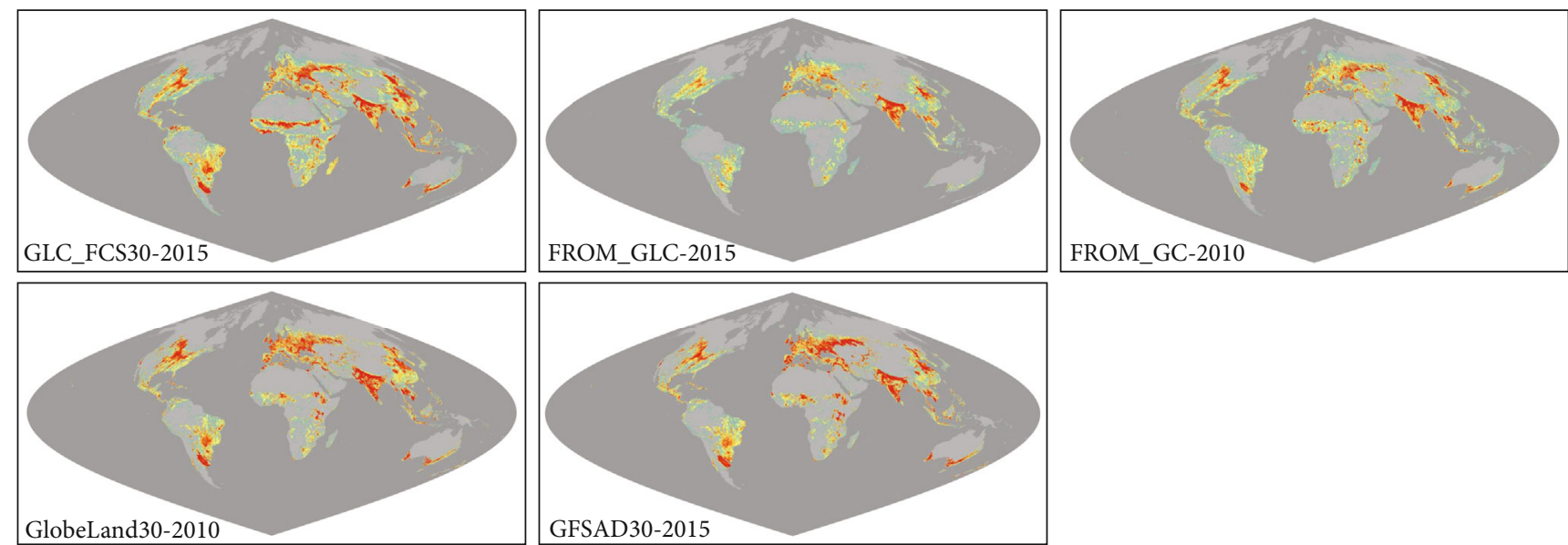

$$
\begin{array}{rr}
.005-.010 & .450-.600 \\
.010-.080 & .600-.700 \\
.080-.150 & .700-.800 \\
.150-.300 & .800-.900 \\
.300-.450 & .900-1.00
\end{array}
$$

FIGURE 11: The spatial distribution of the cropland class in the five $30 \mathrm{~m}$ cropland products after aggregation of the data to a resolution of $0.05^{\circ}$. 

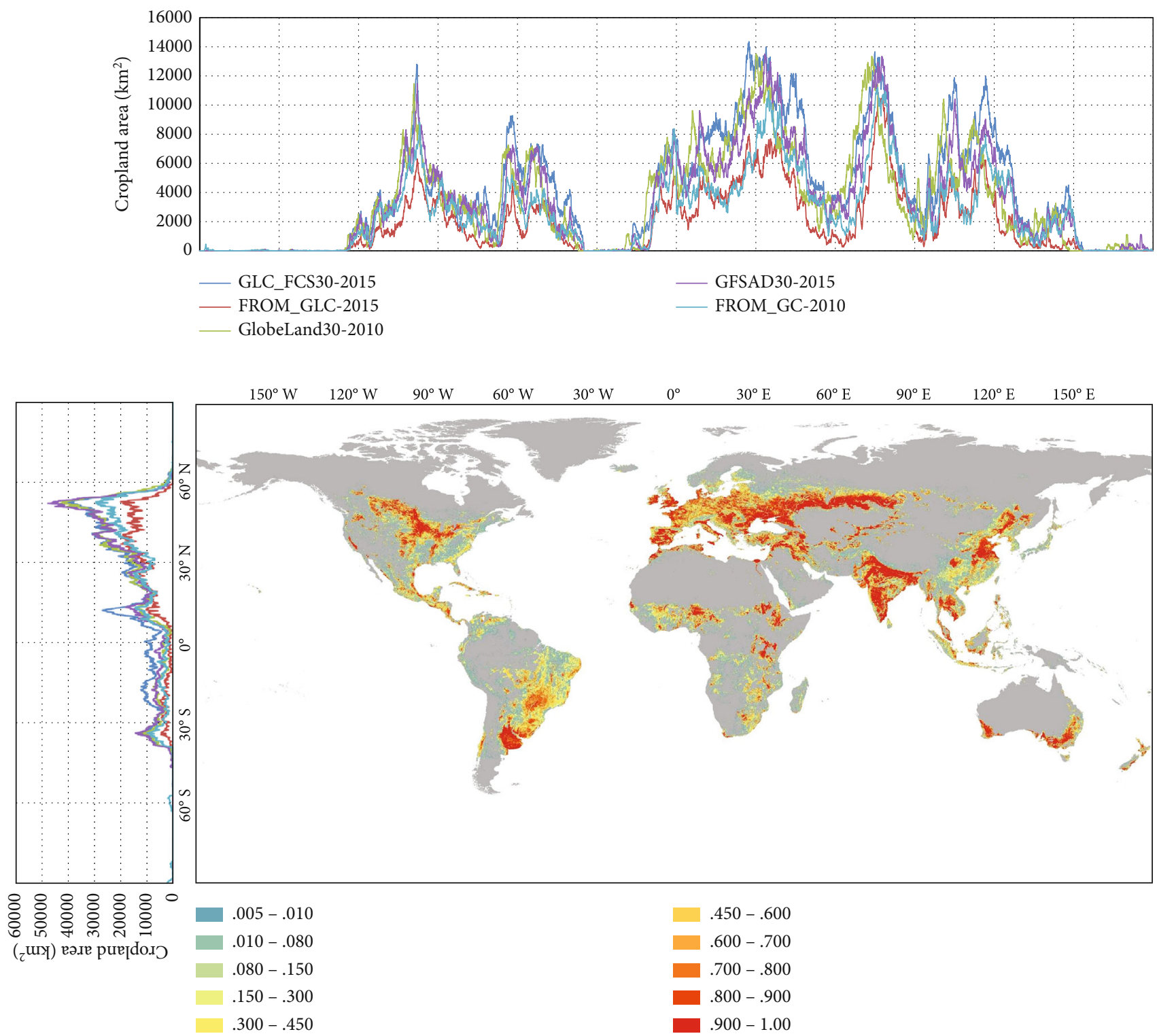

Figure 12: The meridional and zonal distributions of cropland in the five $30 \mathrm{~m}$ global cropland products based on $0.05^{\circ}$ intervals. The global reference cropland map is the cropland layer of GLC_FCS30-2015.

part of North America and the southern regions of Asia, whereas water bodies are relatively sparsely distributed in Africa. However, some discrepancies still exist between these products in specific regions. For example, there are obviously more water bodies in the western part of South America in FROM_GLC than in the other five products.

The spatial consistency between the six global inland water maps can also be seen from the meridional and zonal distributions of this class based on $0.05^{\circ}$ intervals that are shown in Figure 15. These six products have similar trends in the latitudinal and longitudinal directions. However, there are still some obvious disagreements in specific regions.

The distribution of inland water between $15^{\circ} \mathrm{W}$ and $30^{\circ} \mathrm{W}$, $60^{\circ} \mathrm{W}$ and $80^{\circ} \mathrm{W}$, and $50^{\circ} \mathrm{E}$ and $120^{\circ} \mathrm{E}$ is quite different in the different maps. Between $15^{\circ} \mathrm{W}$ and $30^{\circ} \mathrm{W}$ and $60^{\circ} \mathrm{W}$ and $80^{\circ} \mathrm{W}$, the size of the water area in FROM_GLC-2015 is much greater than in the other products. Also, in both FROM_
GLC-2015 and GLADWater-2015, between $50^{\circ} \mathrm{E}$ and $120^{\circ} \mathrm{E}$, there is a much greater water area than in the other products. These patterns are also noticeable in Figure 15, where it can be seen that, in FROM_GLC-2015, there is a greater number of water bodies in northwestern Africa $\left(15^{\circ} \mathrm{W}\right.$ to $\left.30^{\circ} \mathrm{W}\right)$, Iceland $\left(15^{\circ} \mathrm{W}\right.$ to $\left.30^{\circ} \mathrm{W}\right)$, western South America $\left(60^{\circ} \mathrm{W}\right.$ to $\left.80^{\circ} \mathrm{W}\right)$, and eastern North America $\left(60^{\circ} \mathrm{W}\right.$ to $\left.80^{\circ} \mathrm{W}\right)$. Also, in GLADWater-2015 and FROM_GLC-2015, there are more water bodies in mainland Asia $\left(50^{\circ} \mathrm{E}\right.$ to $\left.120^{\circ} \mathrm{E}\right)$.

There are also differences in the latitudinal distribution of inland water between the products. In FROM_GLC2015 and GLADWater-2015, there is a greater area of water than in the other products from $25^{\circ} \mathrm{N}$ to $35^{\circ} \mathrm{N}$ and above $70^{\circ} \mathrm{N}$. This can also be seen from Figure 15. In mid- and high-latitude regions, FROM_GLC and GLADWater exhibit higher proportions of water than the other four products (Figure 15). 

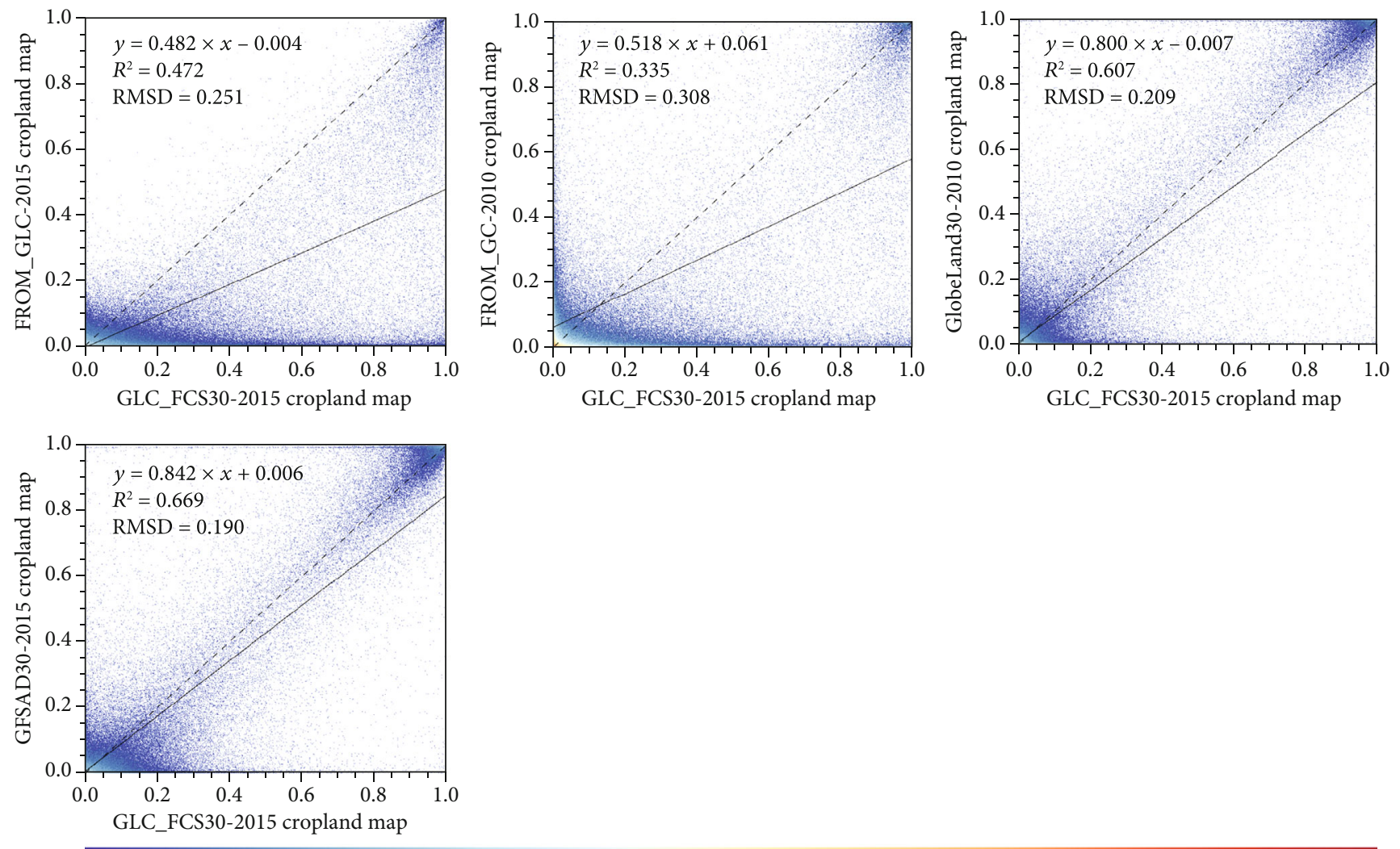
0
20
40
$60 \quad 80$
100
120
140
160
180
200
220

FIGURE 13: Scatter plots between the FROM_GLC-2015, FROM_GC-2010, GlobeLand30-2010, and GFSAD30-2015 global cropland products and the GLC_FCS30-2015 based on a $0.05^{\circ} \times 0.05^{\circ}$ grid. The axes represent the fraction of cropland within each $0.05^{\circ} \times 0.05^{\circ}$ grid cell of five global $30 \mathrm{~m}$ cropland products, and the different colors represent the number of grids with different fractions of cropland.
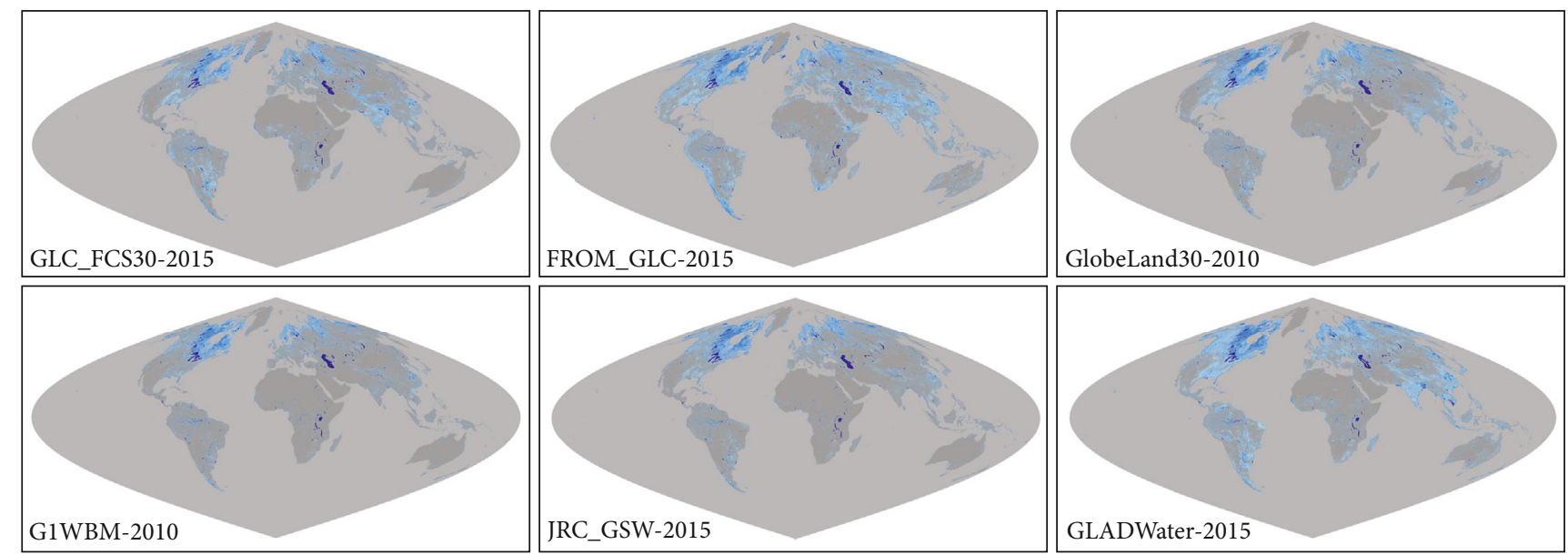

$\begin{array}{ll}\square 0-.001 & \square .300-.450 \\ \square .001-.005 & \square .450-.600 \\ \square .005-.0100 & \square .600-.700 \\ \square .010-.080 & \square .700-.850 \\ \square .080-.150 & \square .850-1 \\ \square .150-.300 & \end{array}$

FIGURE 14: The spatial distribution of the water body class in the six global $30 \mathrm{~m}$ water products after aggregation of the data to a resolution of $0.05^{\circ}$. 

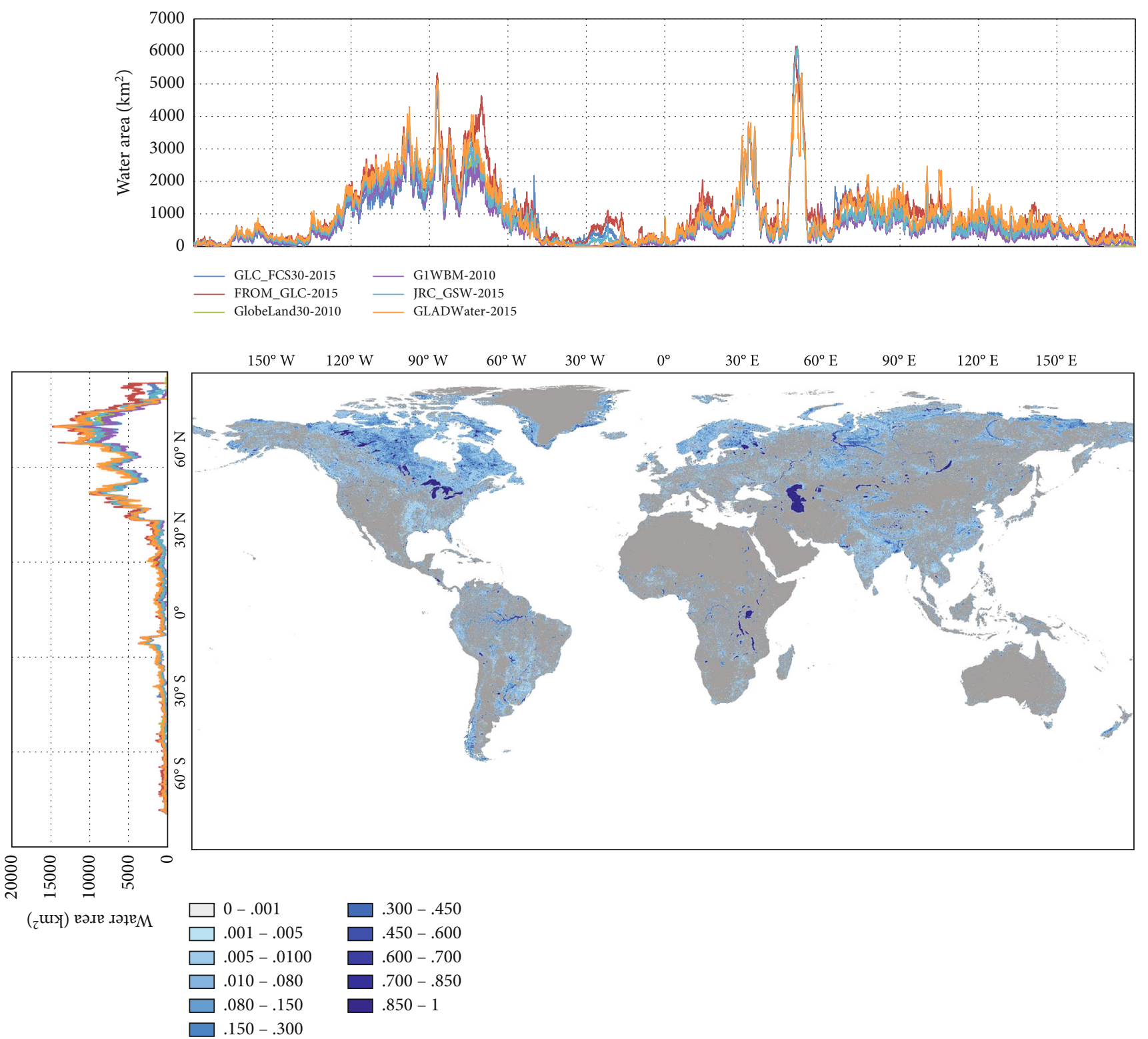

Figure 15: The meridional and zonal area distributions of the water class in the six global $30 \mathrm{~m}$ water products based on $0.05^{\circ}$ intervals. The global reference inland water map is the inland water layer of GLC_FCS30-2015.

In order to quantitatively analyze the differences between the six global inland water maps, scatter plots of the GLC FCS30-2015 water map against the other products were made using a $0.05^{\circ} \times 0.05^{\circ}$ grid and the results are shown in Figure 16. The results show that, for all five pairs of products, the value of $R^{2}$ is greater than 0.82 and all the products have a high degree of consistency with the water map in GLC FCS30-the values of $R^{2}$ range from 0.823 (G1WBM-2010) to 0.913 (JRC_GSW), and the RMSD values range from 0.106 (G1WBM-2010) to 0.068 (JRC_GSW). The inconsistency between GLC_FCS30-2015 and GlobeLand30-2010 and G1WBM-2010 may be partly because these three products were produced in different years. Moreover, since the algorithm used to develop G1WBM-2010 is mainly intended to accurately detect permanent water bodies [24], the uncer- tainty in the detection of seasonal water bodies may also be a cause of some of the differences between G1WBM-2010 and GLC_FCS30-2015.

\section{Perspectives}

Firstly, the synergy between the spectral, spatial, and temporal features derived from multisource satellite datasets can improve the classification accuracy of fine-resolution GLC products. Over recent decades, the volume and number of types of satellite data have grown due to various breakthroughs, providing great opportunities for accurate landcover mapping. Taking the mapping of impervious surfaces as an example, due to the complicated spectral and spatial structures associated with these surfaces, it is very difficult 

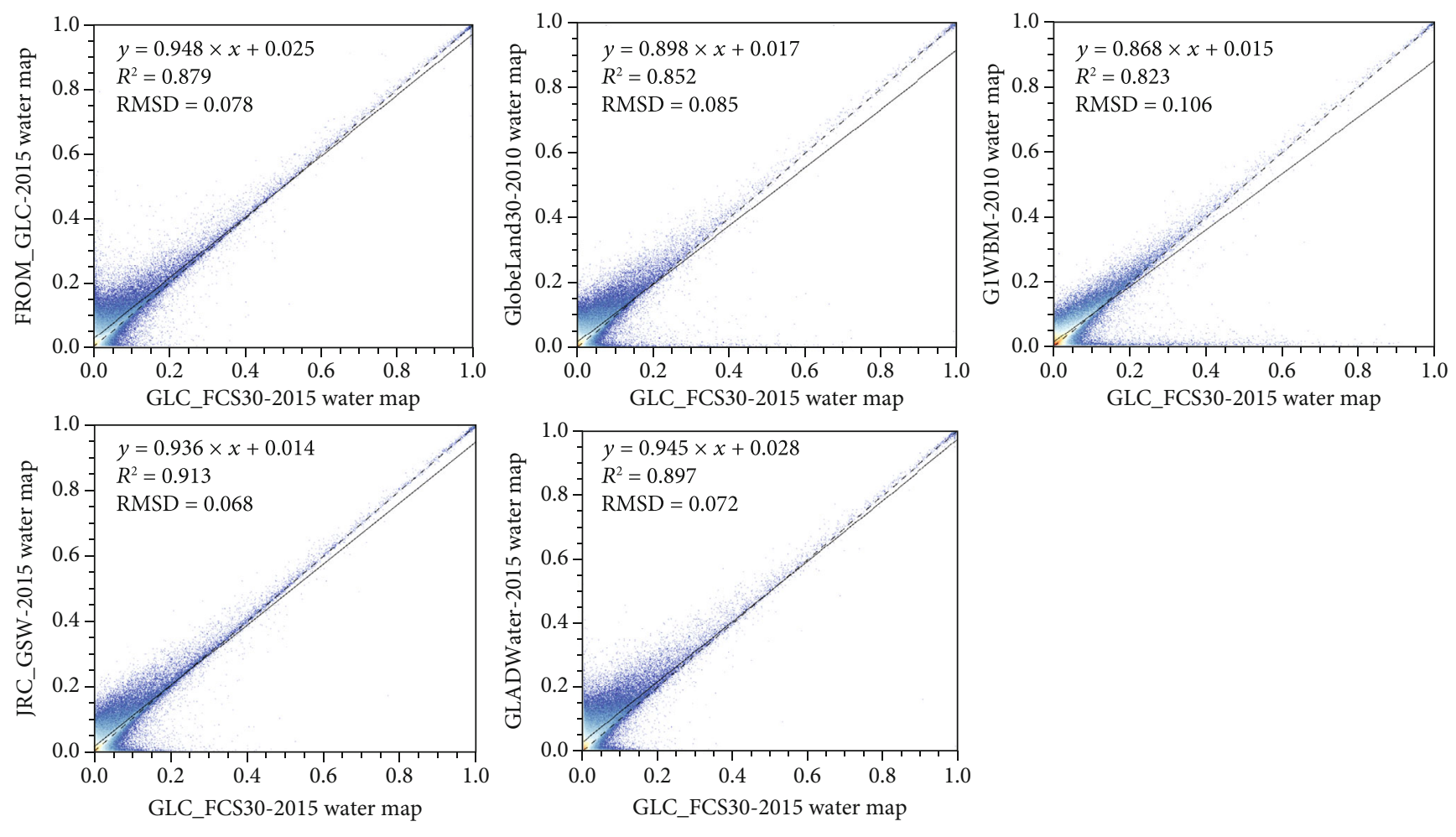

0

20

40

60

80

100

120

140

160

180

200

220

FIGURE 16: Scatter plots between the GLC_FCS30-2015 water map and the FROM_GLC-2015, GlobeLand30-2010, G1WBM-2010, JRC_ GSW-2015, and GLADWater-2015 global water products based on a $0.05^{\circ} \times 0.05^{\circ}$ grid. The axes represent the fraction of water within each $0.05^{\circ} \times 0.05^{\circ}$ grid cell of six global $30 \mathrm{~m}$ water products, and the different colors represent the number of grids with different fractions of water.

to produce accurate large-area impervious surface products using only optical imagery. For example, Liu et al. [19] used Landsat imagery to generate a global $30 \mathrm{~m}$ impervious surface product, but this map suffered from serious omission errors, especially in rural areas and small cities [22, 106]. Furthermore, as free access to Sentinel-1 RADARSAT and ENVISAT synthetic-aperture radar (SAR) imagery has become available, the combination of optical imagery and SAR imagery has been demonstrated to significantly improve the accuracy of the mapping of impervious surfaces. This is because optical imagery can capture surface reflectance characteristics, whereas SAR data can be used to provide information on the structure and dielectric properties of surface materials $[22,106,118]$. Recently, the rapid development of nighttime light remote sensing has also helped to promote accurate impervious surface mapping. For example, Goldblatt et al. [119] combined nighttime light data and Landsat imagery to characterize the built-up land cover in three geographically diverse countries: India, Mexico, and the US. Zhang et al. [22] combined multisource (optical, SAR, nighttime light, and DEM) datasets and spectral and textural features from time series stacks to generate a global $30 \mathrm{~m}$ impervious surface product that had an overall accuracy of $95.1 \%$ and a kappa coefficient of 0.898 .

Secondly, the local adaptive stratified classification scheme is essential for accurate large-scale land-cover mapping. Due to the spectral heterogeneity of land-cover types, it is very difficult to generate an accurately classified product using a single classification model [120]. The stratified classification scheme is more appropriate for regional or global mapping that has a complicated classification system [19, 44]. For example, to improve the mapping accuracy, Chen et al. [14] presented a split-and-merge strategy for handling the classification of 10 different land-cover types: i.e., first, each class in a prioritized sequence was identified, and then the ten types were merged together. Zhang et al. [16] directly used an existing global $30 \mathrm{~m}$ impervious surface map as an independent land-cover type in the global land-cover product, which was superimposed over the global land-cover classifications. In addition, as the distribution of the land-cover types varies with the region, the use of a local adaptive classification scheme is more appropriate $[19,44]$. For instance, Liu et al. [15] divided the global land surface into $5^{\circ} \times 5^{\circ}$ geographical tiles and developed a local random forest model for each tile using the corresponding training samples, then generated a global impervious surface map (MSMT_IS30) by mosaicking 948 geographical tiles. This map, developed using local adaptive classifiers, has a much higher accuracy than the single classifier-based products: MSMT_IS30 has an overall accuracy of 0.95 , which compares with 0.89 for FROM_GLC-2015, 0.903 for GHSL-2015, 0.884 for GlobeLand30-2010, and 0.880 for HBASE-2010 [22]. Furthermore, the classification accuracy of fine-resolution GLC maps can also be improved using deep learning algorithms. For 


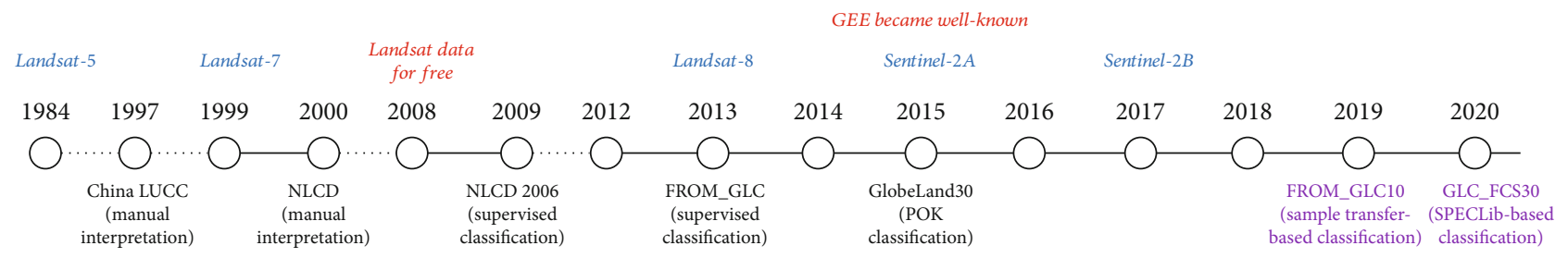

FIGURE 17: Timeline showing some important developments related to fine-resolution global land-cover mapping. Note: the words in purple represent products developed using the GEE cloud computing platform; words in blue represent important Earth observation satellites that have been launched at different times. POK classification is a classification approach based on the integration of pixel- and object-based methods with prior knowledge.

example, using a deep convolutional neural network- (CNN) based classifier, an accurate $30 \mathrm{~m}$ large-scale land-cover map was generated, achieving a classification accuracy of $84.4 \%$, compared to $79.9 \%$ for RF and $80.2 \%$ for SVM $80.2 \%$ [121].

Thirdly, over the last four decades (since the launch of the first Landsat satellite in 1972), land-cover updates based on a time series change detection approach have made it possible to obtain information about land-cover types and changes at a high resolution. Land-cover change (LCC) is, in fact, the key information needed for global change research. Although the existing global land-cover products partially meet users' requirements in terms of performance, none of these global land-cover products meets the requirements in terms of interannual stability due to the limited classification accuracy of results if the GLC map is generated independently for each year. Thus, these temporally independent land-cover products cannot be used to support LCC analysis $[4,8,122-$ 124]. To deal with this issue, change-based land-cover mapping has been adopted by the remote sensing community to generate temporally consistent GLC products. Using the traditional approach, first, an annual land-cover dataset is generated, and then some time series postclassification processing steps are implemented to ensure temporal consistency and logical transition, which requires a large number of subjective rules [125-127]. Recently, the continuous change detection approach has been widely applied to the detection of land-cover changes using time series of remote sensing images. Using this approach, changed pixels are first identified using dense time series of images; the changed regions are then updated using temporal segments instead of specific epochs [128-130]. In this way, an opportunity for generating accurate and consistent annual fine-resolution GLC products that can be used for the analysis of global land-cover changes is provided.

Finally, cloud computing platforms greatly facilitate global fine-resolution land-cover mapping. The volume of data required for generating a fine-resolution GLC product is huge, and this task was previously very labor- and computationally intensive [131]. Figure 17 outlines the development of some representative fine-resolution land-cover products over the years, and it can be seen that the early land-cover products (e.g., the National Land-Cover Database (NLCD) [132] and China's land-use and land-cover (LUCC) product [133]) were mainly based on manual, visual interpretation, which is very laborious and time-consuming. Later, the
Landsat dataset became freely available to the public and more fine-resolution remote sensing datasets (e.g., Landsat8 and Sentinel-2) appeared. In order to promote the automation of land-cover mapping, sample-based classification strategies were employed to reduce the amount of labor required compared to the manual editing approach. Some fine-resolution GLC products, such as GlobeLand30 [14] and FROM_GLC [12], were then developed. However, the amount of labor required for the collection of training samples was still a limitation [44], and the amount of computation required remained a challenge for scientists until cloud-based computing platforms, such as GEE, became available. GEE has proved its potential in many different applications, especially in land-cover mapping, and the Landsat and Sentinel datasets have been extensively utilized by GEE users [44]. Due to GEE's powerful computing ability [134], the production of fine-resolution GLC products can now be completed in a few hours or days [134]. Also, because of the massive data reserves held within GEE, the training datasets can be automatically derived from existing landcover products and multisource remote sensing datasets without any labor input [135]. Gong et al. [18] automatically developed the $10 \mathrm{~m}$ FROM_GLC10 by transferring an existing $30 \mathrm{~m}$ resolution sample set to the $10 \mathrm{~m}$ Sentinel- 2 imagery using the GEE platform. Zhang et al. [16] used the freely available multisource data and the programming environment within GEE to construct a spatiotemporal spectral library to automatically generate GLC_FCS30. Therefore, we can expect more and more GLC products with higher resolutions, finer classification systems, more accurate classification, more real-time releases, and more frequent updates. However, perhaps too many GLC products are being generated by the remote sensing community too quickly. Does having so many datasets really benefit or mislead data users? It is a particularly urgent task to assess the quality of the increasing GLC datasets and their suitability for different user applications. As also reported in numerous research studies, the mapping accuracy varied noticeably for different validation datasets. Therefore, rigorous and transparent validation is much more important than ever.

\section{Conclusions}

Most human impacts on the land cover can be captured at a resolution of $30 \mathrm{~m}$, and the $30 \mathrm{~m}$ GLC products have been widely used in many applications. In this study, the accuracy 
and consistency of, and the recent progress made by, $30 \mathrm{~m}$ GLC products were investigated. Despite the great efforts made toward improving mapping accuracy in recent decades, the current $30 \mathrm{~m}$ GLC products still suffer from a relatively low accuracy-their accuracies range from $46.0 \%$ to $88.9 \%$ for GlobeLand30-2010, $57.71 \%$ to $80.36 \%$ for FROM_GLC-2015, and $65.59 \%$ to $84.33 \%$ for GLC_FCS302015. The reported accuracies for the global $30 \mathrm{~m}$ thematic maps vary from $81.0 \%$ (NUACI) to $95.1 \%$ (MSMT_IS30) for the impervious surface products, $65.5 \%$ (GLADForest) to $97.0 \%$ (GlobeLand30) for the forest products, $76.23 \%$ (FROM_GLC30) to $91.70 \%$ (GFSAD30) for the cropland products, and $81.97 \%$ (FROM_GLC) to $98.50 \%$ (JRC_ GSW) for the inland water products. Given that the target maximum error is $5-15 \%$ either per class or for the overall accuracy [136], most of the current land-cover maps still do not meet the accuracy demands of many applications. In addition, the consistency and comparability of different GLC maps show a good overall agreement in terms of overall spatial patterns but a limited agreement for some vegetation classes (such as shrub, tree, or grassland) in specific areas, mostly transition zones. Unfortunately, land-cover change primarily occurs in these transition zones, which means that it is extremely essential to improve mapping accuracy in these zones. So far, all these temporally independent GLC products cannot be used to support LCC analysis due to the limited classification accuracy. Therefore, more efforts are needed toward improving the classification accuracy and generating temporally consistent GLC products, especially for classes for which the accuracy is currently low (such as shrub, wetland, tundra, and grassland) and for regions with low accuracy (heterogeneous or transition zones, tropical rainforest regions).

\section{Conflicts of Interest}

The authors declare that there is no conflict of interest regarding the publication of this article.

\section{Acknowledgments}

This research was funded by the National Natural Science Foundation of China (41825002), the Strategic Priority Research Program of the Chinese Academy of Sciences (XDA19090200), and the Key Research Program of the Chinese Academy of Sciences (grant number ZDRW-ZS-2019$1)$.

\section{References}

[1] S. Fritz, L. See, and F. Rembold, "Comparison of global and regional land cover maps with statistical information for the agricultural domain in Africa," International Journal of Remote Sensing, vol. 31, no. 9, pp. 2237-2256, 2010.

[2] P. H. Verburg, K. Neumann, and L. Nol, "Challenges in using land use and land cover data for global change studies," Global Change Biology, vol. 17, no. 2, pp. 974-989, 2011.

[3] Y. Ban, P. Gong, and C. Giri, "Global land cover mapping using Earth observation satellite data: recent progresses and challenges," ISPRS Journal of Photogrammetry and Remote Sensing, vol. 103, pp. 1-6, 2015.

[4] C. Gómez, J. C. White, and M. A. Wulder, "Optical remotely sensed time series data for land cover classification: a review," ISPRS Journal of Photogrammetry and Remote Sensing, vol. 116, pp. 55-72, 2016.

[5] X. Zhang, L. Liu, X. Chen, S. Xie, and Y. Gao, "Fine landcover mapping in China using Landsat datacube and an operational Speclib-based approach," Remote Sensing, vol. 11, no. 9 , article 1056, 2019.

[6] M. C. Hansen, R. S. Defries, J. R. G. Townshend, and R. Sohlberg, "Global land cover classification at $1 \mathrm{~km}$ spatial resolution using a classification tree approach," International Journal of Remote Sensing, vol. 21, no. 6-7, pp. 1331-1364, 2010.

[7] T. R. Loveland, B. C. Reed, J. F. Brown et al., "Development of a global land cover characteristics database and Igbp Discover from $1 \mathrm{~km}$ Avhrr data," International Journal of Remote Sensing, vol. 21, no. 6-7, pp. 1303-1330, 2010.

[8] M. Friedl, D. Sulla-Menashe, B. Tan et al., "Modis Collection 5 global land cover: algorithm refinements and characterization of new datasets," Remote Sensing of Environment, vol. 114, no. 1, pp. 168-182, 2010.

[9] P. Bicheron, M. Leroy, B. Carsten et al., "Globcover: a $300 \mathrm{~m}$ global land cover product for 2005 using Envisat Meris time series," in Proceeding of the Second International Symposium on Recent Advances in Quantitative Remote Sensing, pp. 538542, Enschede, Netherlands, 2006.

[10] C. Lamarche, M. Santoro, S. Bontemps et al., "Compilation and validation of Sar and optical data products for a complete and global map of inland/ocean water tailored to the climate modeling community," Remote Sensing, vol. 9, no. 1, p. 36, 2017.

[11] C. Giri, B. Pengra, J. Long, and T. R. Loveland, "Next generation of global land cover characterization, mapping, and monitoring," International Journal of Applied Earth Observation and Geoinformation, vol. 25, pp. 30-37, 2013.

[12] P. Gong, J. Wang, L. Yu et al., "Finer resolution observation and monitoring of global land cover: first mapping results with Landsat Tm and Etm+ data," International Journal of Remote Sensing, vol. 34, no. 7, pp. 2607-2654, 2012.

[13] M. Herold, P. Mayaux, C. E. Woodcock, A. Baccini, and C. Schmullius, "Some challenges in global land cover mapping: an assessment of agreement and accuracy in existing 1 $\mathrm{km}$ datasets," Remote Sensing of Environment, vol. 112, no. 5, pp. 2538-2556, 2008.

[14] J. Chen, J. Chen, A. Liao et al., "Global land cover mapping at $30 \mathrm{~m}$ resolution: A POK-based operational approach," ISPRS Journal of Photogrammetry and Remote Sensing, vol. 103, pp. 7-27, 2015.

[15] L. Liu, X. Zhang, X. Chen, Y. Gao, and J. Mi, GLC_FCS30: global land-cover product with fine classification system at 30 $m$ using time-series Landsat imagery. Version v1, Zenodo, 2020.

[16] X. Zhang, L. Liu, X. Chen, Y. Gao, S. Xie, and J. Mi, "Glc_Fcs30: global land-cover product with fine classification system at $30 \mathrm{~m}$ using time-series Landsat imagery," Earth System Science Data Discussions, vol. 2020, pp. 131, 2020.

[17] CCI_Land-Cover, "Cci land cover - S2 prototype land-cover 20m map of Africa," ESA, 2017. 
[18] P. Gong, H. Liu, M. Zhang et al., "Stable classification with limited sample: transferring a $30-\mathrm{m}$ resolution sample set collected in 2015 to mapping 10-m resolution global land cover in 2017," Science Bulletin, vol. 64, no. 6, pp. 370-373, 2019.

[19] X. Liu, G. Hu, Y. Chen et al., "High-resolution multitemporal mapping of global urban land using Landsat images based on the Google Earth Engine platform," Remote Sensing of Environment, vol. 209, pp. 227-239, 2018.

[20] A. Florczyk, C. Corban, D. Ehrlich et al.et al., "Ghsl data package 2019," 2019.

[21] P. Gong, X. Li, J. Wang et al., "Annual maps of global artificial impervious area (Gaia) between 1985 and 2018," Remote Sensing of Environment, vol. 236, article 111510, 2020.

[22] X. Zhang, L. Liu, C. Wu et al., "Development of a global $30 \mathrm{~m}$ impervious surface map using multisource and multitemporal remote sensing datasets with the Google Earth Engine platform," Earth System Science Data, vol. 12, no. 3, pp. 1625-1648, 2020.

[23] M. Feng, J. O. Sexton, S. Channan, and J. R. Townshend, “A global, high-resolution (30-m) inland water body dataset for 2000: first results of a topographic-spectral classification algorithm," International Journal of Digital Earth, vol. 9, no. 2, pp. 113-133, 2014.

[24] D. Yamazaki, M. A. Trigg, and D. Ikeshima, "Development of a global $\sim 90$ m water body map using multi-temporal Landsat images," Remote Sensing of Environment, vol. 171, pp. 337-351, 2015.

[25] J. F. Pekel, A. Cottam, N. Gorelick, and A. S. Belward, "Highresolution mapping of global surface water and its long-term changes," Nature, vol. 540, no. 7633, pp. 418-422, 2016.

[26] A. H. Pickens, M. C. Hansen, M. Hancher et al., "Mapping and sampling to characterize global inland water dynamics from 1999 to 2018 with full Landsat time-series," Remote Sensing of Environment, vol. 243, article 111792, 2020.

[27] A. J. Oliphant, P. S. Thenkabail, P. Teluguntla et al., "Nasa Making Earth System Data Records for Use in Research Environments (Measures) Global Food Security-Support Analysis Data (Gfsad) cropland extent 2015 Southeast Asia $30 \mathrm{~m}$ V001," 2017.

[28] P. Thenkabail, "Global croplands and their water use for food security in the twenty-first century," Photogrammetric Engineering and Remote Sensing, vol. 78, pp. 797-798, 2012.

[29] L. Yu, J. Wang, N. Clinton et al., "From-Gc: 30 m global cropland extent derived through multisource data integration," International Journal of Digital Earth, vol. 6, no. 6, pp. 521533, 2013.

[30] M. C. Hansen, P. V. Potapov, R. Moore et al., "High-resolution global maps of 21 st-century forest cover change," Science, vol. 342, no. 6160, pp. 850-853, 2013.

[31] J. O. Sexton, M. Feng, S. Channan et al.et al., "Earth science data records of global forest cover and change," User Guide, vol. 38, 2016.

[32] X. Zhang, T. Long, G. He et al., "Rapid generation of global forest cover map using Landsat based on the forest ecological zones," Journal of Applied Remote Sensing, vol. 14, no. 2, p. 1, 2020.

[33] N. E. Tsendbazar, S. de Bruin, and M. Herold, "Assessing global land cover reference datasets for different user communities," ISPRS Journal of Photogrammetry and Remote Sensing, vol. 103, pp. 93-114, 2015.
[34] Y. Yang, P. Xiao, X. Feng, and H. Li, “Accuracy assessment of seven global land cover datasets over China," ISPRS Journal of Photogrammetry and Remote Sensing, vol. 125, pp. 156173, 2017.

[35] Y. Xu, L. Yu, D. Feng et al., "Comparisons of three recent moderate resolution African land cover datasets: CglsLc100, Esa-S2-Lc20, and from-Glc-Africa30," International Journal of Remote Sensing, vol. 40, no. 16, pp. 6185-6202, 2019.

[36] P. Olofsson, G. M. Foody, S. V. Stehman, and C. E. Woodcock, "Making better use of accuracy data in land change studies: estimating accuracy and area and quantifying uncertainty using stratified estimation," Remote Sensing of Environment, vol. 129, pp. 122-131, 2013.

[37] N. E. Tsendbazar, S. de Bruin, B. Mora, L. Schouten, and M. Herold, "Comparative assessment of thematic accuracy of Glc maps for specific applications using existing reference data," International Journal of Applied Earth Observation and Geoinformation, vol. 44, pp. 124-135, 2016.

[38] P. Olofsson, S. V. Stehman, C. E. Woodcock et al., “A global land-cover validation data set, part i: fundamental design principles," International Journal of Remote Sensing, vol. 33, no. 18, pp. 5768-5788, 2012.

[39] J. Kang, Z. Wang, L. Sui, X. Yang, Y. Ma, and J. Wang, “Consistency analysis of remote sensing land cover products in the tropical rainforest climate region: a case study of Indonesia," Remote Sensing, vol. 12, no. 9, article 1410, 2020.

[40] Z. Y. Xu, Q. H. Luo, and Z. L. Xu, "Consistency of land cover data derived from remote sensing in Xinjiang," Journal of Geo-information Science, vol. 21, no. 3, pp. 427-436, 2019.

[41] Y. Bai, M. Feng, H. Jiang, J. Wang, Y. Zhu, and Y. Liu, "Assessing consistency of five global land cover data sets in China," Remote Sensing, vol. 6, no. 9, pp. 8739-8759, 2014.

[42] J. Kang, L. Sui, X. Yang, Z. Wang, C. Huang, and J. Wang, "Spatial pattern consistency among different remote-sensing land cover datasets: a case study in Northern Laos," ISPRS International Journal of Geo-Information, vol. 8, no. 5, p. 201, 2019.

[43] J. Wang, C. Li, and P. Gong, "Adaptively weighted decision fusion in $30 \mathrm{~m}$ land-cover mapping with Landsat and Modis data," International Journal of Remote Sensing, vol. 36, no. 14, pp. 3659-3674, 2015.

[44] X. Zhang, L. Liu, Y. Wang, Y. Hu, and B. Zhang, "A Speclibbased operational classification approach: a preliminary test on China land cover mapping at $30 \mathrm{~m}$," International Journal of Applied Earth Observation and Geoinformation, vol. 71, pp. 83-94, 2018.

[45] Y. Gao, L. Liu, X. Zhang, X. Chen, J. Mi, and S. Xie, "Consistency analysis and accuracy assessment of three global 30-m land-cover products over the European Union using the Lucas dataset," Remote Sensing, vol. 12, no. 21, article 3479, 2020.

[46] B. Sun, X. Chen, and Q. Zhou, "Uncertainty assessment of Globeland30 land cover data set over Central Asia," ISPRS International Archives of the Photogrammetry, Remote Sensing and Spatial Information Sciences, vol. XLI-B8, pp. 13131317, 2016.

[47] S. Dong, Z. Chen, B. Gao, H. Guo, D. Sun, and Y. Pan, "Stratified even sampling method for accuracy assessment of land use/land cover classification: a case study of Beijing, China," International Journal of Remote Sensing, vol. 41, no. 16, pp. 6427-6443, 2020. 
[48] P. Wang, C. Huang, and E. Brown de Colstoun, "Mapping 2000-2010 impervious surface change in India using Global Land Survey Landsat data," Remote Sensing, vol. 9, no. 4, p. 366, 2017.

[49] H. Xing, Y. Meng, D. Hou, F. Cao, and H. Xu, "Exploring point-of-interest data from social media for artificial surface validation with decision trees," International Journal of Remote Sensing, vol. 38, no. 23, pp. 6945-6969, 2017.

[50] F. Yang, Z. Wang, X. Yang et al., "Using multi-sensor satellite images and auxiliary data in updating and assessing the accuracies of urban land products in different landscape patterns," Remote Sensing, vol. 11, no. 22, article 2664, 2019.

[51] M. Marconcini, A. Metz-Marconcini, S. Üreyen et al., "Outlining where humans live, the World Settlement Footprint 2015," Sci Data, vol. 7, no. 1, p. 242, 2020.

[52] M. Pesaresi, D. Ehrlich, S. Ferri et al.et al., Operating procedure for the production of the global human settlement layer from Landsat data of the epochs 1975, 1990, 2000, and 2014, Publications Office of the European Union, 2016.

[53] S. Leyk, J. H. Uhl, D. Balk, and B. Jones, "Assessing the accuracy of multi-temporal built-up land layers across ruralurban trajectories in the United States," Remote Sensing of Environment, vol. 204, pp. 898-917, 2018.

[54] R. Moreno-Sanchez, D. P. Carver, J. M. Torres-Rojo, and P. Anthamatten, "Assessment of the classification accuracy of the Globeland 30 forest class for the temperate and tropical forests of Mexico," Applied Geomatics, 2020.

[55] N. E. Tsendbazar, M. Herold, S. de Bruin et al., "Developing and applying a multi-purpose land cover validation dataset for Africa," Remote Sensing of Environment, vol. 219, pp. 298-309, 2018.

[56] L. K. Hadi, L. Korhonen, A. Hovi, P. Rönnholm, and M. Rautiainen, "The accuracy of large-area forest canopy cover estimation using Landsat in boreal region," International Journal of Applied Earth Observation and Geoinformation, vol. 53, pp. 118-127, 2016.

[57] X. P. Song and H. Tang, "Accuracy assessment of Landsatderived continuous fields of tree cover products using airborne Lidar data in the Eastern United States," in Iwidf 2015, J. Zhang, Z. Lu, and Y. Zeng, Eds., pp. 241-246, International Archives of the Photogrammetry Remote Sensing and Spatial Information Sciences, 2015.

[58] Y. Qin, X. Xiao, J. Dong et al., "Annual dynamics of forest areas in South America during 2007-2010 at 50-m spatial resolution," Remote Sensing of Environment, vol. 201, pp. 73-87, 2017.

[59] T. Jia, Y. Li, W. Shi, and L. Zhu, "Deriving a forest cover map in Kyrgyzstan using a hybrid fusion strategy," Remote Sensing, vol. 11, no. 19, article 2325, 2019.

[60] S. Arjasakusuma, U. A. Pribadi, and G. A. Seta, "Accuracy and spatial pattern assessment of forest cover change datasets in Central Kalimantan," The Indonesian Journal of Geography, vol. 50, no. 2, p. 222, 2018.

[61] D. Cunningham, P. Cunningham, and M. E. Fagan, "Identifying biases in global tree cover products: a case study in Costa Rica," Forests, vol. 10, no. 10, p. 853, 2019.

[62] S. Fritz, L. See, I. McCallum et al., "Mapping global cropland and field size," Global Change Biology, vol. 21, no. 5, pp. 1980-1992, 2015.

[63] Y. Zhong, C. Luo, X. Hu, L. Wei, X. Wang, and S. Jin, "Cropland product fusion method based on the overall consistency difference: a case study of China," Remote Sensing, vol. 11, no. 9, article 1065, 2019.

[64] M. Lu, W. B. Wu, L. Zhang, A. P. Liao, S. Peng, and H. J. Tang, "A comparative analysis of five global cropland datasets in China," Science China Earth Sciences, vol. 59, no. 12, pp. 2307-2317, 2016.

[65] J. Chen, X. Cao, S. Peng, and H. Ren, "Analysis and applications of Globeland30: a review," ISPRS International Journal of Geo-Information, vol. 6, no. 8, p. 230, 2017.

[66] A. Pérez-Hoyos, F. Rembold, H. Kerdiles, and J. Gallego, "Comparison of global land cover datasets for cropland monitoring," Remote Sensing, vol. 9, no. 11, article 1118, 2017.

[67] X.-y. Chen, Y. Lin, M. Zhang, L. Yu, H.-c. Li, and Y.-q. Bai, "Assessment of the cropland classifications in four global land cover datasets: a case study of Shaanxi Province, China," Journal of Integrative Agriculture, vol. 16, no. 2, pp. 298-311, 2017.

[68] A. Jacobson, J. Dhanota, J. Godfrey et al., “A novel approach to mapping land conversion using Google Earth with an application to East Africa," Environmental Modelling \& Software, vol. 72, pp. 1-9, 2015.

[69] J. C. Laso Bayas, L. See, C. Perger et al., "Validation of automatically generated global and regional cropland data sets: the case of Tanzania," Remote Sensing, vol. 9, no. 8, p. 815, 2017.

[70] K. Samasse, N. Hanan, G. Tappan, and Y. Diallo, "Assessing cropland area in West Africa for agricultural yield analysis," Remote Sensing, vol. 10, no. 11, article 1785, 2018.

[71] P. Teluguntla, P. S. Thenkabail, J. Xiong et al.et al., "Global Cropland Area Database (Gcad) derived from remote sensing in support of food security in the twenty-first century: current achievements and future possibilities," 2015.

[72] K. Yadav and R. G. Congalton, "Accuracy assessment of Global Food Security-Support Analysis Data (Gfsad) cropland extent maps produced at three different spatial resolutions," Remote Sensing, vol. 10, no. 11, article 1800, 2018.

[73] P. Teluguntla, P. S. Thenkabail, A. Oliphant et al., "A 30-m Landsat-derived cropland extent product of Australia and China using random forest machine learning algorithm on Google Earth Engine cloud computing platform," ISPRS Journal of Photogrammetry and Remote Sensing, vol. 144, pp. 325-340, 2018.

[74] A. R. Phalke, M. Özdoğan, P. S. Thenkabail et al., "Mapping croplands of Europe, Middle East, Russia, and Central Asia using Landsat, random forest, and Google Earth Engine," ISPRS Journal of Photogrammetry and Remote Sensing, vol. 167, pp. 104-122, 2020.

[75] J. Xiong, P. Thenkabail, J. Tilton et al., "Nominal 30-m cropland extent map of Continental Africa by integrating pixelbased and object-based algorithms using Sentinel-2 and Landsat-8 data on Google Earth Engine," Remote Sensing, vol. 9, no. 10, article 1065, 2017.

[76] J. Xiong, P. S. Thenkabail, M. K. Gumma et al., "Automated cropland mapping of Continental Africa using Google Earth Engine cloud computing," ISPRS Journal of Photogrammetry and Remote Sensing, vol. 126, pp. 225-244, 2017.

[77] A. J. Oliphant, P. S. Thenkabail, P. Teluguntla et al., "Mapping cropland extent of Southeast and Northeast Asia using multi-year time-series Landsat 30-m data using a random forest classifier on the Google Earth Engine cloud," 
International Journal of Applied Earth Observation and Geoinformation, vol. 81, pp. 110-124, 2019.

[78] C. B. Mouw, S. Greb, D. Aurin et al., "Aquatic color radiometry remote sensing of coastal and inland waters: challenges and recommendations for future satellite missions," Remote Sensing of Environment, vol. 160, pp. 15-30, 2015.

[79] S. C. J. Palmer, T. Kutser, and P. D. Hunter, "Remote sensing of inland waters: challenges, progress and future directions," Remote Sensing of Environment, vol. 157, pp. 1-8, 2015.

[80] Y. W. Sheng, C. Song, J. Wang et al., "Representative lake water extent mapping at continental scales using multi- temporal Landsat-8 imagery," Remote Sensing of Environment, vol. 185, pp. 129-141, 2016.

[81] X. Cao, J. Chen, A. Liao, L. Chen, and J. Chen, "Global land surface water mapping and analysis at $30 \mathrm{~m}$ spatial resolution for years 2000 and 2010," in Multitemporal Remote Sensing, pp. 373-389, Springer, 2016.

[82] L. Ji, P. Gong, X. Geng, and Y. Zhao, "Improving the accuracy of the water surface cover type in the $30 \mathrm{~m}$ from-Glc product," Remote Sensing, vol. 7, no. 10, pp. 13507-13527, 2015.

[83] Z. Guo, C. Wang, X. Liu, G. Pang, M. Zhu, and L. Yang, "Accuracy assessment of the from-Glc30 land cover dataset based on watershed sampling units: a continental-scale study," Sustainability, vol. 12, no. 20, article 8435, 2020.

[84] Y. Wang, J. Zhang, D. Liu, W. Yang, and W. Zhang, "Accuracy assessment of Globeland30 2010 land cover over China based on geographically and categorically stratified validation sample data," Remote Sensing, vol. 10, no. 8, article 1213, 2018.

[85] D. Feng, Y. Zhao, L. Yu et al., "Circa 2014 African land-cover maps compatible with from-Glc and Glc2000 classification schemes based on multi-seasonal Landsat data," International Journal of Remote Sensing, vol. 37, no. 19, pp. 46484664, 2016.

[86] D. Ikeshima, D. Yamazaki, S. Yoshikawa, and S. Kanae, "The spatial resolution improvement of global water body map using multi-temporal Landsat data," Journal of Japan Society of Civil Engineers Ser B1 (Hydraulic Engineering), vol. 72, no. 4, pp. I_421-I_426, 2016.

[87] N.-E. Tsendbazar, S. de Bruin, S. Fritz, and M. Herold, "Spatial accuracy assessment and integration of global land cover datasets," Remote Sensing, vol. 7, no. 12, pp. 15804-15821, 2015.

[88] L. See, J. Laso Bayas, D. Schepaschenko et al., "Laco-Wiki: a new online land cover validation tool demonstrated using Globeland30 for Kenya," Remote Sensing, vol. 9, no. 7, p. 754, 2017.

[89] C. C. Fonte, M. Minghini, J. Patriarca, V. Antoniou, L. See, and A. Skopeliti, "Generating up-to-date and detailed land use and land cover maps using Openstreetmap and Globeland30," ISPRS International Journal of Geo-Information, vol. 6, no. 4, p. 125, 2017.

[90] M. Brovelli, M. Molinari, E. Hussein, J. Chen, and R. Li, “The first comprehensive accuracy assessment of Globeland30 at a national level: methodology and results," Remote Sensing, vol. 7, no. 4, pp. 4191-4212, 2015.

[91] A.-L. Balogun, S. A. Mohd Said, A. T. Sholagberu, Y. A. Aina, O. F. Althuwaynee, and A. Aydda, "Assessing the suitability of Globeland30 for land cover mapping and sustainable development in Malaysia using error matrix and unbiased area estimation," Geocarto International, pp. 1-21, 2020.
[92] I. Manakos, C. Karakizi, I. Gkinis, and K. Karantzalos, "Validation and inter-comparison of spaceborne derived global and continental land cover products for the Mediterranean region: the case of Thessaly," Land, vol. 6, no. 2, p. 34, 2017.

[93] Y. Zhang, J. Chen, L. Chen et al., "Characteristics of land cover change in Siberia based on Globeland30, 2000-2010," Progress in Geography, vol. 34, no. 10, pp. 1324-1333, 2015.

[94] J. Jokar Arsanjani, A. Tayyebi, and E. Vaz, "Globeland30 as an alternative fine-scale global land cover map: challenges, possibilities, and implications for developing countries," Habitat International, vol. 55, pp. 25-31, 2016.

[95] J. Jokar Arsanjani, L. See, and A. Tayyebi, "Assessing the suitability of Globeland30 for mapping land cover in Germany," International Journal of Digital Earth, vol. 9, no. 9, pp. 873891, 2016.

[96] L. Yu, J. Wang, X. C. Li, C. C. Li, Y. Y. Zhao, and P. Gong, “A multi-resolution global land cover dataset through multisource data aggregation," Science China Earth Sciences, vol. 57, no. 10, pp. 2317-2329, 2014.

[97] Y. Zhao, P. Gong, L. Yu et al., "Towards a common validation sample set for global land-cover mapping," International Journal of Remote Sensing, vol. 35, no. 13, pp. 4795-4814, 2014.

[98] S. Dong, B. Gao, Y. Pan, R. Li, and Z. Chen, “Assessing the suitability of from-Glc10 data for understanding agricultural ecosystems in China: Beijing as a case study," Remote Sensing Letters, vol. 11, no. 1, pp. 11-18, 2020.

[99] Z. Guo, K. Yang, C. Liu, C. Liang, and M. Li, "Seasonal accuracy assessments of three land cover datasets in Pakistan," Remote Sensing Technology and Application, vol. 3, 2020.

[100] X. Zhang and L. Liu, "Development of a global 30-m impervious surface map using multi-source and multi-temporal remote sensing datasets with the Google Earth Engine platform," 2019.

[101] X. H. Chen, X. Cao, A. P. Liao et al., "Global mapping of artificial surfaces at 30-m resolution," Science China Earth Sciences, vol. 59, no. 12, pp. 2295-2306, 2016.

[102] P. Wang, C. Huang, E. C. B. de Colstoun, J. C. Tilton, and B. Tan, Documentation for the global Human Built-up and Settlement Extent (Hbase) dataset from Landsat, NASA Socioeconomic Data and Applications Center (SEDAC), Palisades, NY, 2017.

[103] P. Wang, C. Huang, J. C. Tilton, B. Tan, and E. C. Brown de Colstoun, "Hotex: an approach for global mapping of human built-up and settlement extent," in 2017 IEEE International Geoscience and Remote Sensing Symposium (IGARSS), Fort Worth, TX, July 2017.

[104] T. Esch, M. Marconcini, A. Felbier et al., "Urban footprint processor-fully automated processing Chain generating settlement masks from global data of the Tandem-X mission," IEEE Geoscience and Remote Sensing Letters, vol. 10, no. 6, pp. 1617-1621, 2013.

[105] T. Esch, W. Heldens, A. Hirner et al., "Breaking new ground in mapping human settlements from space-the global urban footprint," ISPRS Journal of Photogrammetry and Remote Sensing, vol. 134, pp. 30-42, 2017.

[106] Z. Sun, R. Xu, W. du, L. Wang, and D. Lu, "High-resolution urban land mapping in China from Sentinel 1a/2 imagery based on Google Earth Engine," Remote Sensing, vol. 11, no. 7, p. 752, 2019. 
[107] C. Liu, X. Huang, Z. Zhu, H. Chen, X. Tang, and J. Gong, "Automatic extraction of built-up area from Zy3 multi-view satellite imagery: analysis of 45 global cities," Remote Sensing of Environment, vol. 226, pp. 51-73, 2019.

[108] J. O. Sexton, X.-P. Song, M. Feng et al., "Global, 30-m resolution continuous fields of tree cover: Landsat-based rescaling of Modis vegetation continuous fields with Lidar-based estimates of error," International Journal of Digital Earth, vol. 6, no. 5, pp. 427-448, 2013.

[109] J. R. Townshend, J. G. Masek, C. Huang et al., "Global characterization and monitoring of forest cover using Landsat data: opportunities and challenges," International Journal of Digital Earth, vol. 5, no. 5, pp. 373-397, 2012.

[110] P. V. Potapov, S. A. Turubanova, A. Tyukavina et al., "Eastern Europe's forest cover dynamics from 1985 to 2012 quantified from the full Landsat archive," Remote Sensing of Environment, vol. 159, pp. 28-43, 2015.

[111] Z. Yang, J. Dong, J. Liu et al., “Accuracy assessment and intercomparison of eight medium resolution forest products on the Loess Plateau, China," Isprs International Journal of Geo-Information, vol. 6, no. 5, p. 152, 2017.

[112] D. Zhang, H. Wang, X. Wang, and Z. Lü, "Accuracy assessment of the Global Forest Watch tree cover 2000 in China," International Journal of Applied Earth Observation and Geoinformation, vol. 87, article 102033, 2020.

[113] B. Pengra, J. Long, D. Dahal, S. V. Stehman, and T. R. Loveland, "A global reference database from very high resolution commercial satellite data and methodology for application to Landsat derived $30 \mathrm{~m}$ continuous field tree cover data," Remote Sensing of Environment, vol. 165, pp. 234-248, 2015.

[114] P. Teluguntla, P. S. Thenkabail, J. Xiong et al., "Spectral Matching Techniques (Smts) and Automated Cropland Classification Algorithms (Accas) for mapping croplands of Australia using Modis 250-m time-series (2000-2015) data," International Journal of Digital Earth, vol. 10, no. 9, pp. 944-977, 2016.

[115] Q. Yu, Q. Hu, J. van Vliet, P. H. Verburg, and W. Wu, "Globeland30 shows little cropland area loss but greater fragmentation in China," International Journal of Applied Earth Observation and Geoinformation, vol. 66, pp. 37-45, 2018.

[116] I. Manakos, K. Chatzopoulos-Vouzoglanis, Z. Petrou, L. Filchev, and A. Apostolakis, "Globalland30 mapping capacity of land surface water in Thessaly, Greece," Land, vol. 4, no. 1, pp. 1-18, 2015.

[117] J. Worden and K. M. de Beurs, "Surface water detection in the Caucasus," International Journal of Applied Earth Observation and Geoinformation, vol. 91, article 102159, 2020.

[118] H. Zhang, T. Wang, M. Liu et al., "Potential of combining optical and dual polarimetric Sar data for improving mangrove species discrimination using rotation forest," Remote Sensing, vol. 10, no. 3, p. 467, 2018.

[119] R. Goldblatt, M. F. Stuhlmacher, B. Tellman et al., "Using Landsat and nighttime lights for supervised pixel-based image classification of urban land cover," Remote Sensing of Environment, vol. 205, pp. 253-275, 2018.

[120] H. K. Zhang and D. P. Roy, "Using the $500 \mathrm{~m}$ Modis land cover product to derive a consistent continental scale $30 \mathrm{~m}$ Landsat land cover classification," Remote Sensing of Environment, vol. 197, pp. 15-34, 2017.
[121] W. Li, R. Dong, H. Fu, J. Wang, L. Yu, and P. Gong, "Integrating Google Earth imagery with Landsat data to improve 30-m resolution land cover mapping," Remote Sensing of Environment, vol. 237, article 111563, 2020.

[122] A. Singh, "Review article digital change detection techniques using remotely-sensed data," International Journal of Remote Sensing, vol. 10, no. 6, pp. 989-1003, 2010.

[123] G. M. Foody, "Status of land cover classification accuracy assessment," Remote Sensing of Environment, vol. 80, no. 1, pp. 185-201, 2002.

[124] D. Sulla-Menashe, J. M. Gray, S. P. Abercrombie, and M. A. Friedl, "Hierarchical mapping of annual global land cover 2001 to present: the Modis Collection 6 land cover product," Remote Sensing of Environment, vol. 222, pp. 183-194, 2019.

[125] T. Hermosilla, M. A. Wulder, J. C. White, N. C. Coops, and G. W. Hobart, "Disturbance-informed annual land cover classification maps of Canada's forested ecosystems for a 29-year Landsat time series," Canadian Journal of Remote Sensing, vol. 44, no. 1, pp. 67-87, 2018.

[126] S. E. Franklin, O. S. Ahmed, M. A. Wulder, J. C. White, T. Hermosilla, and N. C. Coops, "Large area mapping of annual land cover dynamics using multitemporal change detection and classification of Landsat time series data," Canadian Journal of Remote Sensing, vol. 41, no. 4, pp. 293314, 2015.

[127] D. Liu and S. Cai, "A spatial-temporal modeling approach to reconstructing land-cover change trajectories from multitemporal satellite imagery," Annals of the Association of American Geographers, vol. 102, no. 6, pp. 1329-1347, 2012.

[128] Z. Zhu and C. E. Woodcock, "Continuous change detection and classification of land cover using all available Landsat data," Remote Sensing of Environment, vol. 144, pp. 152171,2014

[129] Z. Zhu, Y. Fu, C. E. Woodcock et al., "Including land cover change in analysis of greenness trends using all available Landsat 5, 7, and 8 images: A case study from Guangzhou, China (2000-2014)," Remote Sensing of Environment, vol. 185, pp. 243-257, 2016.

[130] Y. Guan, Y. Zhou, B. He, X. Liu, H. Zhang, and S. Feng, "Improving land cover change detection and classification with Brdf correction and spatial feature extraction using Landsat time series: a case of urbanization in Tianjin, China," IEEE Journal of Selected Topics in Applied Earth Observations and Remote Sensing, vol. 13, pp. 4166-4177, 2020.

[131] G. Azzari and D. B. Lobell, "Landsat-based classification in the cloud: an opportunity for a paradigm shift in land cover monitoring," Remote Sensing of Environment, vol. 202, pp. 64-74, 2017.

[132] U.S., Geological Survey, National Land Cover Database (Nlcd) 1992 land cover conterminous, U.S. Geological Survey Data Release, United States, 2000.

[133] J. Liu, "National resources and environment remote sensing macro survey and dynamic monitoring research," Journal of Remote Sensing, vol. 1, pp. 225-230, 1997.

[134] N. Gorelick, M. Hancher, M. Dixon, S. Ilyushchenko, D. Thau, and R. Moore, "Google Earth Engine: planetaryscale geospatial analysis for everyone," Remote Sensing of Environment, vol. 202, pp. 18-27, 2017. 
[135] S. Xie, L. Liu, X. Zhang, J. Yang, X. Chen, and Y. Gao, “Automatic land-cover mapping using Landsat time-series data based on Google Earth Engine," Remote Sensing, vol. 11, no. 24, article 3023, 2019.

[136] M. Herold, A. van Groenestijn, L. Kooistra, V. Kalogirou, and O. Arino, "User requirements documents: land cover Cci." Université catholique de Louvain (UCL)-Geomatics, ESA, Louvain-la-Neuve, Belgium, 2011. 